OECD Local Economic and Employment Development (LEED) Papers

\title{
Better using skills in the workplace in the Leeds City Region, United Kingdom
}

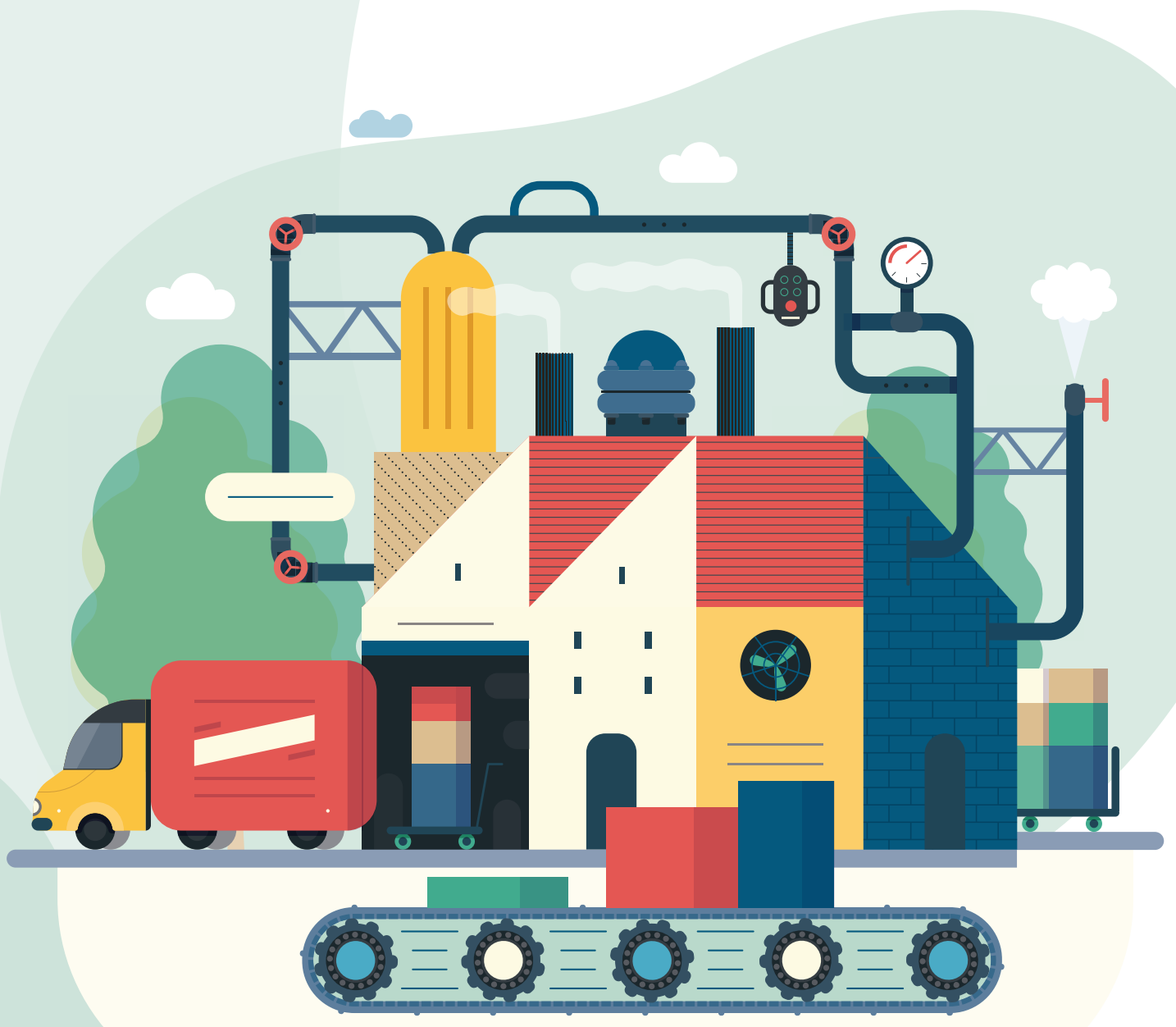

D. $\gg \mathrm{OECD}$ 
OECD Local Economic and Employment Development (LEED) Papers

\title{
Better using skills in the workplace in the Leeds City Region, United Kingdom
}

\begin{abstract}
This paper reviews the different definitions and measures of skills use and shows why it matters for local development policies. Based on findings from the Annual Population Survey and the UK Employer Skills Survey, it provides unique local analysis on how the Leeds City Region compares on skills use relative to other Local Enterprise Partnerships. It then outlines opportunities for new actions that could be implemented in the Leeds City Region to work closer with firms to promote skills use in the workplace.
\end{abstract}

JEL codes: J24, J21, J62, 126

Keywords: Regional disparities, skills utilisation, industrial composition

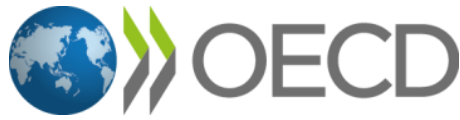




\section{ABOUT THE OECD}

The OECD is a multi-disciplinary inter-governmental organisation of 36 member countries which engages in its work an increasing number of non-members from all regions of the world. The Organisation's core mission today is to help governments work together towards a stronger, cleaner, fairer global economy. Through its network of 250 specialised committees and working groups, the OECD provides a setting where governments compare policy experiences, seek answers to common problems, identify good practice, and co-ordinate domestic and international policies. More information available: www.oecd.org.

\section{ABOUT OECD LOCAL ECONOMIC AND EMPLOYMENT DEVELOPMENT (LEED) PAPERS}

A series of papers from the OECD Local Economic and Employment Development (LEED) Programme. The LEED Programme identifies, analyses and disseminates innovative ideas for local development, governance and the social economy. Governments work with the LEED Programme to generate innovative guidance on policies to support employment creation and economic development through locally based initiatives.

OECD papers should not be reported as representing the official views of the OECD or of its member countries. The opinions expressed and arguments employed are those of the author(s). Papers describe preliminary results or research in progress by the author(s) and are published to stimulate discussion on a broad range of issues on which the OECD works. Comments on papers are welcome, and may be sent to the Centre for Entrepreneurship, SMEs, Regions and Cities, OECD, 2 rue André-Pascal, 75775 Paris Cedex 16, France.

This paper is authorised for publication by Lamia Kamal-Chaoui, Director, Centre for Entrepreneurship, SMEs, Regions and Cities, OECD.

This document, as well as any statistical data and map included herein, are without prejudice to the status of or sovereignty over any territory, to the delimitation of international frontiers and boundaries and to the name of any territory, city or area.

\section{C) OECD (2020)}

You can copy, download or print OECD content for your own use, and you can include excerpts from OECD publications, databases and multimedia products in your own documents, presentations, blogs, websites and teaching materials, provided that suitable acknowledgement of OECD as source and copyright owner is given. All requests for public or commercial use and translation rights should be submitted to rights@oecd.org. 


\section{Acknowledgements}

This paper was prepared by the Centre for Entrepreneurship, SMEs, Regions and Cities (CFE) led by Lamia Kamal-Chaoui, Director. This work was conducted as part of the OECD's Local Economic and Employment Development (LEED) Programme.

The principal authors of this paper are Jonathan Barr and Michela Meghnagi (OECD/CFE), Christopher Warhurst (Director of the Institute for Employment Research at Warwick University), Ewart Keep (Director of the Centre on Skills, Knowledge \& Organisational Performance at Oxford University) and Pauline Anderson (Chancellor's Fellow at the University of Strathclyde Glasgow). Useful and constructive feedback was provided on the paper by Joaquim Oliveira Martins (OECD/CFE) and Karen Maguire (OECD/CFE).

The OECD would like to sincerely thank Michelle Burton (Head of Employment and Skills at the West Yorkshire Combined Authority) and Peter Glover (Economic Evidence Manager at the West Yorkshire Combined Authority) from the Leeds City Region Enterprise Partnership who played an instrumental role working with the OECD on this paper. To support the development of this paper, the OECD worked with an expert group. Two meetings of the expert group were conducted in March and September 2019 in Leeds, UK to discuss the OECD findings and recommendations. In addition to Michelle Burton and Peter Glover, the OECD expert group was composed of the following individuals: Pauline Anderson, Chancellor's Fellow at University of Strathclyde; John Cope, Head of Education and Skills Policy at the Confederation of British Industry; Alison Fuller, Professor of Vocational Education and Work and Pro-Director for Research and Development at the UCL Institute of Education; Leslie Giles, Director at the Work Foundation; Irena Grugulis, Professor of Work and Skills at Leeds University Business School; Ewart Keep, Director at Centre for Skills Knowledge \& Organisational Performance - SKOPE; Kirsi Kekki, Policy Officer at the Trades Union Congress; Nayyara Tabassum, Evidence Officer at the Centre for Ageing Better; Chris Warhurst, Director at Institute for Employment Research, University of Warwick; and Patrick Watt, Head of Evaluation and Research at Skills Development Scotland.

The OECD would also like to thank Richard Garrett and Ramona Franklyn from the United Kingdom (UK) Department for Education (DfE) as well as David Campbell and Rosa Fernandez from the UK Department for Business, Energy \& Industrial Strategy (BEIS). All provided valuable comments and advice throughout the project and significantly contributed to the work of the OECD expert working group for this project. The OECD would thanks Peter Dickinson of the Institute for Employment Research at Warwick University for his inputs. The OECD's Local Economic and Employment Development Programme Directing Committee approved this paper for declassification at its $75^{\text {th }}$ Session on 14-15 November 2019. 


\section{Table of contents}

Acknowledgements 3

$\begin{array}{ll}\text { Abbreviations and acronyms } & 7\end{array}$

Executive Summary 9

1 What is skills use and why does it matter for local development policies?

Introduction 11

Maximising local labour market performance requires a focus on better skills use at work

Better using skills at work can support job quality and productivity

How do workers and firms use their skills in England?

Better using skills at work provides an opportunity for local development in the United Kingdom

2 Challenges and opportunities in the Leeds City Region 23

How is the labour market evolving in the Leeds City Region?

What are the productivity challenges facing the Leeds City Region? 28

3 Improving the balance between the supply and demand for skills in the Leeds City Region

Skills mismatches are costly and represent an inefficient allocation of workers

The Leeds City Region faces a number of challenges related to skills mismatches

4 Making intensive use of skills through high-performance work practices 43

High-performance work practices can help to better use skills among workers in the Leeds City Region

Assessing the prevalence of high-performance workplace practices in England

Assessing the prevalence of high-performance workplace practices in the Leeds City Region

5 What can the Leeds City Region do to improve skills use? 52

Skills policy in the United Kingdom is increasingly being devolved to the local level 52 Skills development programmes in the Leeds City Region 55

Creating an action plan for skills use policies in the Leeds City Region $\quad 57$ 
What UK and international examples could inspire action in the Leeds City Region on skills use policies?

How can the Leeds City Region evaluate success of skills use policies?

Table 1.1. Factors that need to be considered when defining better skills use at work Table 4.1. The AMO (Ability - Motivation - Opportunity) framework to skills utilisation Table 5.1. Key requirements for an action plan on skills use in the Leeds City Region

\section{Figures}

Figure 1.1. How education, skills and skills use affect job satisfaction in England (UK)

Figure 1.2. Labour productivity and the use of reading skills at work $\quad 17$

Figure 1.3. Skills use at work and skills proficiency in OECD countries 18

Figure 1.4. Use of information-processing skills at work, by firm size 19

Figure 1.5. An increasing supply of skills in the United Kingdom 20

Figure 1.6. Gap in GDP per capita and per hour worked relative to the upper half of OECD countries, 1991 2018

Figure 1.7. Regional disparities in labour productivity, OECD countries, 2017

Figure 1.8. Share of people aged 16-64 with NVQ4 qualification and above and labour productivity, UK regions, 2017

Figure 2.1. Understanding the geography of the Leeds City Region

Figure 2.2. Employment rate in the Leeds City Region and the United Kingdom, 2009-2018

Figure 2.3. Unemployment rate in the Leeds City Region and the United Kingdom, 2009-2018

Figure 2.4. Employment by industry in the Leeds City Region and the United Kingdom, 2018

Figure 2.5. Employment shares by occupation, Leeds City Region, 2005-2018

Figure 2.6. Educational attainment in the Leeds City Region and the United Kingdom, 2018

Figure 2.7. Trends in productivity, Leeds City Region, 2002-2017

Figure 2.8. Productivity in selected Local Enterprise Partnerships, 2017

Figure 2.9. GVA per worker (GBP) by industry, West Yorkshire (WY) and Great Britain (GB), 2014

Figure 2.10. Employment and Gross Value Added by sector, Leeds City Region, 2017

Figure 3.1. Qualification mismatch in OECD countries

Figure 3.2. Comparing skills supply and demand in Local Enterprise Partnerships, 2017

Figure 3.3. Skills mismatch in selected Local Enterprise Partnerships, 2017

Figure 3.4. Incidence of staff who are not fully proficient in their job in selected Local Enterprise Partnerships, 2017

Figure 3.5. Proficiency of staff and underutilisation by sector in the Leeds City Region, 2017

Figure 3.6. Staff that are not fully proficient by skills requirement for the occupation in selected Local Enterprise Partnerships, 2017

Figure 3.7. Implications of skills gaps in selected Local Enterprise Partnerships, 2017

Figure 3.8. Training provision in the last 12 months in selected Local Enterprise Partnerships, 2017

Figure 3.9. Incidence of training by occupation in the Leeds City Region and the United Kingdom, 2017

Figure 3.10. Type and incidence of vacancies by sector in the Leeds City Region, 2017

Figure 3.11. Actions taken to overcome difficulties finding candidates to fill hard-to-fill vacancies in selected Local Enterprise Partnerships, 2017

Figure 4.1. Linking business, organisational and workforce development

Figure 4.2. High performance work practices and the use of skills in the workplace in OECD countries

Figure 4.3. High-performance work practices in OECD countries 
Figure 4.4. Share of firms having adopted HPWPs in selected Local Enterprise Partnerships, 201749 Figure 4.5. Different types of HPWPs in selected Local Enterprise Partnerships, 2017

Figure 5.1. Employment and skills programmes in Leeds $\quad 55$

\section{Boxes}

Box 1.1. What was the purpose of this OECD project and how was it implemented? Box 1.2. Looking beyond the jargon: What is skills use (or utilisation)? Box 3.1. Data on skills mismatch and use at the local level in the United Kingdom 32 Box 4.1. Good work - The Taylor Review of modern working practices, United Kingdom 44 Box 4.2. People, place and practice workshops in Scotland, United Kingdom 51 Box 5.1. Local Enterprise Partnerships (LEPs) 53 Box 5.2. Opportunity to introduce a skills use audit in the Leeds City Region: What is it and how could it work? 59 Box 5.3. Innovative workplaces in East Midlands, United Kingdom

Box 5.4. Drawing on interesting examples from Scotland and Manchester, United Kingdom

Box 5.5. The United Kingdom Commission for Employment and Skills (UKCES) Futures Programme: Learning from past programme interventions

Box 5.6. The Manufacturing Extension Partnership, United States

Box 5.7. Practice labs for workforce innovation in Flanders, Belgium

Box 5.8. Scottish Funding Council Skills Utilisation Projects, United Kingdom 65

Box 5.9. Workforce Innovation Centres, Canada 


\section{Abbreviations and acronyms}

BEIS

United Kingdom Department for Business, Energy and Industrial Strategy

BIS

Former United Kingdom Department for Business, Innovation and Skills

Cedefop

European Centre for the Development of Vocational Training

CPCA

Cambridgeshire and Peterborough Combined Authority

DCLG

Former United Kingdom Department for Communities and Local Government

DfE

United Kingdom Department for Education

EEA

European Economic Area

EMDA

East Midlands Development Agency

ESF

European Social Fund

ESIF

European Structural and Investment Funds

ESS

United Kingdom Employer Skills Survey

ETS

Enterprise Training Support

Eurostat

European Statistical Office

FE

Further Education

GB

Great Britain

GBP

Great Britain Pound

GDP

Gross Domestic Product

GMCA

Greater Manchester Combined Authority

GVA

Gross Value Added

HE

Higher Education

HPWP

High-performance work practices

HR

Human Resources

ICT

Information and communications technology

LEP

Local Enterprise Partnership

LIS

Local Industrial Strategies

MCA

Mayoral Combined Authorities 
Manufacturing Extension Partnership

NEET

Young people not in education, employment or training

NIST MEP

National Institute of Standards and Technology's Manufacturing Extension Partnership

NVQ

National Vocational Qualification

OECD

Organisation for Economic Co-operation and Development

ONS

United Kingdom Office for National Statistics

PIAAC

Programme for the International Assessment of Adult Competencies

SAP

Skills Advisory Panel

SCER

Scottish Centre for Employment Research

SEP

Strategic Economic Plan

SES

Skills and Employment Survey

SFC

Scottish Funding Council

SME

Small and medium-sized enterprise

STUC

Scottish Trades Union Congress

TL2

OECD Territorial Level 2

UK

United Kingdom

UKCES

United Kingdom Commission for Employment and Skills

USD

US Dollar

WALF

Working as Learning Framework

WECA

West of England Combined Authority

WIC

Workforce Innovation Centre

WMCA

West Midlands Combined Authority

WY

West Yorkshire

WYCA

West Yorkshire Combined Authority 


\section{Executive Summary}

The traditional focus of skills policies has been on raising the number of people with higher level qualifications. This is important as high levels of educational attainment can translate into better employment outcomes. However, less attention is paid to working with firms to look at how they demand and use skills within the workplace. This is a new area for public policy that requires working closer with firms to encourage them to make skills use an organisational priority. As opposed to "fire-fighting" skills shortages reported by firms, a skills use approach seeks to understand if there are broader issues related to the way a job is designed as well as the pay and working conditions on offer.

Evidence from the OECD's Survey of Adult Skills demonstrates that better using skills is beneficial to both workers and firms. Workers benefit from increased wages and job satisfaction, which are important dimensions of job quality. Firms benefit from a more productive workforce and less employee turn-over. From a place-based perspective, a focus on better using skills is especially important for labour markets with sub-optimal productivity performance. Previous OECD research has demonstrated that improving skills use could result in aggregate productivity gains of $5 \%$ in the United Kingdom (UK).

This paper focuses on how the Leeds City Region in the UK could implement actions to improve skills use among local firms. The Leeds City Region continues to face a widening productivity gap with the overall national UK average - productivity is only $86 \%$ of the UK average, compared to $91 \%$ a decade ago. The overall positive increase in educational attainment in the Leeds City Region has not translated into better productivity outcomes. The industry structure of the Leeds City Region is close the UK average. This is especially important because one of the main drivers of lower productivity levels in the region relates to under-performance of its sectors as opposed to an adverse sector mix. The region has sub-optimal productivity outcomes in sectors which are associated with high-skilled jobs, such as information and communications, as well as professional scientific occupations.

Given this gap, there is a strong rationale in the region to look at how to work closer with firms to encourage them to use their skills better. While there is an increasing amount of evidence about the benefits, less is known about what actions can be taken, especially at a local level to identify and embed practices that enable the better use of skills inside companies.

One potential avenue for better skills use is promoting high-performance working practices (HPWPs). Such practices include, for example, employee reward programmes, more flexible working hours, mentoring and leadership development courses, as well as a company culture that promotes training and development.

The good news is that the share of firms adopting these practices in the Leeds City Region is $10 \%$, which is slightly above the UK average of $9 \%$. However, the region performs below other leading English regions, such as Greater Manchester, Greater Birmingham and Solihull, and the Humber. When looking at the specific types of HPWPs, employers in the Leeds City Region are less likely than other Local Enterprise Partnerships in the UK to conduct training needs assessments. They are also less likely to take action to overcome hard-to-fill vacancies by increasing salaries, redefining existing jobs, or providing more recruitment incentives to make a job more attractive. 
In the Leeds City Region, there is an opportunity to support firms by raising awareness about the benefits of improved organisational and management practices, including teamwork, task discretion, mentoring, job rotation, applying new learning, incentive pay, and flexible working hours. The Leeds City Region can disseminate good practices among firms, while also developing diagnostic tools to help them identify room for improvement, and promote knowledge transfer. The OECD has identified the following opportunities for the Leeds City Region to promote the better use of skills:

- Outline a local strategy which emphasizes skills use policies: While the Leeds City Region has a comprehensive range of skills development programmes, there is no explicit focus on improving skills use as an overall objective. A well-articulated local strategy would help to join-up thinking and action to support short-term employer skills needs, while linking them to business performance and development as well as longer-term local economic development aspirations.

- Appoint a local coordinator if feasible to act as a catalyst for engagement: The success and sustainability of any new initiative focused on better using skills requires the coordination and marshalling of stakeholders and resources. Having an identifiable person within the Leeds City Region who can raise awareness, while engaging local firms and linking them with human resources consultants, could help operationalise such actions.

- Identify businesses that already demonstrate good company practices and can provide champions for change among local firms: A peer network with mentors drawn from exemplar local firms can help provide mentoring support and advice, particularly for SMEs and start-ups, as well as within industries and supply chains. These champions could help drive a local "business case" about how and why skills use policies benefit local firms.

- Encourage appropriate programmes through the training and local business development system: The Leeds City Region could look at how to structure support for business managers, which would be important if their awareness and capabilities are to be raised. Ensuring that students, who are next-generation managers, have more awareness about good company management practices is also important to ensure sustained change. The Leeds City Region could work with relevant national departments to initiate a review of management education across the further and higher education system to help identify human resources gaps among local firms.

- Benchmark and measure progress on better using skills through the development of a selfassessment tool: Such a self-assessment tool would serve as a "skills audit" of local firms to help benchmark and measure efforts to improve skills use. It could comprise a number of questions about the skills of employees and how those skills are used. It could then link these questions to other information about the firms' management practices and business strategy to identify opportunities for improvement in the organisation of work and job design. 


\section{1 What is skills use and why does it matter for local development policies?}

There is untapped potential for public policies to place greater emphasis on both the development and deployment of skills at the local level to close regional productivity gaps. Traditional approaches to skills focus on increasing the number of people with qualifications. However, more can be done to work with local firms to assess how they maximize the use of skills within the workplace. There is strong evidence that better using skills can increase job quality and local economic development opportunities.

\section{Introduction}

Across the OECD, traditional policy approaches to skills focus mainly on the supply side with a strong emphasis on boosting the number of people with high level qualifications. However, there is increasing recognition that policy makers should also look at the demand for skills by firms, including how skills are used and deployed in the workplace. In other words, both skill development and skill deployment are needed. There are both economic and social reasons to look at how to better use skills in the workplace. As further outlined in this paper, workers who better use their skills are more likely to have greater job satisfaction and earn better wages as well as be more prepared to adapt to changes in the future of work. Employers benefit from a more productive and innovative workforce, enabling them to maximise business performance and profitability.

\section{Box 1.1. What was the purpose of this OECD project and how was it implemented?}

Workers and firms across the OECD continue to report that their skills are not fully utilised in the workplace. Evidence from the UK Employer Skills Survey (ESS) shows that 1 in 3 employers reported having at least one member of staff whose skills were under-used, with considerable variation between sectors: from $40 \%$ in Hotels and Restaurants, to $20 \%$ in Agriculture. This gap represents a drag on local economic opportunity placing downward pressure on job quality as well as industry diversification possibilities.

The challenge remains how to adopt an implementation approach at the local level and how to evaluate action. To tackle this issue, the OECD has worked with the United Kingdom Departments for Education as well as Business, Energy and Industrial Strategy to set-up an expert advisory group with the goal of: 1) identifying the policy rationale for why local economies, such as the Leeds City Region, should focus on better using skills in the workplace; 2) providing advice on what tools, measures and approaches can be used to implement a coordinated approach among skills, employment, and economic development portfolios; and 3) provide a framework for evaluating the performance of adopted actions in this policy area. 
Maximising local labour market performance requires a focus on better skills use at work

\section{The development and deployment of skills is fundamental for local economic opportunity}

Skills are vital to enable both people and places to thrive in an increasingly complex and rapidly changing world (OECD, 2019 $\left.{ }_{[1]}\right)$. Investing in skills contributes to boosting innovation and development, while also raising productivity. Employers play a key role in contributing to the skills development of their staff by providing good quality training (ILO, 2011 ${ }_{[2]}$ ). For example, using European-wide industry level data, the European Centre for the Development of Vocational Training (Cedefop) found a positive and statistically significant increase in productivity growth with employer-funded training (Cedefop, 2012[3]). Moreover, productivity gains increase as the number of days of employer-funded training increases. Focusing on the UK, (Dearden, Reed and Van Reenen, 2006[4]) found that for every additional 10 per cent of employees who engage in job-related training, productivity increases by 6 per cent. The effect is found to be stronger in firms of all sizes in manufacturing and weaker in services, though it is recognised that measuring productivity is more difficult in the service sector so any effects are likewise difficult to capture (Cedefop, 2011[5]) (Bender et al., 2016[6]). Very few studies examine whether and how these workers have the opportunity to use these acquired skills in their work.

The failure to fully utilise skills in the workplace results in a waste of the initial investment in human capital. It also results in the depreciation and obsolescence of the skills that are left unused and the potential loss of people with higher levels of skills who could move to places where the returns on skills are higher (OECD, 2019 $\left.9_{[1]}\right)$. Improving skills utilisation requires that public programmes work closer with employers to look more comprehensively at how they use the skills of their employees, as well as how skills are aligned to the needs of the business (OECD/ILO, 2017[7]). Better using skills at work is a key pillar of the OECD Skills Strategy, which highlights the importance for countries to focus on 1) developing relevant skills over the life course; 2) using skills effectively in work and society; and 3) strengthening the government of skills systems (OECD, 2019 $\left.{ }_{[1]}\right)$.

\section{How does the literature define skills use?}

Despite an increasing amount of literature generated in the last 15 years, there is no commonly agreed international definition of skills use (which is often referred to as skills utilisation in the literature). A variety of terms have been used to conceptualise the concept across different fields of research (see Box 1.2 for more information). At its core, skills use refers to the way that employers use the skills of employees in the workplace, and the alignment of the competences of workers to the demands and needs of the business. A working definition was developed by the Scottish Government and includes the following: "skills utilisation is about ensuring the most effective application of skills in the workplace to maximise performance through the interplay of a number of key agents (e.g. employers, employees, learning providers and the state) and the use of a range of human resources, management and working practices." (CFE, 2008[8]). 


\section{Box 1.2. Looking beyond the jargon: What is skills use (or utilisation)?}

A variety of terms have been used to conceptualise the better use of skills. The list below provides several examples of how issues related to skills use are generally discussed in the literature:

High road vs. low road employers. Economic development professionals and advocates for low-wage workers often refer to high road vs. low road employers. In their study of low-wage work in the Netherlands, (Van Klaveren, 2008[9]) identifies four aspects of firm strategies that distinguish between high and low road firms: 1) product market strategies (focus on high value-added, high quality production and services vs. low cost, low quality; 2) work organisation (enhanced forms of work organisation versus traditional, strict divisions of labour); 3) human resource policies; and 4) job quality.

High performance/high-involvement working. A considerable body of evidence looks into human resources practices known as high performance or high-involvement workplaces. High performance working practices are bundles of activities that include both aspects of work organisation (e.g. team work, employee autonomy, task discretion, mentoring, job rotation, and applying new learning) and management practices - employee participation, incentive pay, training practices and flexibility in working hours) (OECD, 2016[10]) (Johnston and Hawke, 2002[11]). In general, there are two broad schools of thought within the literature: "high commitment management" emphasises the improvement of employee autonomy and intrinsic satisfaction, while "high-involvement management" focusses instead on the ability of employees to make decisions to improve production processes (Harley, Allen and Sargent, 2007[12]) (Guthrie, 2001 [13]).

Organisational capital. The economists (Prescott and Visscher, $1980_{[14]}$ ) made early reference to what they called organisational capital. (Black and Lynch, $\left.2005_{[15]}\right)$ identify three aspects of "organisational capital" that have a significant impact on productivity: 1) employer provided workforce training 2) employee voice, especially in relation to decision making associated with the design of production processes as well as greater autonomy and discretion in work structure; and 3) work design, including the use of cross-functional production processes that result in more flexible allocation and re-allocation of labour in the firm. However, other researchers define organisational capital somewhat differently. For example, (Youndt, Subramaniam and Snell, 2004 $\left.{ }_{[16]}\right)$ define it as the institutionalised knowledge and codified experience residing within and utilised through databases, patents, manuals, structures, systems, and processes.

Organisational forms and learning dynamics. Using the European Survey on Working Conditions, four types of organisational forms are identified: 1) learning (e.g. high levels of autonomy, task complexity, learning and problem-solving and low levels of monotony, repetitiveness, and work rate constraints); 2) lean (e.g. strong learning dynamics and reliance on employees contributions to problemsolving but low autonomy in work and tight quantitative production norms); 3) Taylorist (e.g. minimal learning dynamics, low complexity, low autonomy and constraints on the pace of work); and 4) simple (e.g. work organisation methods that are for the most part informal and non-codified).

Workplace innovation. The term "workplace innovation" is commonly used in a European context. The (Dortmund Brussels Position Paper on Workplace Innovation, 2012[17]) defines workplace innovation as a social process which shapes work organisation and working life, combining human, organisational and technological dimensions.

Source: (OECD/ILO, 2017[7]) 
In trying to define the term, it is important to keep in mind that the term "skills use" or "skills utilisation" has yet to permeate the mainstream language of business and may not be the best "headline" to promote or market such a policy initiative (Keep, 2016[18]). In mapping out a framework for skills use policies, Table 1.1 provides a list of factors that need to be considered when defining the concept.

\section{Table 1.1. Factors that need to be considered when defining better skills use at work}

\begin{tabular}{l|l}
\hline Dimensions of skills use & \multicolumn{1}{c}{ Considerations } \\
\hline Job match & $\begin{array}{l}\text { The extent to which the skills being developed by the education and training system meet } \\
\text { labour market demands }\end{array}$ \\
\hline $\begin{array}{l}\text { Promoting conditions for } \\
\text { workforce innovation }\end{array}$ & $\begin{array}{l}\text { The extent to which firms adopt workplace practices that aim to create opportunities to use a } \\
\text { wider range of skills }\end{array}$ \\
\hline $\begin{array}{l}\text { A firm's business } \\
\text { approach }\end{array}$ & $\begin{array}{l}\text { The extent to which firms are improving their competitive and product market strategies which } \\
\text { in turn require higher-levels of skills in the workplace }\end{array}$ \\
\hline
\end{tabular}

Source: Adapted from (Keep, 2016 $\left.6_{[18]}\right)$, (Ashton and Sung, 2009 [19]]), and (Findlay and Warhurst, 2012[20]).

From a firm perspective, "effective" skills use can simply mean aligning its skills demands to its business approach. In some cases, doing so can mean maintaining a low-skilled workforce. Following (Finegold and Soskice, 1988[21] skills equilibrium theory, firms that opt for what is sometimes now called the "low road" business approach producing low cost goods and services will tend to have low-skilled workers. This match is self-reinforcing, leading to a "lock-in", with firms having no incentive to invest in the skills of their workforce, which in turn does little to improve local economic development. The absence of higher skilled workers also constrains these firms from being able to respond to changing economic circumstances. This low skills equilibrium is likely a contributing factor to the UK's productivity problem. Thus, a good match is not necessarily good for business: equilibrium can be achieved by having and maintaining low skill levels, which in the long term negatively impacts firm competitiveness.

There is evidence that the skills workers possess often exceed those needed for the job, resulting in a mismatch and an under-use of the skills available to firms. Indeed, with about $30 \%$ of the UK workforce over-qualified for their jobs, some studies point out that this type of mismatch dwarfs that of the skills shortages reported by employers (see for example (Felstead et al., 2007[22]), (Felstead, Gallie and Green, $\left.2017_{[23]}\right)$. The under-utilisation of workers' skills can impact firm productivity in a number of ways. Lack of use leads to a decay or even loss of these skills. It can also lead to less job satisfaction (Clark, 1995[24]); (OECD, 2011[25]).

Skills under-utilisation thus represents untapped talent at best (Skills Australia, 2012[26]) or, at worst, a waste of human resources (OECD, 2011 $\left.{ }_{[25]}\right)$. This under-utilisation can be a reason why a performance gap exists in many firms between how productive they are and how productive they could be, according to (Livingston, 2017[27]). Two issues arise: first, many workers have higher skills than they are currently being asked to use and, second, there is a need to find ways for them to be able to use those skills. The second point, about the better use of workers' skills, suggests that there are two approaches to thinking about skills use (Warhurst and Luchinskaya, 2018[28]). The first is the matching approach suggested above. It simply seeks to ensure that the skills possessed by workers align with the skills needed to do the job, whether that job requires low, intermediate or high-level skills. It is a "no change" approach to skills policy and practice. The second is the enablers approach. In contrast to the first approach, it seeks to identify how the skills possessed by workers might be better used, and so offers opportunity to improve organisational performance. 
In trying to understand how to measure the challenge, it is important to broadly understand how the alignment of skills to labour market demand is measured. Drawing on (Buchanan et al., 2010[29]) and the wider literature, skills mismatch measurements usually falls into three categories:

- Individual measures: which includes an individual's perceptions of how their skills are used. While detailed, measures collected in this way are somewhat limited by an individual's understanding of the skills required for a particular job. The OECD's Survey of Adult Skills is an example of this type of survey instrument.

- Employer measures: These types of surveys try to combine data collected from both workers and employers to measure skills use in the workplace. The UK Employer Skills Survey is an example of this type of measure.

- Population measures: These are usually defined by some combination of the occupation held by people (and the assumed qualification requirements associated with them) along with the education, training, and experience of individuals in those jobs in the population or sub-population of interest.

This paper draws on all three of these measures to identify why skills use is important and how firms in the Leeds City Region (which was selected as a case study) use the available skills within the local economy.

\section{Better using skills at work can support job quality and productivity}

\section{Skills use positively impacts an individual's perceptions of job quality}

Better using skills in the workplace has a positive impact on wages and job satisfaction, which are often associated with different definitions of job quality. The use of ICT skills, followed by the use of reading and writing at work, are particularly significant in explaining high wage returns for working-age individuals in the United Kingdom. Looking further at data from the OECD's Survey of Adult Skills, skills proficiency, skills use and years of education positively impact a worker's perception of job satisfaction (see Figure 1.1). Looking across these three dimensions, except for the use of numeracy at work, skills use has a higher impact on job satisfaction than skills proficiency and years of education. These patterns are similar across OECD countries. In particular, the relationships between the use of reading, writing and ICT skills at work and job satisfaction are statistically significant in nearly all OECD countries (OECD, 2016[30]). 
Figure 1.1. How education, skills and skills use affect job satisfaction in England (UK)

Percentage-point change in job satisfaction associated with a standard deviation (a) increase in skills proficiency, skills use at work and (b) years of education

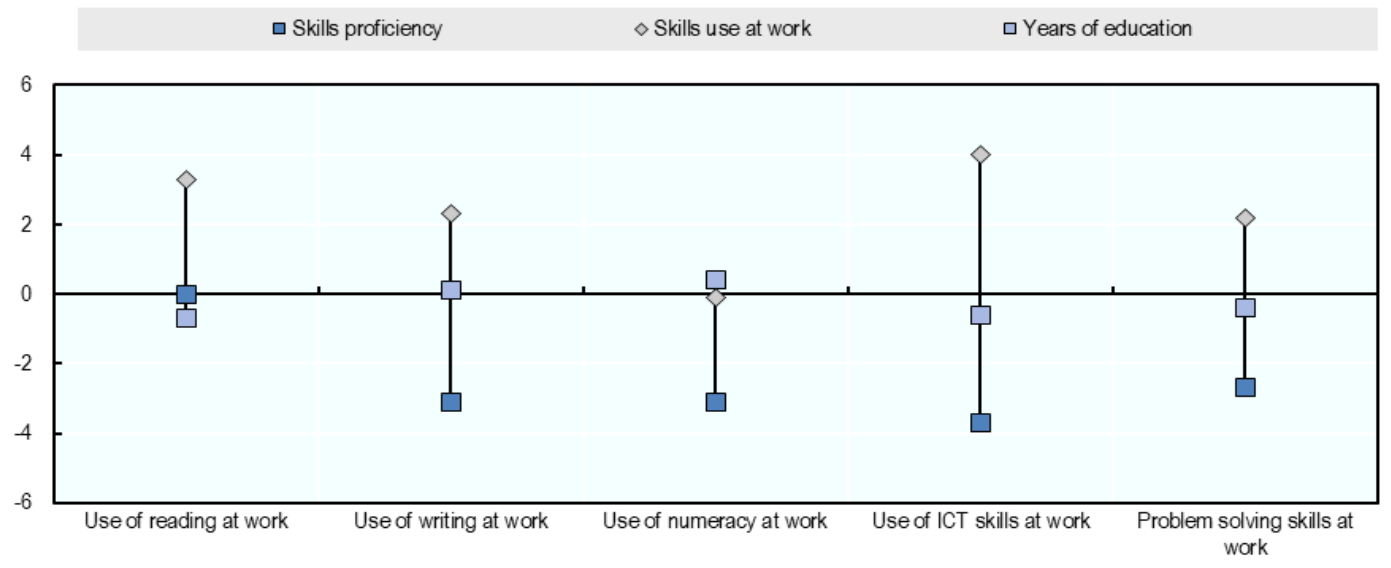

Note: a) One standard deviation corresponds to the following: 2.9 years of education; 47 points on the literacy scale; 53 points on the numeracy scale; 44 points on the problem solving in technology-rich environments scale; 1 for reading use at work; 1.2 for writing and numeracy use at work; 1.1 for ICT use at work; and 1.3 for problem solving at work.. b) Marginal probability estimates from probit regressions with individuals reporting being extremely satisfied in their current job as the dependent variable. One model is estimated for each skills use variable, with years of education and the corresponding skills use and proficiency as independent variables (literacy scores for reading and writing use at work, numeracy scores for numeracy use at work and problem solving in technology-rich environment scores for ICT and problem-solving use at work). All models include controls for age, age squared, gender, foreign-born status, tenure and gross hourly wages.

Source: OECD calculations based on OECD (2017) Survey of Adults Skills database (PIAAC) (2012, 2015), www.oecd.org/skills/piaacl.

\section{Skills use can also positively impact productivity}

OECD research shows that improving skills use could result in considerable gains in aggregate productivity. Gains range between $3 \%$ in North America, Poland and Sweden and more than $9 \%$ in Southern European countries and Chile. The United Kingdom sits in the middle of the distribution at $5 \%$ (Adalet McGowan and Andrews, 2017[31]). Some research has noted that changes in workplace organisation - such as re-engineering job design, incentivising teamwork, introducing incentive pay and encouraging employee autonomy and feedback - are a "significant component of the turnaround in productivity growth in the US during the 1990s" (Black and Lynch, 2005[32]). An analysis of the OECD Survey of Adult Skills (i.e. PIAAC) shows that even after accounting for average proficiency scores in literacy and numeracy, the use of reading skills at work accounts for a statistically significant share of the variation in labour productivity across OECD countries (see Figure 1.2). 
Figure 1.2. Labour productivity and the use of reading skills at work

Adjusted for literacy and numeracy proficiency

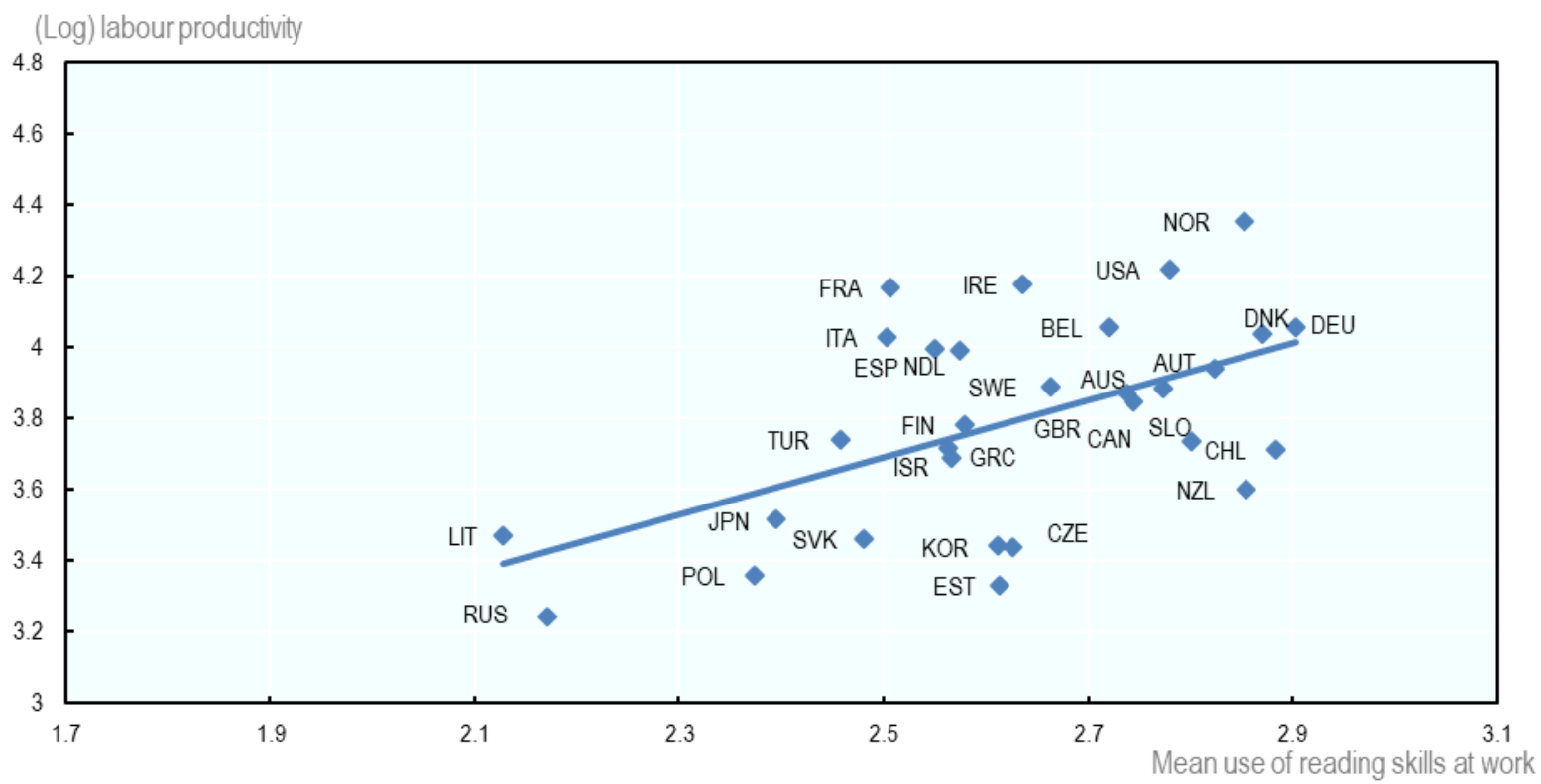

Note: Line is best linear prediction. Labour productivity is equal to the GDP per hour worked, in USD current prices 2012 for round-1 and 2014 for round-2 countries/economies. Adjusted estimates are based on OLS regressions including controls for literacy and numeracy proficiency scores. The sample for the Russian Federation does not include the population of the Moscow municipal area.

Source: Survey of Adult Skills (PIAAC) $(2012,2015)$, adapted from (OECD, 2018[33]).

\section{How do workers and firms use their skills in England?}

\section{England tends to make good use of literacy skills but sits at the OECD average on the use of numeracy skills}

The bulk of international evidence available relies on an individual's perceptions of skills use in the workplace. This literature on skills use has broadly studied whether skills use is linked to proficiency. There seems to be a relationship between these two dimensions in England, and this is not always the case across OECD countries. Compared to other OECD countries, workers in England tend to make good use of literacy skills at work, however, this is not necessarily true for numeracy skills. England scores among the top performing countries for both skills use and proficiency in reading and literacy skills at work, and shows performance closer to the OECD average when looking at the use and proficiency of numeracy skills at work. 
Figure 1.3. Skills use at work and skills proficiency in OECD countries

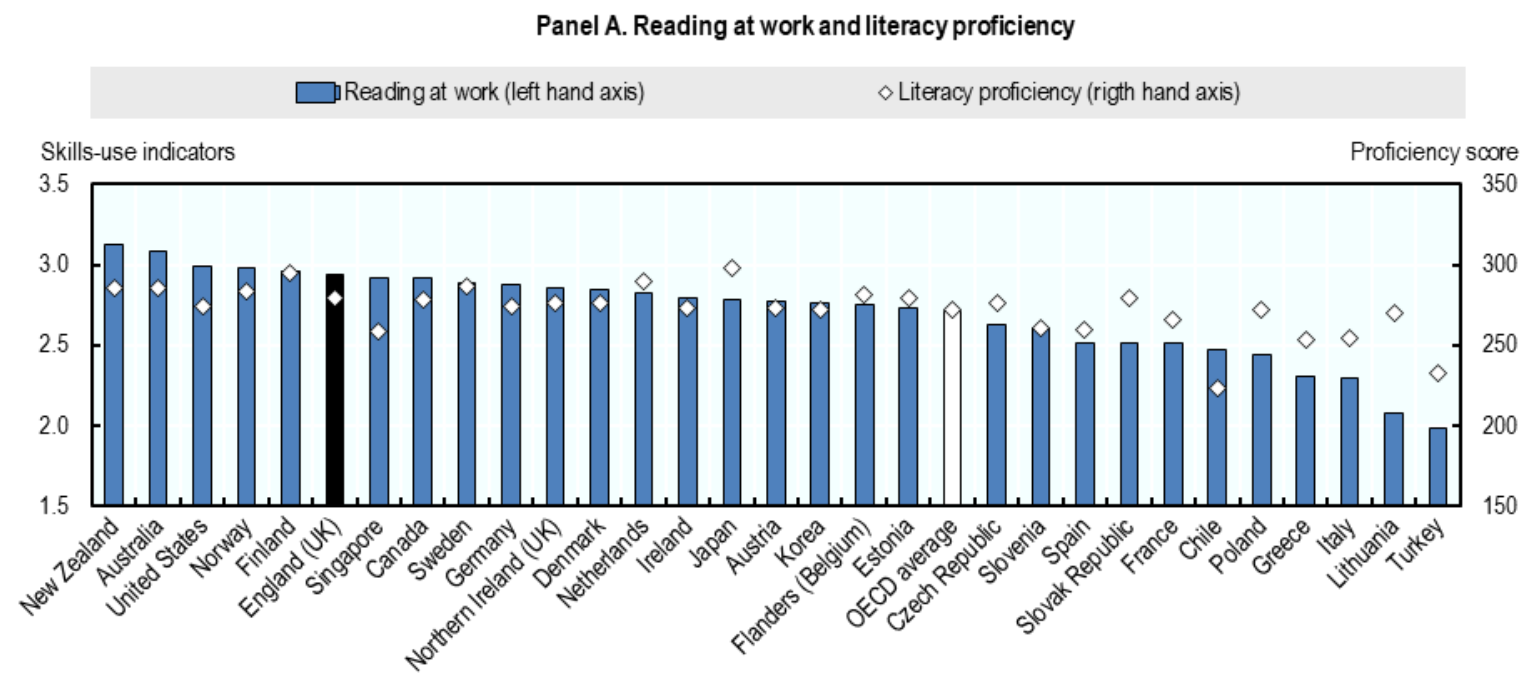

Panel B. Numeracy use at work and numeracy proficiency

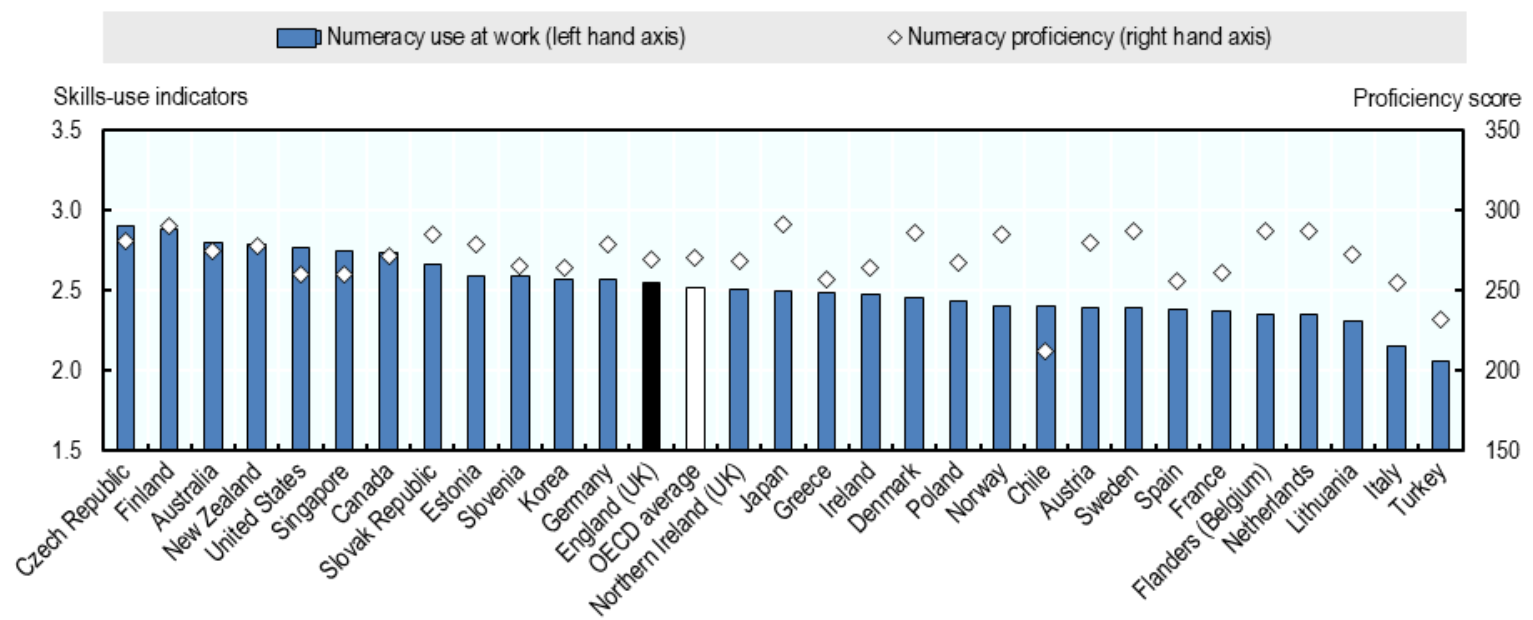

Note: Data only include the working population. For reading, writing, numeracy and ICT skills, skills use indicators are scales between 1 "Never" and 5 "Every day". Problem-solving skills use refers to respondent answers to "How often are you usually confronted with more complex problems that take at least 30 minutes to find a good solution?" The set of possible answers also ranges between 1 "Never" and 5 "Every day". Proficiency scores range from 0 to 500 .

Source: (OECD, 2016[34]), Skills Matter: Further Results from the Survey of Adult Skills.

\section{Small and medium-sized enterprises in the United Kingdom face unique challenges in better using the skills of their workers}

Firm size has an impact on the use of skills at work, with smaller firms (e.g. SMEs) showing lower levels of skills use in comparison to bigger firms. This is related to the lack of capacity, both in terms of financial and human resources, that SMEs have in comparison to larger firms (OECD, 2016[10]). England performs very close to the OECD average when looking at the use of reading skills at work but below average in numeracy and information and communications technology (ICT). The gap on these two dimensions is particularly high for smaller firms in England indicating that they have more challenges in using skills compared to the OECD average. Many studies have highlighted that SMEs in general have less human 
and financial resources than bigger firms that might prevent them from putting in place the right human resources practices to effectively deploy skills within the firm (Osterman, 2008[35]) (OECD/ILO, 2017[7]) (Lloyd, Warhurst and Dutton, 2013[36]).

Figure 1.4. Use of information-processing skills at work, by firm size

England (UK) and OECD average

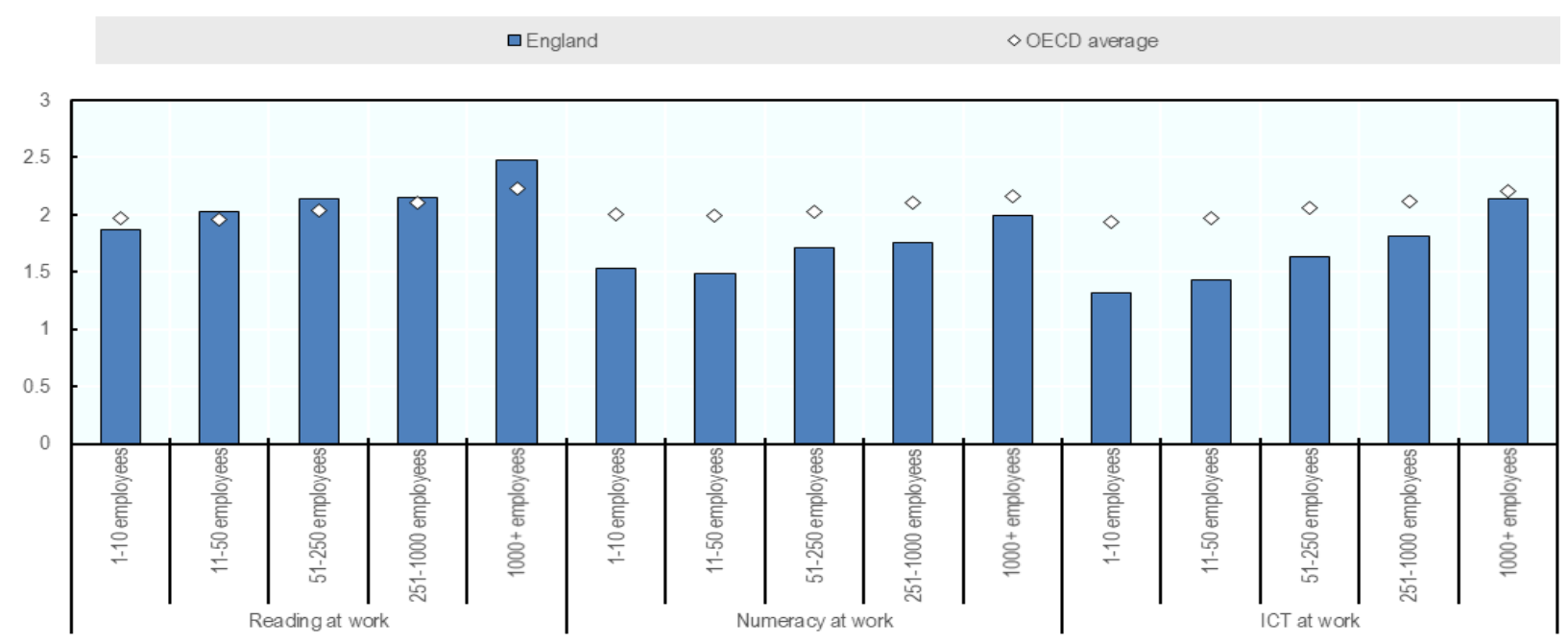

Source: OECD calculations based on OECD (2017) Survey of Adults Skills database (PIAAC) $(2012,2015)$.

\section{Better using skills at work provides an opportunity for local development in the United Kingdom}

\section{A focus in the United Kingdom on increasing qualifications has not translated into better regional productivity outcomes}

Impressive growth in increasing the overall supply of skills has been achieved throughout the United Kingdom over the last 13 years as the population has become more educated. Considering the percentage of the population with a National Vocational Qualification of level 4 and above (which is equivalent to higher education), there has been a 12.7 percentage point increase in the number of working-age individuals attaining this level of skills, increasing from $26.5 \%$ in 2005 to $39.2 \%$ in 2018 (see Figure 1.5). 
Figure 1.5. An increasing supply of skills in the United Kingdom

Percentage of the population aged 16-64 years with a NVQ4 qualification and above, 2005-2018

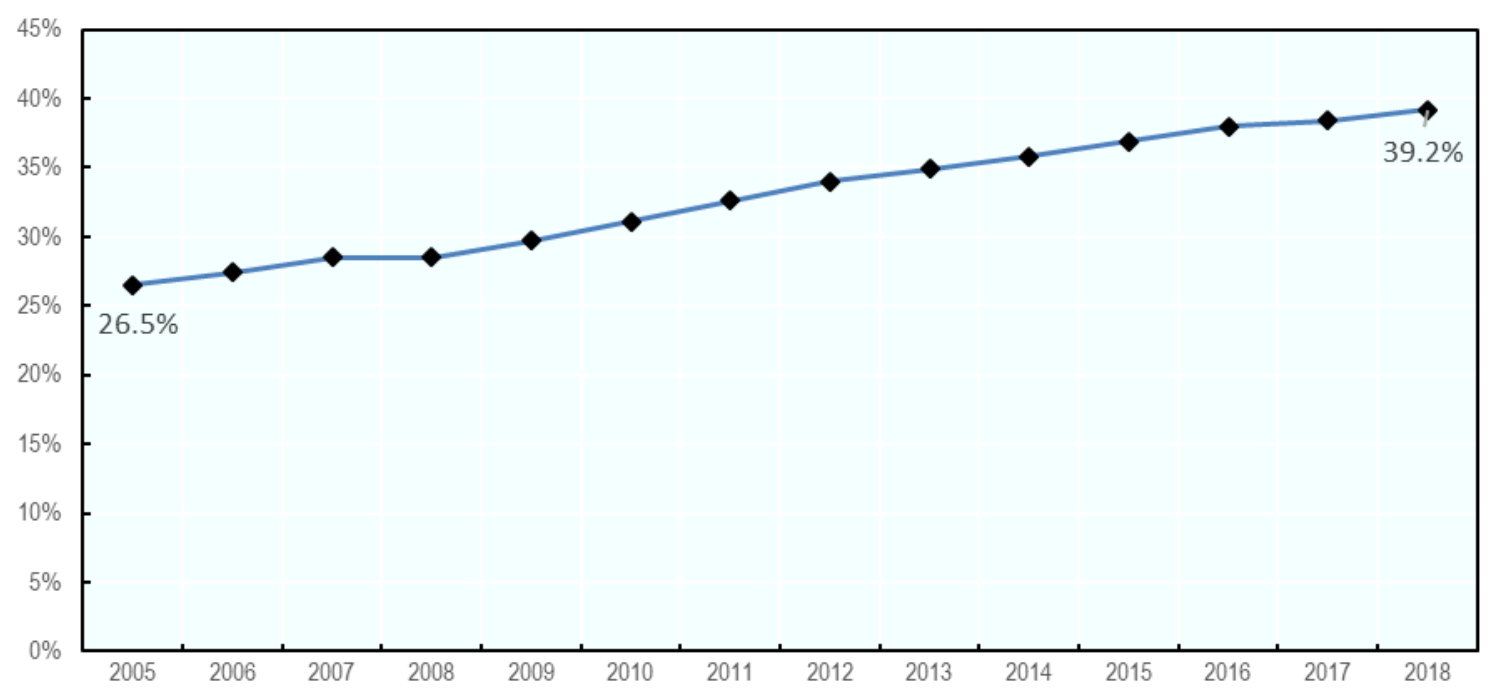

Note: NVQ4+ represents the National Vocational Qualifications level 4 and above, corresponding to a degree-level or equivalent qualification or above.

Source: UK Annual Population Survey.

While skills levels have risen in the UK, low productivity growth remains a drag on living standards in comparison to many other OECD economies (OECD, 2017[37]). When comparing 18 OECD countries with the highest GDP per capita, the United Kingdom has a strong gap in both GDP per capita and GDP per hour worked (see Figure 1.6). Following a narrowing of the gap from 2000-2007, the gap started increasing again after the 2008 financial crisis. This can be explained by the stagnation of productivity in the UK, even in the post-crisis period. This trend is generally referred to as the UK productivity puzzle. 
Figure 1.6. Gap in GDP per capita and per hour worked relative to the upper half of OECD countries, 1991-2018

Values in percentage

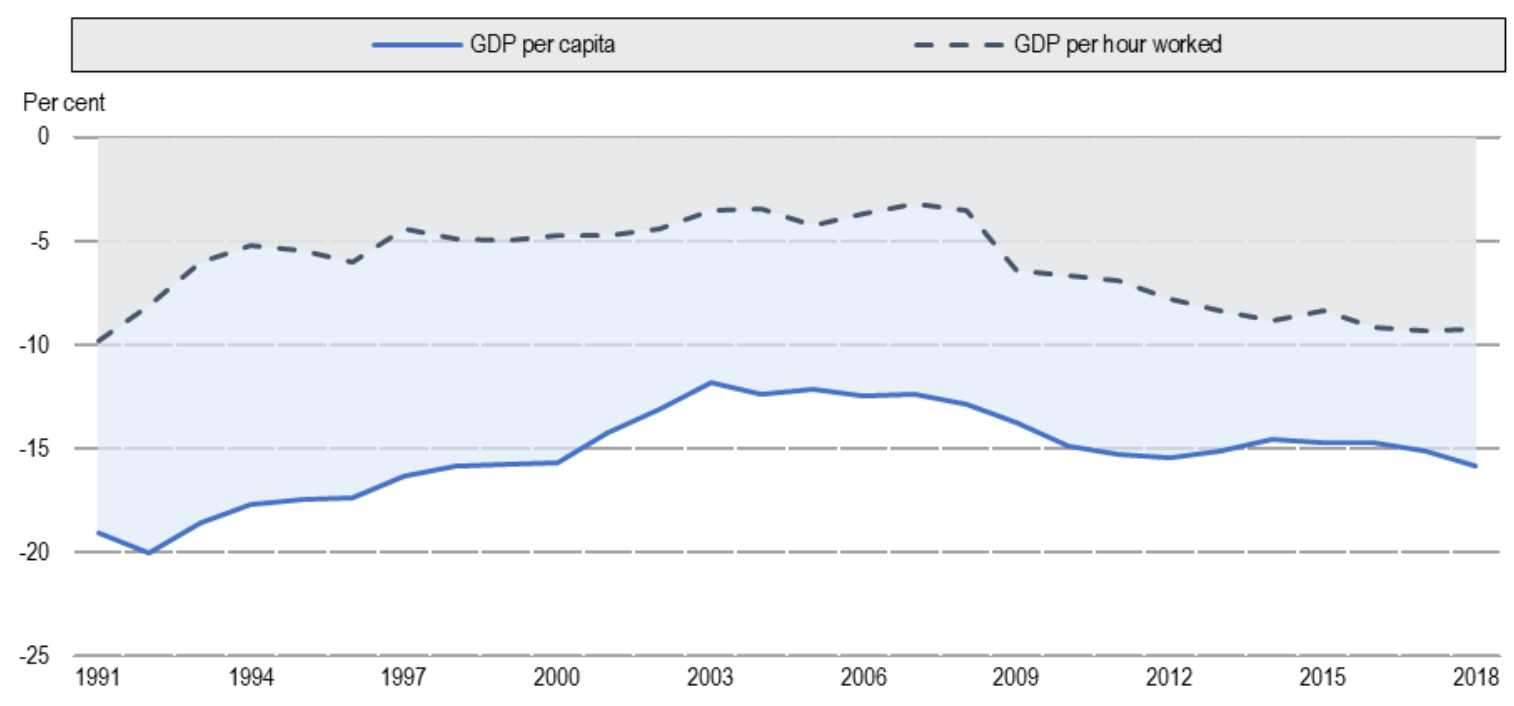

Note: Percentage gap with respect to the weighted average using population weights of the highest 18 OECD countries in terms of GDP per capita (in constant 2010 PPPs). The 2018 value of the average hours worked per person employed has been estimated for Australia, Canada, Finland, Israel, Mexico, Switzerland and the United States.

Source: OECD, National Accounts and Productivity Databases.

Regional disparities in labour productivity in the UK are the highest among OECD countries (Gal and Egeland, 2018[38]). In addition, the gap between the top performing region (i.e. London) and the second best performing region (i.e. the South East) is the third highest among OECD countries (see Figure 1.7). London is the UK's key driver of economic growth (OECD, 2017[37]) (OECD, 2020[39]). London's economy, measured in terms of GDP, is larger than that of Belgium and Sweden and twice as much as the GDP of other major cities such as Paris or Madrid (GLA, 2014[40]).

While London was been badly hit by the 2009 crisis following the contraction of the financial and insurance sectors, its economy has been resilient in the following years, with the highest Gross Value Added (GVA) growth rate among UK regions (Orellana, 2018[41]). London's economy is also driven by the highest startup rate of the UK and the highest high-growth firm incidence rate ${ }^{1}$ of England (ERC, 2019 $\left.{ }_{[42]}\right)$. Spatial variation in productivity relates to the educational attainment of the working age population across English regions (OECD, 2017[37]) (OECD, 2020[39]) (Tsvetkova et al., 2020[43]). When comparing regional productivity performance to the overall proportion of the population with NVQ level 4, it clearly demonstrates that skills attainment plays a role in driving strong regional productivity outcomes (see Figure 1.8).

\footnotetext{
${ }^{1}$ In the paper high-growth is defined as annualised average growth in employment of $20 \%$ or more over a three-year period (2015-18) and is restricted to a business having at least 10 employees in 2015. This definition is in line with the OECD methodology, more information can be found in (Eurostat and OECD, $2007_{[119]}$ ).
} 
Figure 1.7. Regional disparities in labour productivity, OECD countries, 2017

Index average level across regions $=100$

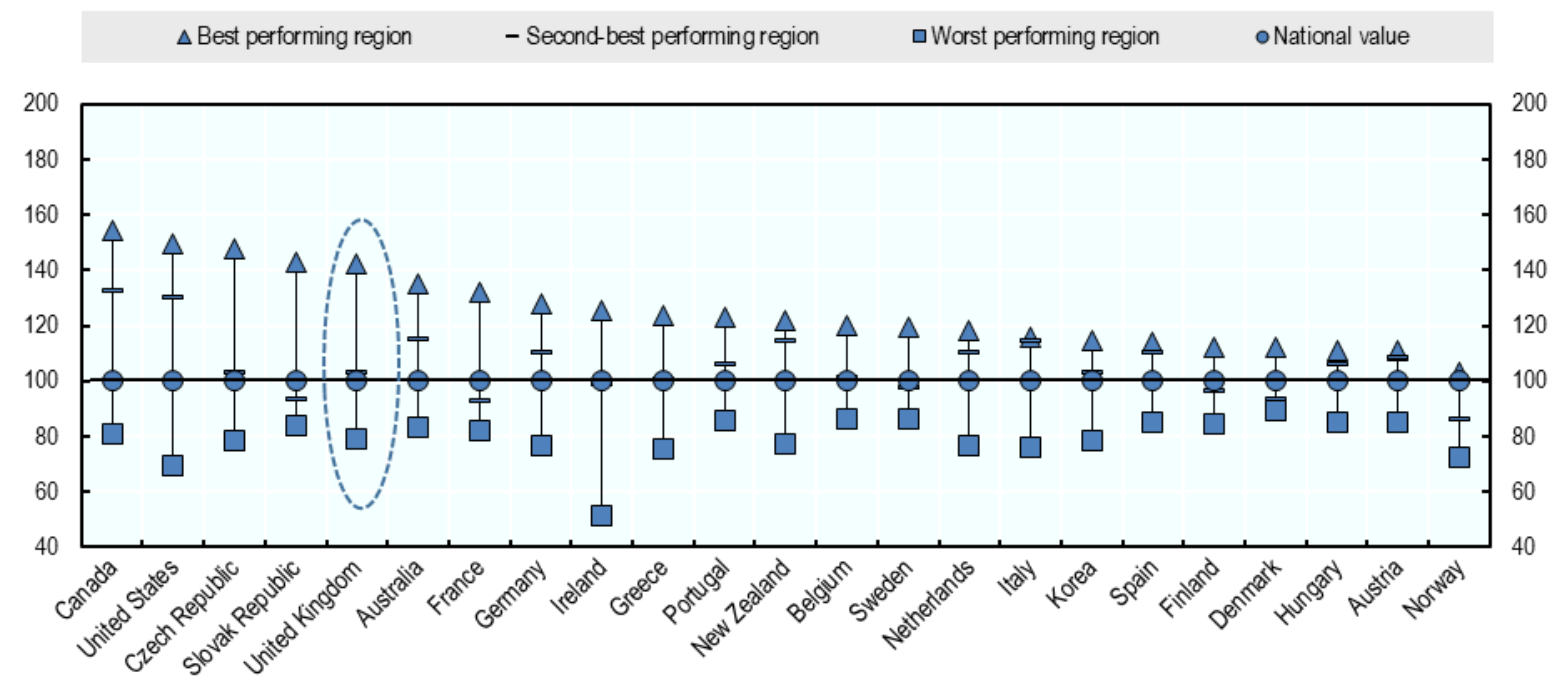

Note: The analysis is conducted at the OECD TL2 level. Gross Value Added per worker has been used as a proxy for labour productivity. Data for Canada, New Zealand and Norway are for 2016.

Source: (OECD, 2020[44]), OECD Regional Statistics, Regional economy, https://dx.doi.org/10.1787/6b288ab8-en.

Figure 1.8. Share of people aged 16-64 with NVQ4 qualification and above and labour productivity, UK regions, 2017

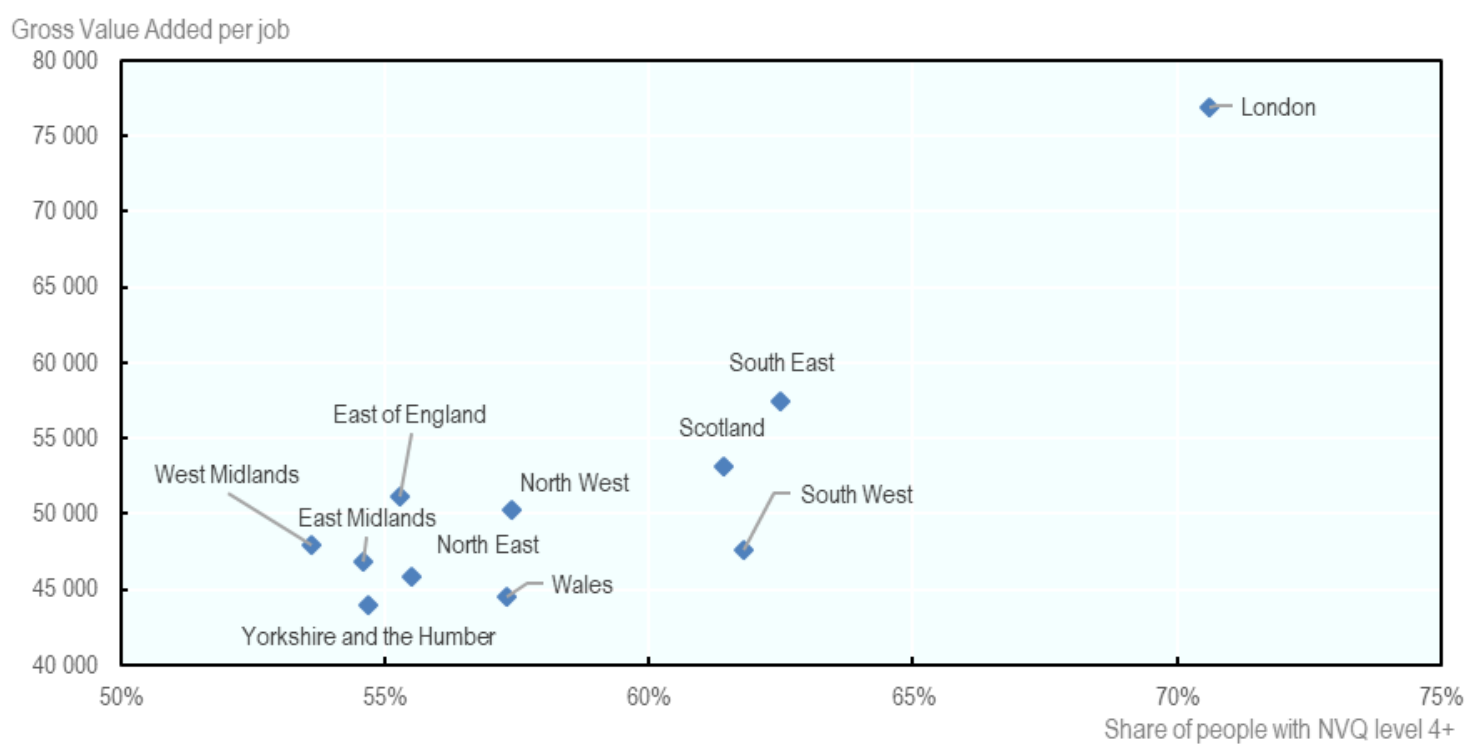

Note: Labour productivity is measured as Gross Value Added per worker as defined by the OECD. Data on labour productivity refers to 2016. Source: OECD regional accounts and UK Annual Population Survey. 


\section{Challenges and opportunities in the Leeds City Region}

The Leeds City Region was chosen as a case study to better understand how Local Enterprise Partnerships can work closer with firms on better using skills in the workplace. This section highlights the rationale for why the Leeds City Region could consider looking at action in this area. While the Leeds City Region has shown signs of an improving labour market, a focus on skills use policies could help to tackle the region's productivity gap with the UK average, which relates to the under-performance of local firms.

\section{Understanding the Leeds City Region}

The Leeds City Region is located in the Yorkshire and the Humber, in the North of England. It includes ten districts (see Figure 2.1) with Leeds, Bradford and York being the biggest ones in terms of population size. The Leeds City Region has a population of over three million people, of which $47 \%$ are in employment (i.e. employed or self-employed), slightly below the UK average. With 107000 enterprises, the Leeds City Region hosts $58 \%$ of the total enterprises of the Yorkshire and the Humber region. Leeds also sits under the West Yorkshire Combined Authority (WYCA) which was established in 2014. The WYCA brings together local councils and businesses to build a dynamic local economy and promote growth. Its work is led by Combined Authority members and the Local Enterprise Partnership (LEP) Board. The responsibilities of Combined Authorities are related to transport, economic development and regeneration. Power and resources are devolved from the national government. 
Figure 2.1. Understanding the geography of the Leeds City Region
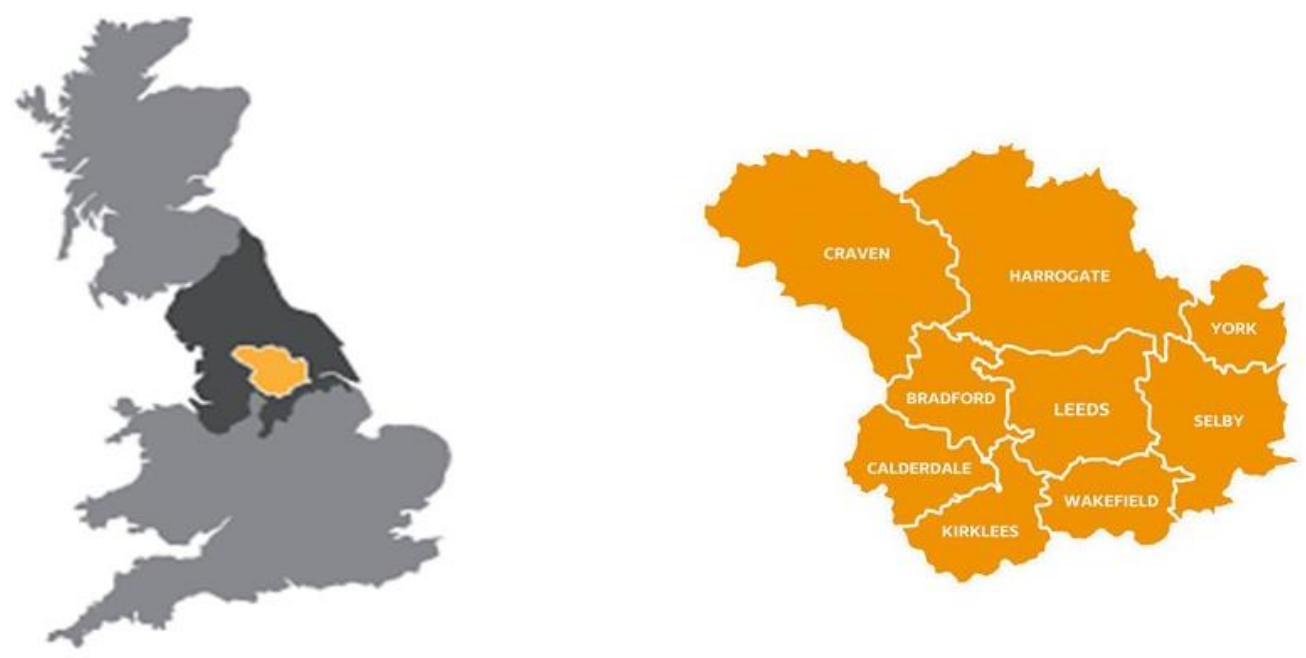

Source: https://www.the-lep.com/why-leeds-city-region/ and https://leeds.papi.org.uk/

How is the labour market evolving in the Leeds City Region?

\section{Employment and unemployment rates have improved in the Leeds City Region over the last decade}

With around 1.5 million economically active people, the Leeds City Region is, after London and the South East, the biggest Local Enterprise Partnership (LEP) in terms of number of workers in the labour force. After a decrease in employment during the crisis, the Leeds City Region labour market has shown significant improvements, with the employment rate increasing from $69 \%$ in 2009 to $73 \%$ in 2018 , back to the pre-crisis level. The unemployment rate was just below the UK average at $4 \%$ in 2018 (see Figure 2.3). 
Figure 2.2. Employment rate in the Leeds City Region and the United Kingdom, 2009-2018

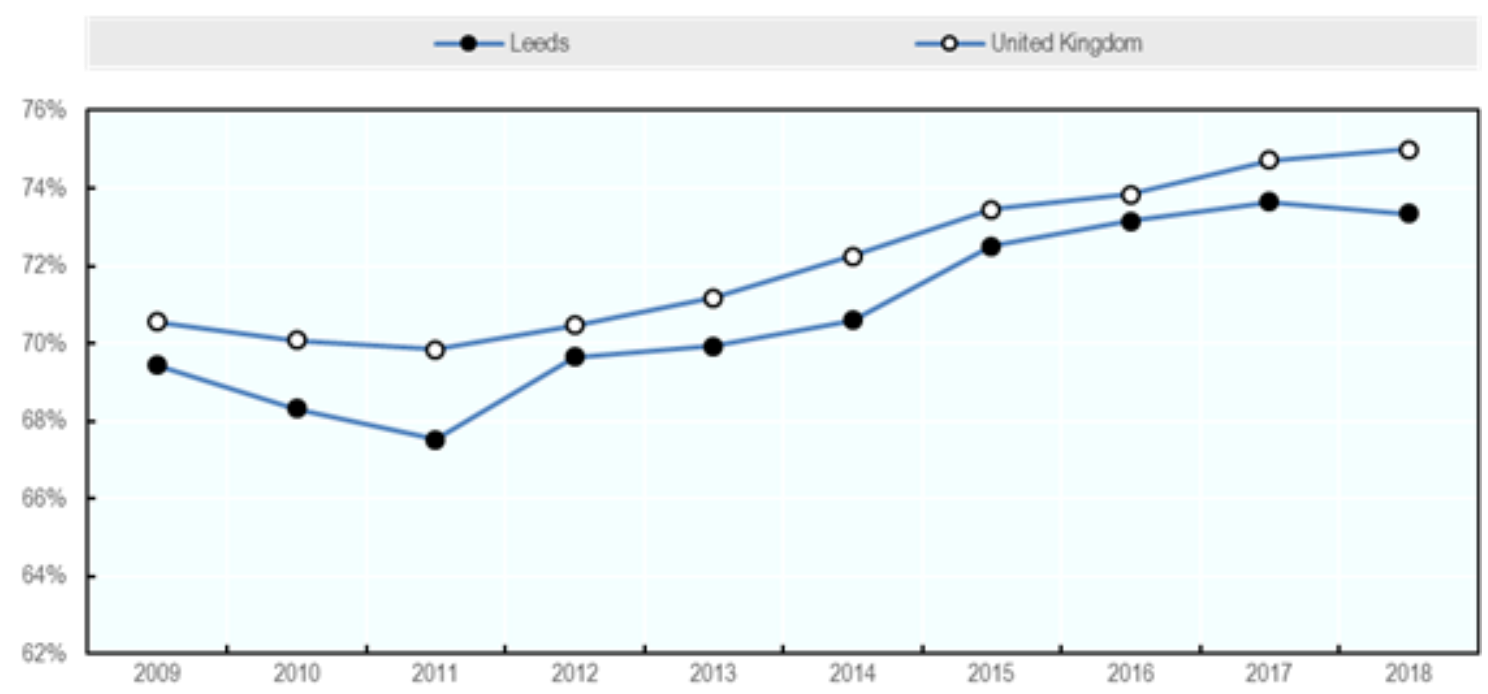

Source: UK Annual Population Survey.

Figure 2.3. Unemployment rate in the Leeds City Region and the United Kingdom, 2009-2018

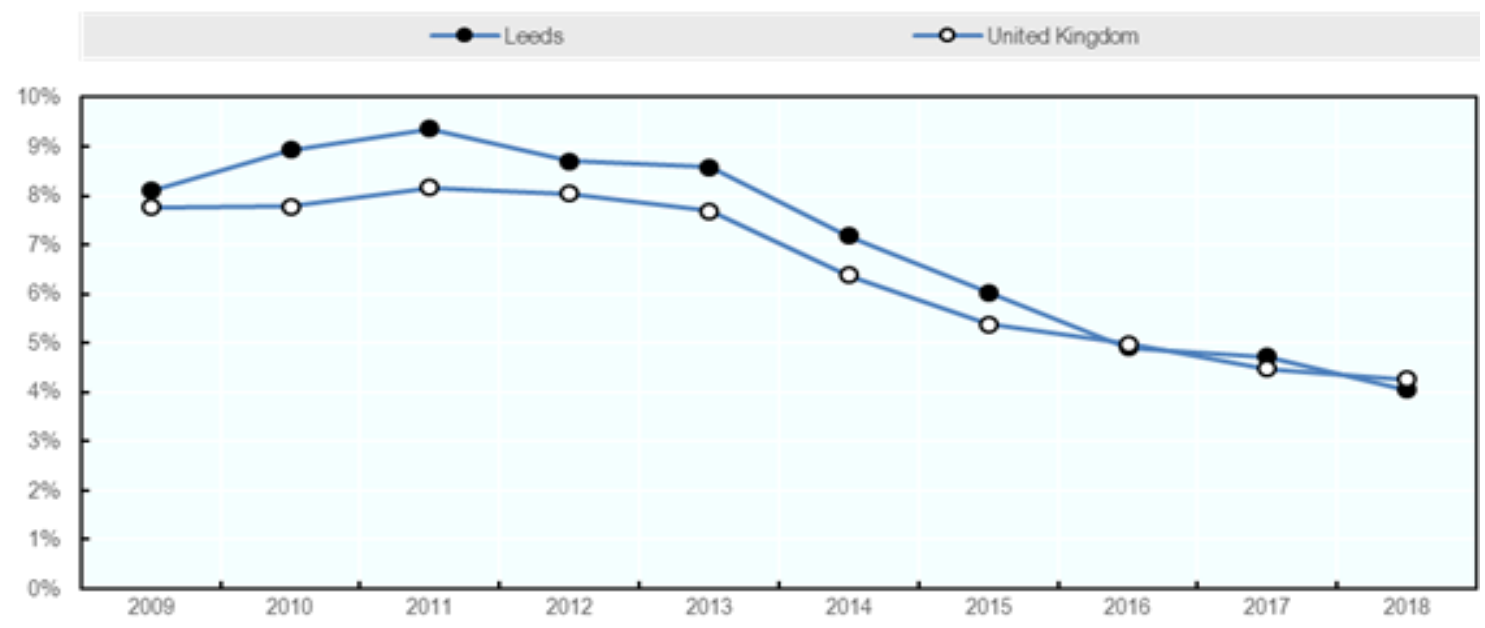

Source: UK Annual Population Survey.

Similar to the sectoral composition of the UK overall, the Leeds City Region is characterised by high employment in the public administration, education and health sectors, which employ around a third of the overall workforce (see Figure 2.4). In the Leeds City Region, this is followed by employment in the distribution, hotels and restaurant sector, and in the banking, finance and insurance sector, representing $19 \%$ and $15 \%$ of the labour force respectively. These sectors are characterised by different skills requirements, with distribution, hotels and restaurants primarily demanding lower levels of skills while public administration, education and health primarily demanding higher-levels of skills. 
Figure 2.4. Employment by industry in the Leeds City Region and the United Kingdom, 2018

As a percentage of total employment

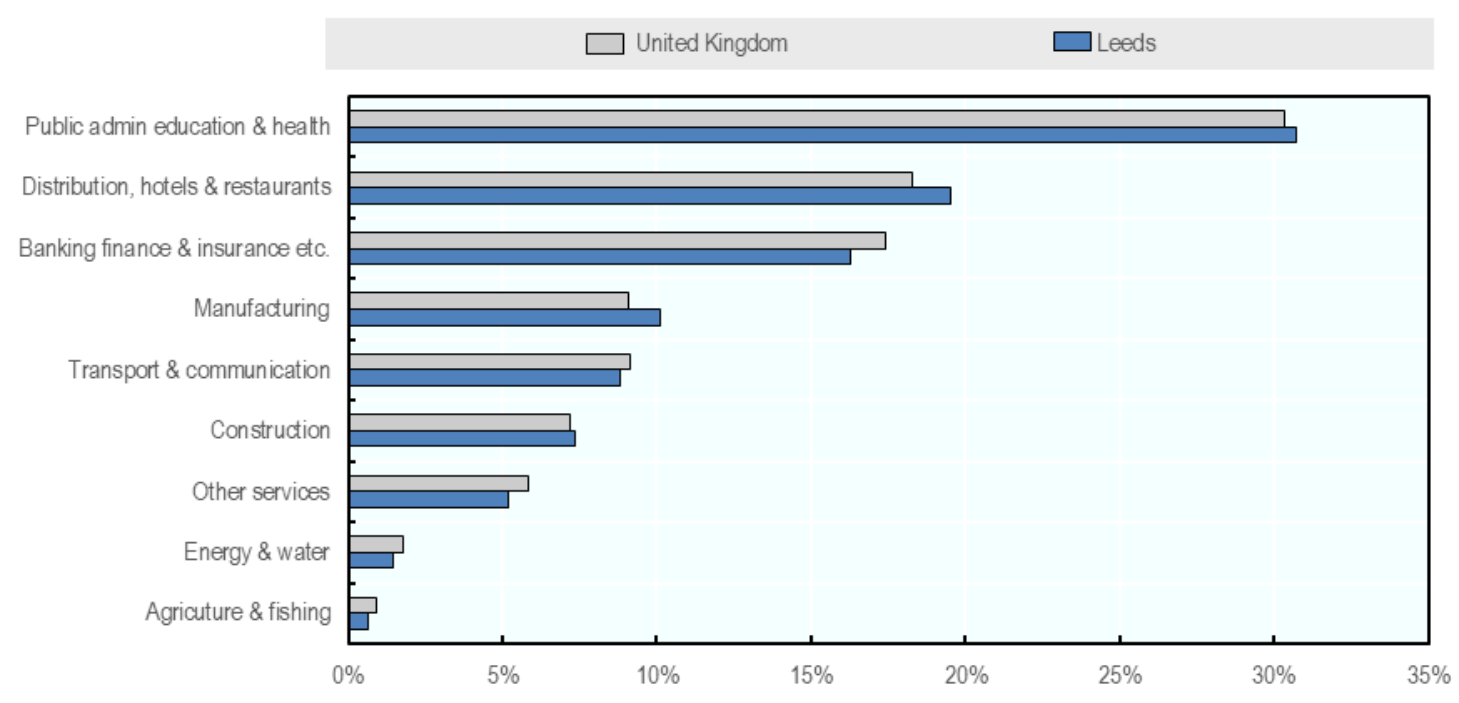

Source: UK Annual Population Survey.

\section{The Leeds City Region is moving towards higher skilled jobs}

Between 2005 and 2018, the labour market of the Leeds City Region has shifted. The share of employment in highly skilled occupations (i.e. managers, directors and senior officials; professional occupations; associate professional and technical occupations) has increased by 5 percentage points, compared to 6 percentage points in the UK. Opposite trends exist for medium-skilled (i.e. process, plant and machine operatives; sales and customer service occupations; skilled trades occupations; administrative and secretarial occupations) and low-skilled occupations (i.e. elementary occupations and skilled trades occupations) that declined from $38 \%$ to $35 \%$ and from $24 \%$ to $22 \%$ over the same period. These findings show that the Leeds City Region labour market is moving towards higher skilled jobs, however at a slower pace than the country average.

That being said, employment in caring, leisure and other service occupations has increased in the City Region, representing nearly $10 \%$ of total employment in 2018, a two percentage point increase since 2005. This category often includes low-paid occupations that do not contribute significantly to increasing the overall productivity of the area. While the UK Industrial Strategy emphasises particular high-skill sectors, digital and ICT, these sectors employ a small share of the overall labour force in the Leeds City Region. 
Figure 2.5. Employment shares by occupation, Leeds City Region, 2005-2018

As a percentage of total employment

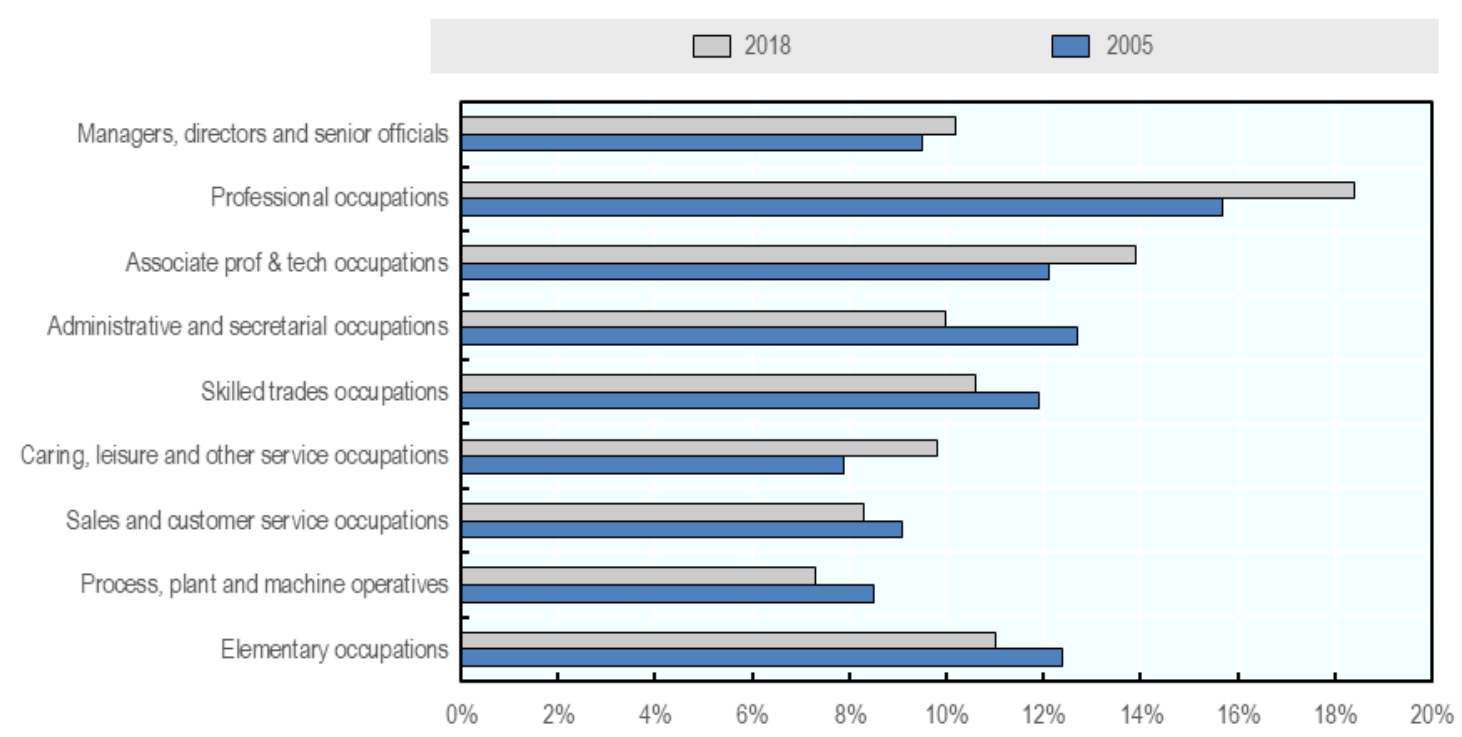

Source: UK Annual Population Survey.

\section{Educational attainment in the Leeds City Region has increased but remains below the UK average}

As highlighted previously, the number of highly educated people has significantly increased in the UK in recent years and this also applies to the Leeds City Region. With more than 115000 people enrolled in tertiary education in 2016-2017, young people represent an important source of future labour supply in the Leeds City Region that could potentially contribute to economic growth. Slightly less than $60 \%$ of graduates were employed in the Leeds City Region six months after graduation (West Yorkshire Combined Authority, 2018[45]). The share of individuals employed with NVQ3 (corresponding to secondary education) increased by 2 percentage points in the last decade while the share of people with NVQ4 and above (corresponding to tertiary education) increased by nearly 7 percentage points over the same period. At the same time, the share of people with no qualification and with basic skills has decreased by 2.5 and 2 percentage points respectively. While this data show an overall increase in educational attainment, the Leeds City Region still lags behind the overall UK average. For example, the share of people aged 16-64 with a NVQ level 4 and above is almost $40 \%$ in the UK, yet only $34 \%$ in the Leeds City Region (e.g. a 6 percentage point gap). The Leeds City Region also has higher shares of people with no or very low education levels in comparison to the national average (see Figure 2.6). 
Figure 2.6. Educational attainment in the Leeds City Region and the United Kingdom, 2018

As a share of the population aged 15-64 years

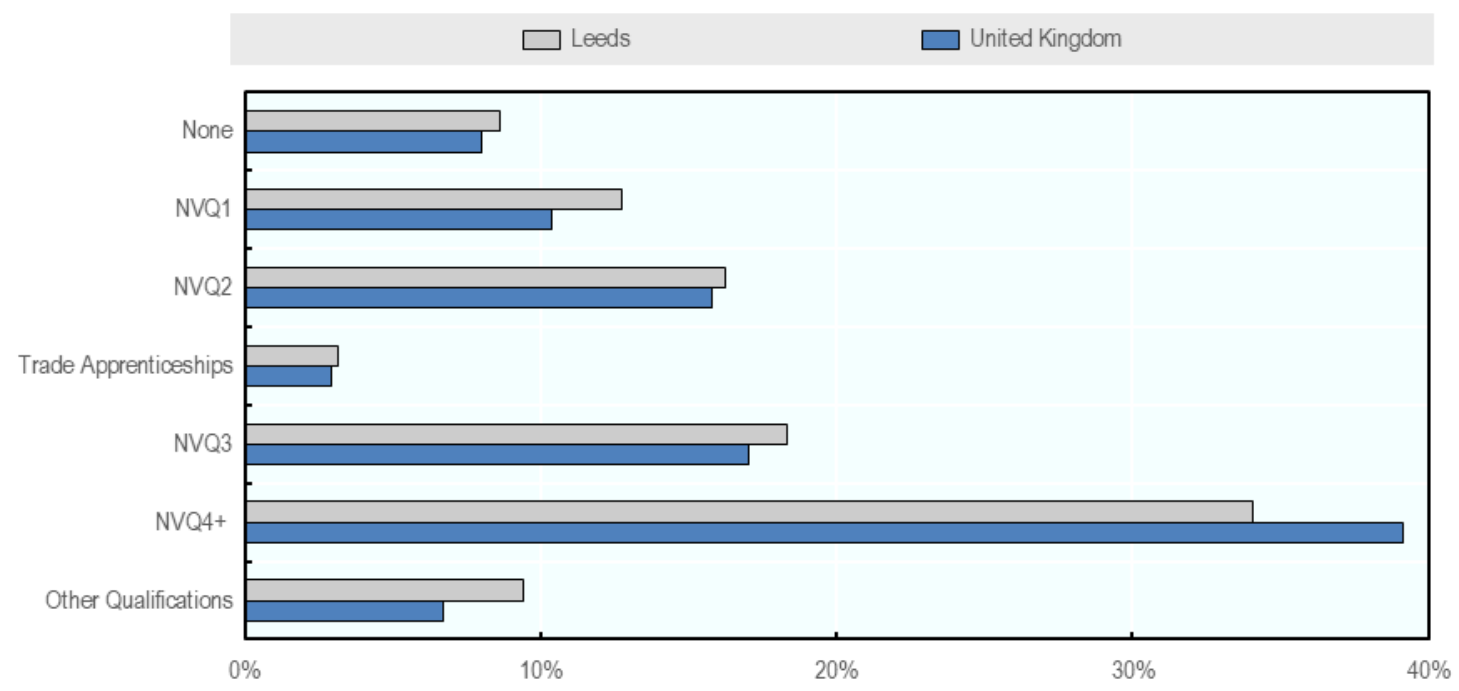

Source: UK Annual Population Survey.

\section{What are the productivity challenges facing the Leeds City Region?}

\section{The productivity gap in the Leeds City Region has widened compared to the UK average}

One of the major challenges facing the Leeds City Region is a growing productivity gap, which has increased since 2008 (see Figure 2.7). Productivity, measured as Gross Value Added per filled job, in the Leeds City Region is only $85 \%$ of the UK average, as compared with $91 \%$ a decade ago. According to the 2018 labour market report produced by the Leeds City Region, there are three main factors that partly explain this productivity gap. These include the overall skills composition of the labour force, lower average wages and an increasing share of employment in part-time work. In 2008, output per hour in the Leeds City Region stood at GBP 25.92, around $90 \%$ of UK output. As of 2017, output per hour in the City Region had risen to GBP 29.33 - just $87 \%$ of UK levels. The lower proportion of workers in high-skilled occupations is also important in explaining the relatively lower levels of productivity in the City Region. The Leeds City Region falls behind key comparative labour markets, such as the West of England, Greater Birmingham, Greater Manchester, the Liverpool City Region, and the North-East (see Figure 2.8). 
Figure 2.7. Trends in productivity, Leeds City Region, 2002-2017

Gross Value Added per filled job index, United Kingdom=100

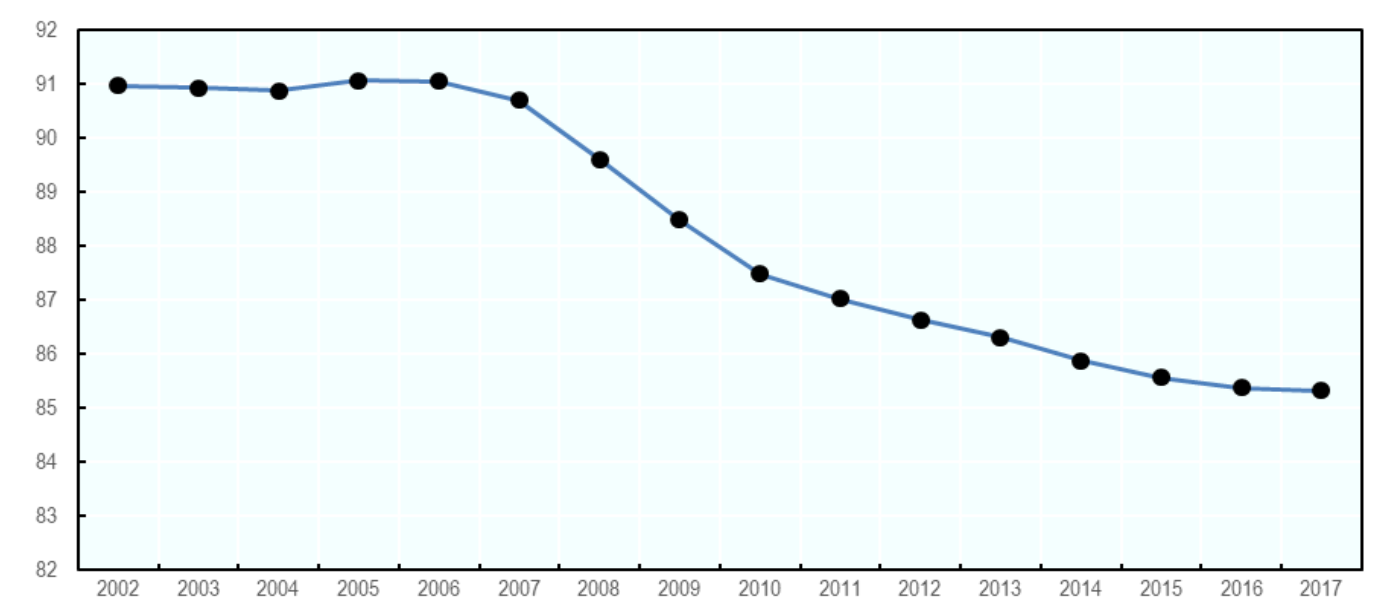

Source: (Office for National Statistics, 2019[46]).

Figure 2.8. Productivity in selected Local Enterprise Partnerships, 2017

Gross Value Added per filled job index, United Kingdom=100

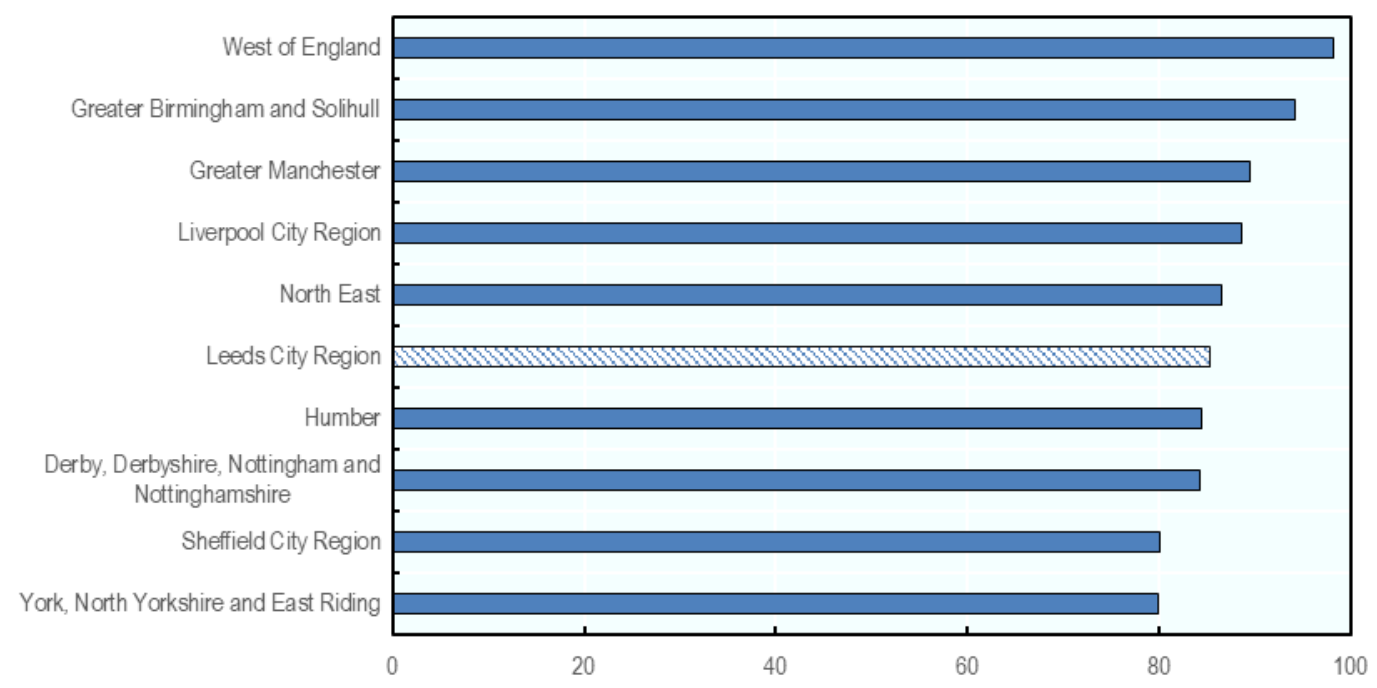

Note: This figure shows 10 LEPs, including Leeds City Region, of a total of 38 LEPs across England. These benchmark LEPs were chosen based on consultations with the Leeds City Region and the OECD's Expert Advisory Group that was established for this project. They LEPs include eight core city LEPs as well as the Humber and the York, North Yorkshire and East Riding LEPs because of their geographical proximity to Leeds.

Source: (Office for National Statistics, 2019[46]).

\section{Productivity gaps in the Leeds City Region are linked to under-performing firms}

While the industrial structure of the Leeds City Region is more similar to the overall UK average than any other Local Enterprise Partnership, the City Region has a higher proportion of businesses with relatively lower productivity. In comparison to Great Britain, the West Yorkshire (which encompasses the Leeds City 
Region) has lower levels of productivity in all sectors except the manufacturing sector, the wholesale and retail sector, the administrative support services sector, as well as the other services sector. The gap in productivity is also strong in sectors characterised by highly-skilled employment such as the information and communication sector (see Figure 2.9). These findings are in line with previous studies which find that more than $90 \%$ of the productivity deficit in comparison to the UK average is estimated to be due to underperformance within sectors as opposed to an adverse sector mix (West Yorkshire Combined Authority, 2018[45]). The majority of the people employed in the Leeds City Region operates within the 1) public administration, education, and health sector as well as the 2) distribution, hotels, and restaurants sector, which represent together around $50 \%$ of total employment in the region. Both of these sectors demonstrated limited productivity output in terms of GVA per worker (see Figure 2.10).

Figure 2.9. GVA per worker (GBP) by industry, West Yorkshire (WY) and Great Britain (GB), 2014

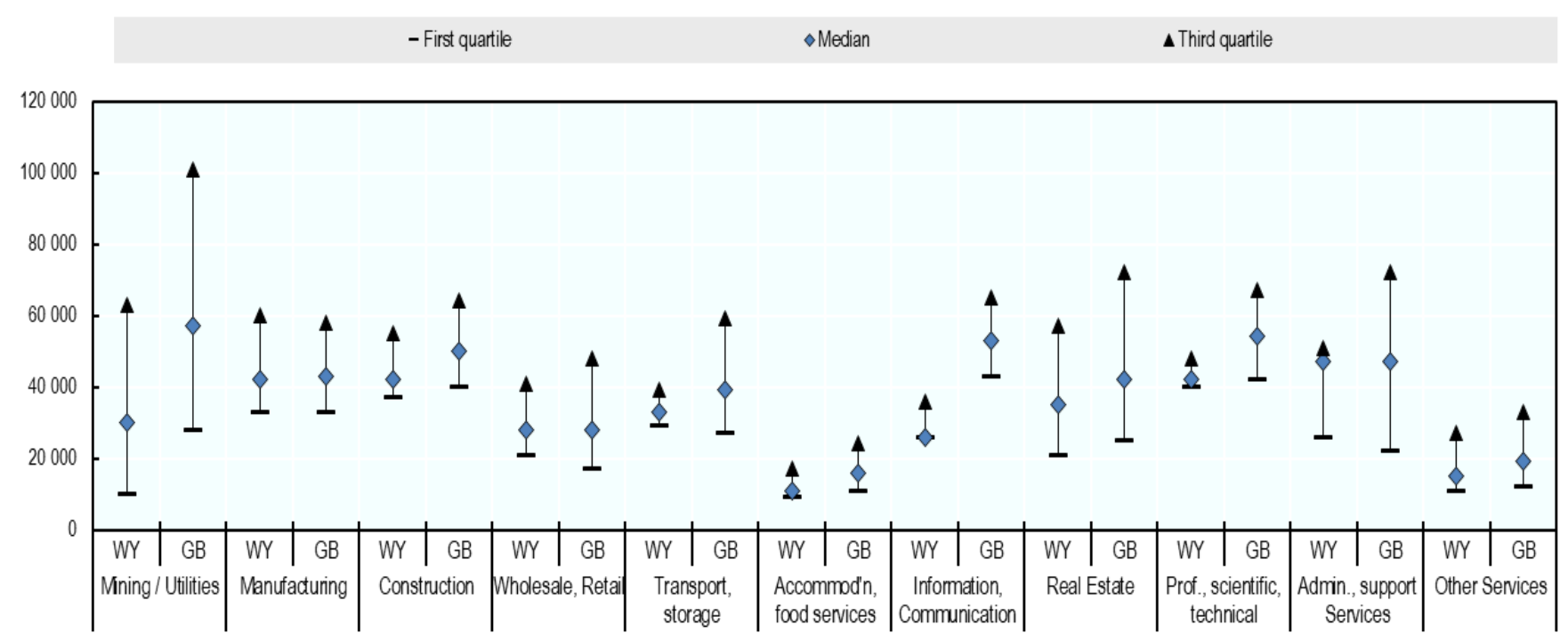

Note: Data for West Yorkshire are used as a proxy for Leeds City Region.

Source: ONS Regional firm-level productivity analysis.

Figure 2.10. Employment and Gross Value Added by sector, Leeds City Region, 2017

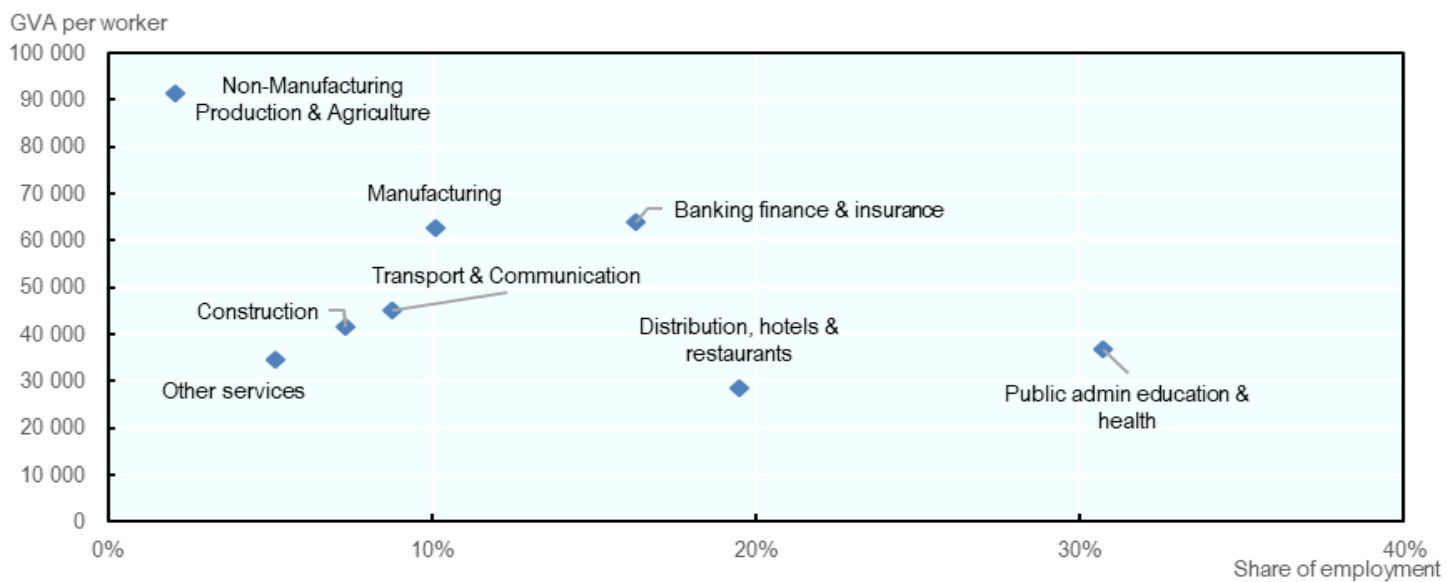

Note: Gross Value Added per worker is computed for the Yorkshire and the Humber region as data was not available for the Leeds City Region. The share of employment refers to the Leeds City Region.

Source: UK Annual Population Survey and Regional accounts. 


\title{
3 Improving the balance between the supply and demand for skills in the Leeds City Region
}

\begin{abstract}
In order to better understand how the Leeds City Region should move forward on implementing policies that aim to better use skills in the workplace, it is important to understand where local firms are reporting skills mismatches (e.g. either over or under-qualified staff). Mismatches represent either unnourished talent or untapped potential. This section examines unique subnational data from the United Kingdom to highlight the extent to which firms in the Leeds City Region are facing mismatches. Evidence from the UK Employer Skills Survey demonstrates that many firms in the Leeds City Region have over-qualified staff. Furthermore, while several firms continue to report hard-to-fill vacancies, they have taken limited action to address these issues by improving their human resources and management practices.
\end{abstract}

\section{Skills mismatches are costly and represent an inefficient allocation of workers}

\section{Many OECD countries are dealing with challenges related to skills mismatch}

Skills mismatch represents a challenge in many OECD countries. Evidence shows that high skills mismatch has a negative impact on labour productivity because of the inefficient allocation of resources (Adalet McGowan and Andrews, $\left.2015_{[47]}\right)$. In the UK, the incidence of skills mismatch (i.e. both over and underqualification) among people employed is $41 \%$, compared to $36 \%$ for the OECD. This gap is mainly driven by the relatively high share of workers reporting being under-qualified for their job (see Figure 3.1). In addition, $38 \%$ of people employed has a job in a field different to the one in which they studied in school, which is one of the highest shares among OECD countries (OECD, 2017[48]). As highlighted in the updated OECD Jobs Strategy, it is critical to look at whether the skills being provided by the education and training system are meeting the needs of the labour market (OECD, 2018[49]). Individuals reporting being underqualified for their job have skills lower than what is needed and could benefit from potential to grow through firm investments in training to avoid being stuck in a "dead end" job. Given the evidence highlighted earlier in this paper, there are significant benefits that could accrue to firms from investing in training individuals representing this type of mismatch. 
Figure 3.1. Qualification mismatch in OECD countries

As a percentage of people employed

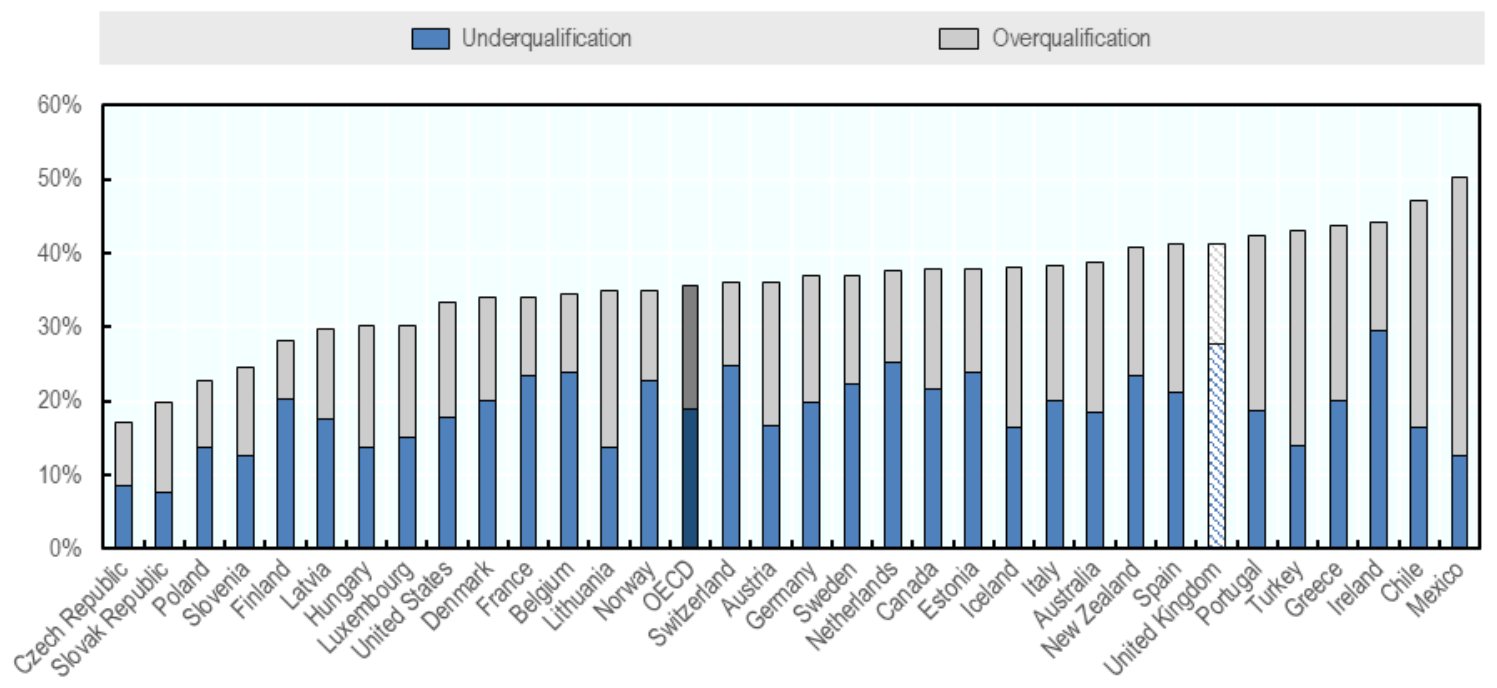

Note: According to the OECD definition, qualification mismatch is computed by comparing the modal (i.e. most common) educational attainment level for each occupation in each country and point in time, and which is used as a benchmark to measure whether individual workers' qualifications match the "normal" education requirement of the occupation. Over-qualification (under-qualification) depicts a situation for which the highest level of education achieved by an individual worker in an occupation is above (below) the modal level for all workers in that occupation. Data refer to 2015 for Canada, Chile and Turkey and to 2013 for Germany. OECD is the unweighted average of the countries shown. Source: OECD Skills for Jobs Database, 2018, https://stats.oecd.org/Index.aspx?DataSetCode=MISMATCH.

\section{Box 3.1. Data on skills mismatch and use at the local level in the United Kingdom}

Measuring skills mismatches are difficult and subject to a number of considerations in quantifying the problem, since most measures are based on individual and firm perceptions. In the UK, one of the main sources of data on skills and work organisation is the Skills and Employment Survey (SES), which has been conducted for the last 30 years and provides an assessment of how skills utilisation has varied over time. The survey focuses on the following themes: i) the skills required for the job; ii) the way work is organised; iii) the existence of opportunities for skill and career development; and iv) the perceptions of different types of insecurity. However, while this survey provides valuable data at the national level, it doesn't allow regional and local comparisons.

In order to compare the Leeds City Region with other Local Enterprise Partnerships (LEPs) in the UK, the UK Employer Skills Survey (ESS) is used in this paper. This survey, conducted by the UK Department for Education, is based on over 87000 telephone interviews with UK employers. Therefore, it is one of the largest employer surveys on skills in the world. The survey gathers information on the skills challenges that employers face within their existing workforces, the levels and nature of training investment and the relationship between skills challenges, training activity and business strategy, including high performance management practices. 


\section{Assessing skills mismatches in local economies}

Data on the different forms of skills mismatch tend to focus on measures of over- or under-qualification or over- or under-skilling. In contrast, firm-level measures of skills gaps and skills shortages are arguably more important to assess the level of skills utilisation (OECD/ILO, 2017 $[7])$. However, data are not always available at the sub-national level or does not directly measure the perspective of employers.

To fill this gap, the OECD has developed a typology to understand whether skills are being put to good use at the level of local economies. This analysis assesses the matching between supply of and demand for skills at the local level. Local areas can fall into one of four categories: (1) high skills equilibrium, where both the supply of and demand for skills is relatively high; (2) skills surplus, where the supply of skills is relatively high but the demand is relatively low; (3) skills deficit, where the demand is relatively high but the supply is relatively low; and (4) low skills trap, where both the supply of and demand for skills is relatively low.

A low skills trap can create a vicious cycle of low investments in skills and poor quality jobs. In such a situation, workers will not have the incentives to upgrade their skills, knowing they will not be able to find jobs in the local economy that use them, and employers may be reluctant to move to more skill-intensive production and services, knowing that they are unlikely to find the workers with the skills needed to fill these positions. The Leeds City Regions falls in the low skills trap, indicating that both the supply and the demand for skills are low in comparison to the other LEPs (see Figure 3.2). This match between low supply and low demand for skills can have a "lock-in" effect for the region, whereby firms are low incentives to invest in higher valued add activities, which can have negative impacts on the overall competitiveness and productivity of a region.

Figure 3.2. Comparing skills supply and demand in Local Enterprise Partnerships, 2017

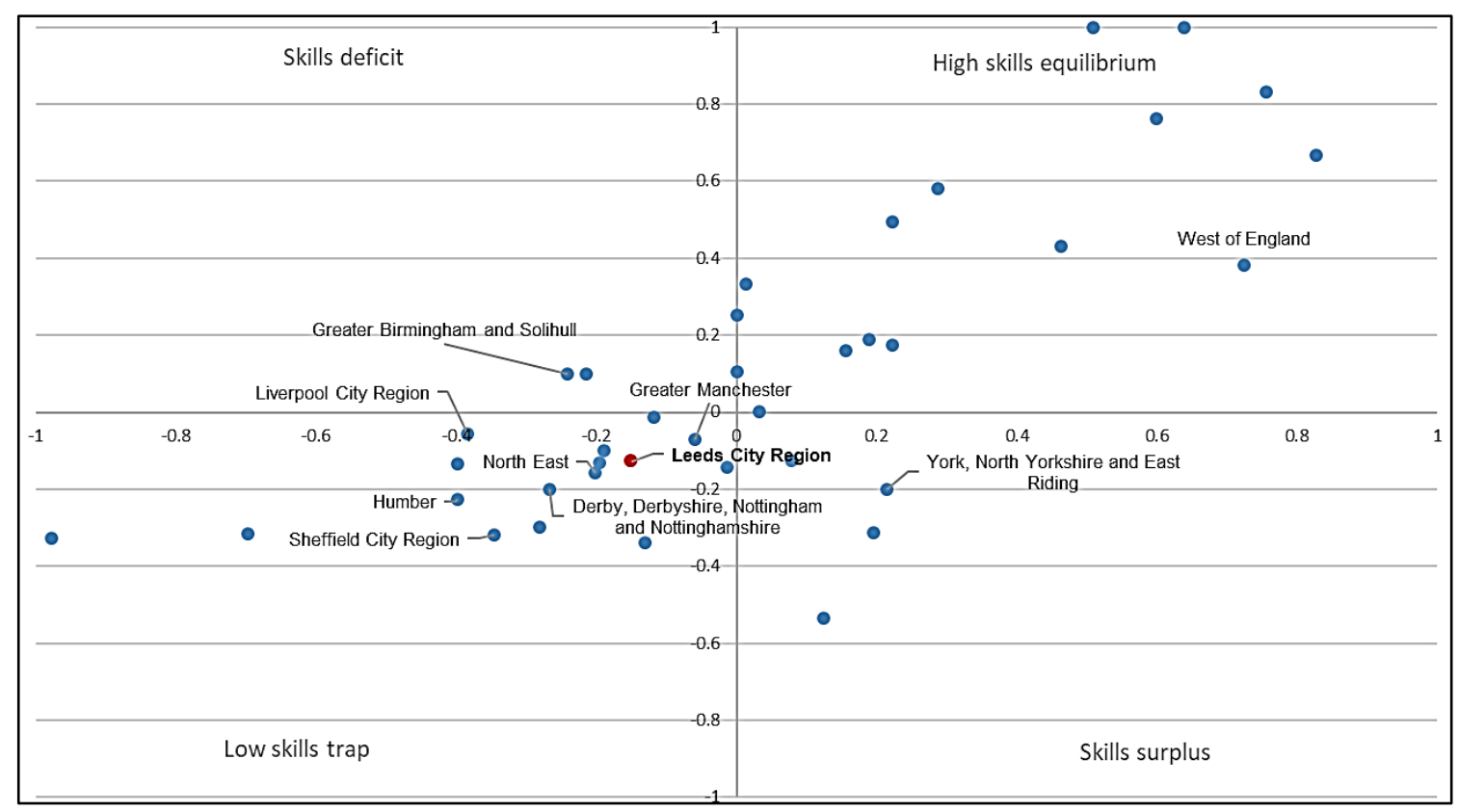

Note: The supply of skills was measured by the percentage of the population with post-secondary education. The demand for skills was approximated using a composite index: percentage of the population employed in medium-high skilled occupations and GVA per worker (weighted at .25 and .75 respectively). The indices are standardised using the inter-decile method and are compared with the national median. Further explanations on the methodology can be found in (Froy, Giguère and Meghnagi, 2012[50]).

Source: OECD calculations based on the UK Annual Population Survey and Regional Accounts, ONS. 


\section{The Leeds City Region faces a number of challenges related to skills mismatches}

\section{The Leeds City Region has a higher share of firms with over-qualified staff}

When looking at subnational level data from the UK Employer Skills Survey, the Leeds City Region had $43 \%$ of establishments reporting over-qualified staff - a relatively high share among the benchmark Local Enterprise Partnerships included in the analysis (Figure 3.3). Over-qualified staff are those who have qualifications more advanced than those required for their job. This share is similar to the Greater Manchester and the York, North Yorkshire and East Riding LEPs. This is contrasted by one of the lowest shares of firms reporting under-utilised staff $(34 \%)$, which is just below the UK average of $35 \%$. These findings indicate that there is an untapped potential in the Leeds City Region and establishments could improve their productivity and competitiveness by better using skills especially of over-qualified staff. Trend data show that both measures of skills mismatch (i.e. over-qualified and under-qualified staff) have increased in the UK between 2015 and 2017 and that smaller firms tend to have higher risks of underutilised staff.

\section{Figure 3.3. Skills mismatch in selected Local Enterprise Partnerships, 2017}

As a share of total establishments

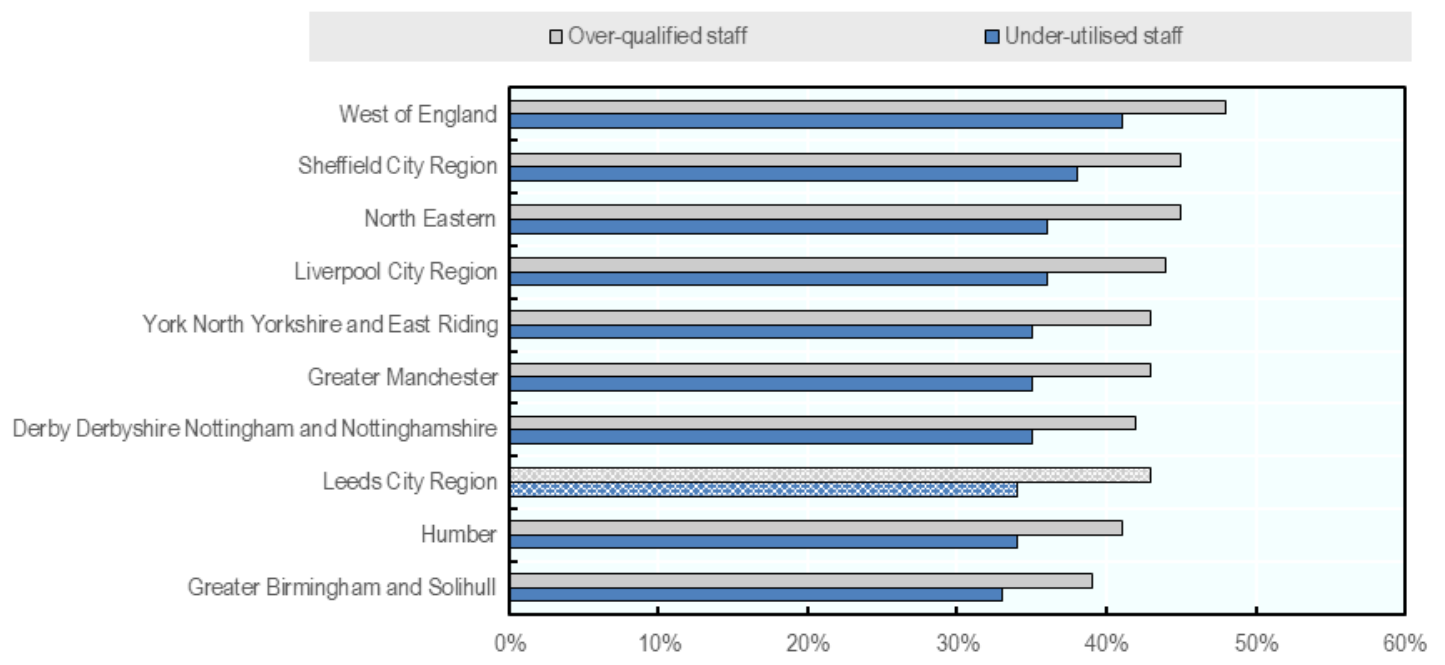

Note: In the Employer Skills Survey over-qualified staff corresponds to the proportion of staff that have qualifications more advanced than required for their current job role; under-utilised staff have both qualifications and skills that are more advanced than required for their current job role. The survey captures what employers are aware of and report. This figure shows 10 LEPs, including Leeds City Region, of a total of 38 LEPs across England. These benchmark LEPs were chosen based on consultations with the Leeds City Region and the OECD's Expert Advisory Group that was established for this project. These LEPs include eight core city LEPs as well as the Humber and the York, North Yorkshire and East Riding LEPs because of their geographical proximity to Leeds.

Source: UK Employer Skills Survey.

According to the Employer Skills Survey, skills gaps are defined as the share of staff who are not fully proficient in their job. The incidence of skills gaps was $14 \%$ in the Leeds City Region, which was slightly above the UK average of $13 \%$. In comparison to other Local Enterprise Partnerships (LEPs), the Leeds City Region is on par with York, North, Yorkshire and East Riding, as well as Greater Birmingham and Solihull. The West of England has a particularly high share of employers reporting skills gaps, at $21 \%$ (Figure 3.4) 
Figure 3.4. Incidence of staff who are not fully proficient in their job in selected Local Enterprise Partnerships, 2017

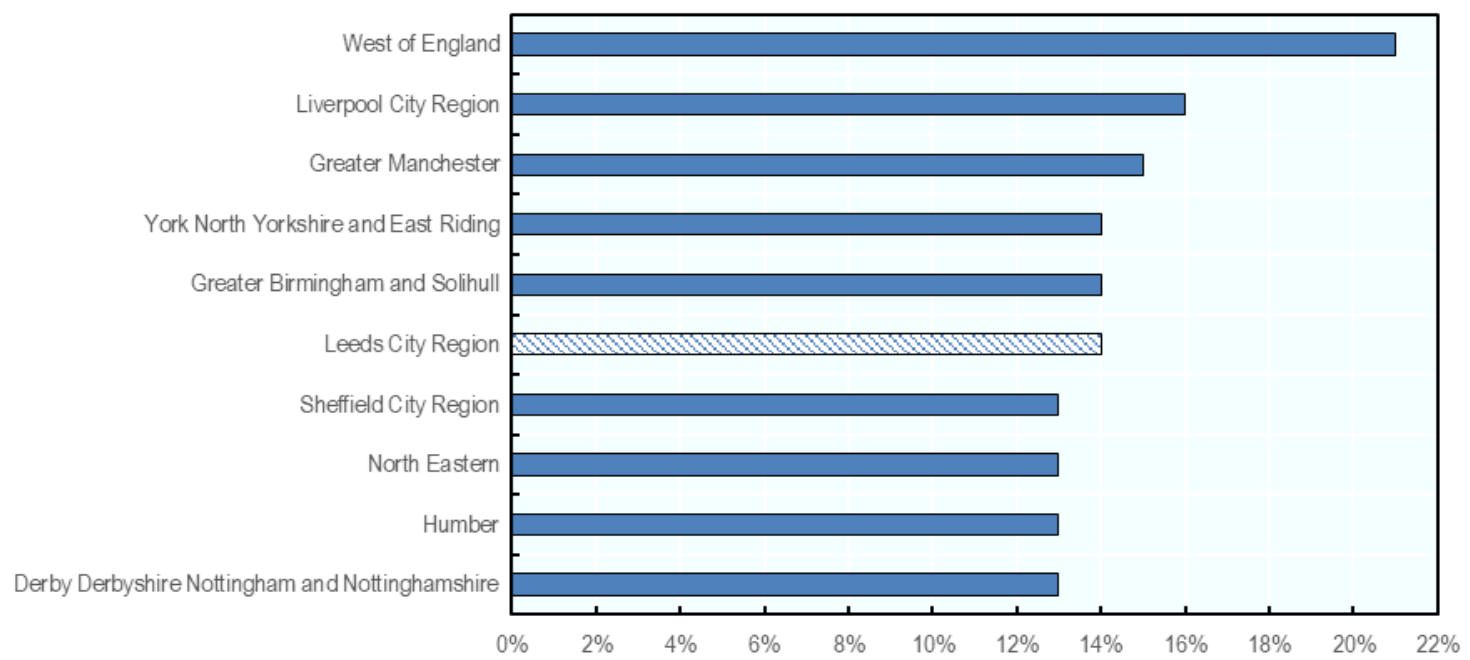

Note: In the Employer Skills Survey skills gaps are defined as the share of staff who are not fully proficient in their job. The survey captures what employers are aware of and report. This figure shows 10 LEPs, including Leeds City Region, of a total of 38 LEPs across England. These benchmark LEPs were chosen based on consultations with the Leeds City Region and the OECD's Expert Advisory Group that was established for this project. These LEPs include eight core city LEPs as well as the Humber and the York, North Yorkshire and East Riding LEPs because of their geographical proximity to Leeds.

Source: UK Employer Skills Survey.

\section{Some sectors in the Leeds City Region are more likely to experience under-utilisation of skills}

Issues related to skills underutilisation are more prevalent than skills deficiencies across all sectors within the Leeds City Region (Figure 3.5). The share of staff who are not fully proficient (e.g. do not have the required skills for the job as perceived by employers) is relatively low in the primary sector and utilities, both in Leeds City Region and in the UK, at 7\% and 9\% respectively. Similarities with the national values also exist in relation to sectors experiencing a high incidence of staff not fully proficient, namely the manufacturing, the hotels and restaurants, and the education sectors. Around one in five establishments in these sectors have staff that are not fully proficient. Leeds City Region performs better than the rest of the UK in the public administration sector, where $12 \%$ of staff is not fully proficient versus $20 \%$ nationally.

Similar to the UK average, for the Leeds City Region around one in three establishments report having underutilised staff in all sectors. Both in the Leeds City Region and in the UK, the share of underutilised staff is above $40 \%$, in the hotels and restaurants sector, the education sector, the health and social work sector as well as the art and other services sectors (see Figure 3.5). However, the Leeds City Region has a lower incidence (four percentage points) of establishments with underutilised staff in the hotels and restaurants sector, transport and storage sector, information and communications sector, and public administration sector. The opposite is true in the financial sector, where $36 \%$ of establishments have underutilised staff in Leeds, compared to $32 \%$ in the UK. The indicators presented in Figure 3.5 show that in the Leeds City Region, there are a number of firms that could better use the skills of their employees, especially in sectors with high levels of employment such as the hotels and restaurants sector, the public administration sector, the education sector and the health and social work sector. 
Figure 3.5. Proficiency of staff and underutilisation by sector in the Leeds City Region, 2017

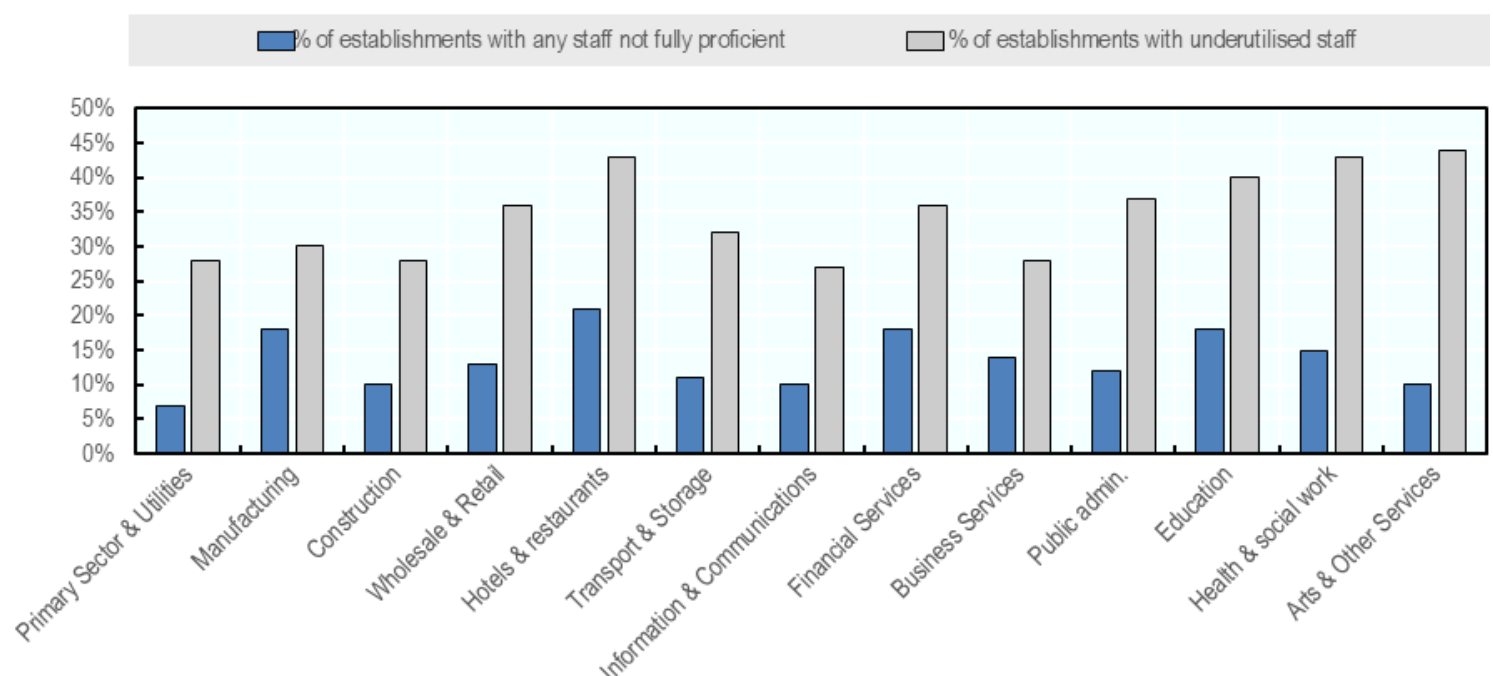

Note: Underuse of skills was measured by asking employers how many staff, if any, had both qualifications and skills more advanced than required for their current job role.

Source: UK Employer Skills Survey.

For all skill levels, the Leeds City Region is located in the middle of the distribution in comparison to the peer LEPs selected for this study. Around $45 \%$ of people who report that their skills are not fully proficient for their job work in medium-skilled occupations. While this value is close to the UK average, it is much lower than in the North Eastern and in the Humber LEPs, where the lack of proficiency in medium-skilled jobs is just below $60 \%$. The share of staff who are not fully proficient working in highly skilled jobs is $21 \%$, similar to the UK average and just below Liverpool City Region, Greater Birmingham and Solihull, and Greater Manchester. In the Leeds City Region, the incidence of staff that is not fully proficient seems to be related to firms with lower skill needs. For example, while highly skilled occupations represent $42 \%$ of total employment, only $21 \%$ of firms have employees that are not fully proficient within this skills category. The opposite is true for low-skilled jobs, which represent $21 \%$ of the total employment and $33 \%$ of the establishments having staff who are not fully proficient. This is interesting as it is perhaps these types of firms (e.g. those employing lower skilled people) who could benefit the most from investments in training and staff development. 
Figure 3.6. Staff that are not fully proficient by skills requirement for the occupation in selected Local Enterprise Partnerships, 2017

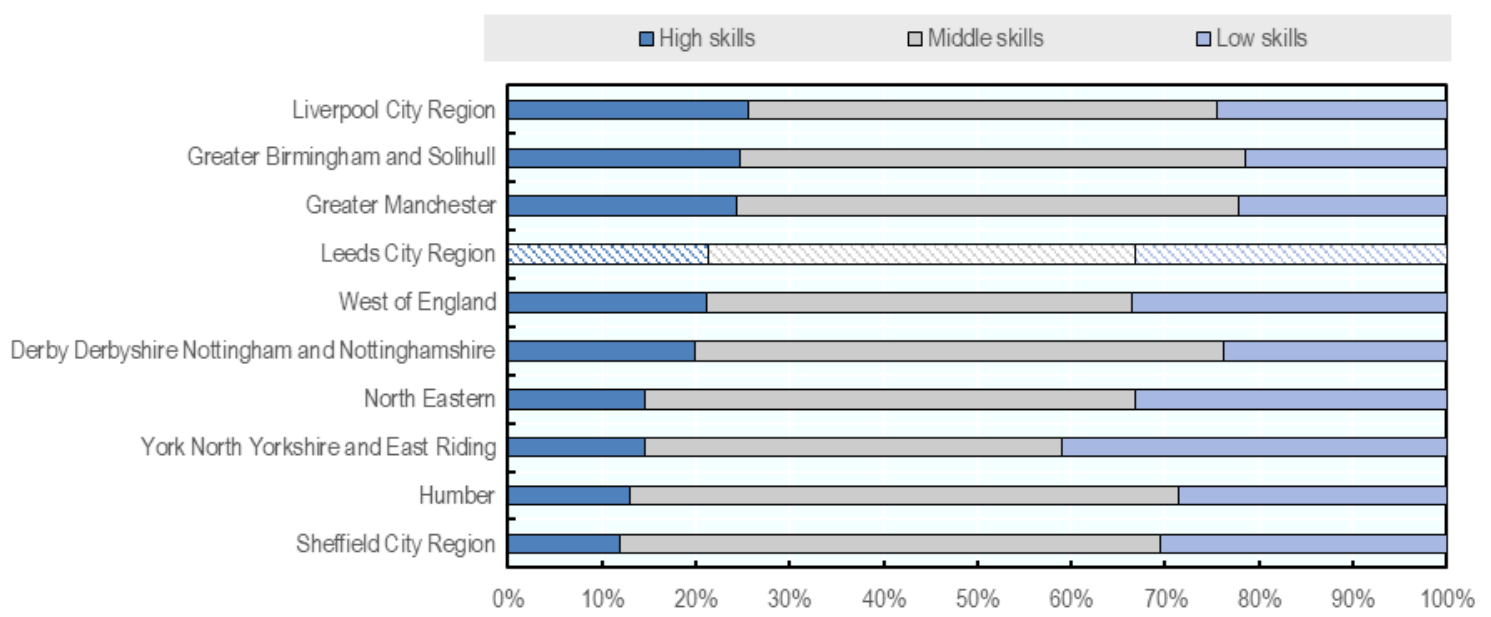

Note: High-skilled occupation include managers, professionals and associate professionals; middle-skilled occupations include process, plant and machine operatives, sales and customer service occupations, skilled trades occupations and administrative and secretarial occupations; low-skilled occupations include elementary occupations and caring, leisure and other service occupations. This figure shows 10 LEPs, including Leeds City Region, of a total of 38 LEPs across England. These benchmark LEPs were chosen based on consultations with the Leeds City Region and the OECD's Expert Advisory Group that was established for this project. These LEPs include eight core city LEPs as well as the Humber and the York, North Yorkshire and East Riding LEPs because of their geographical proximity to Leeds.

Source: UK Employer Skills Survey.

Skills gaps (i.e. staff who are not fully proficient) can limit a company's overall competitiveness as well as its optimal internal functioning (e.g. the way work is organised, the implementation of new working practices and the workload of their staff). In the Leeds City Region, similar to the UK average, $50 \%$ of firms noted that the main consequence of having skills gaps was an increase of the workload for current staff. This rate is relatively homogenous across Local Enterprise Partnerships, with the exception of Derby Derbyshire Nottingham and Nottinghamshire, and Sheffield City Region at $42 \%$ and $45 \%$ respectively (Figure 3.7, Panel D). In most cases, firms in the Leeds City Region tend to report fewer challenges than other LEPs in relation to skills gaps. Looking further at the negative impacts of reported skills gaps, firms in the Leeds City Region tend to report that the consequences include losing business orders, and delaying new products or services. That being said, $20 \%$ of firms in the Leeds City Region noted that skills gaps could cost them new business, and acted as an impediment to the adoption of networking practices (see Figure 3.7). 
Figure 3.7. Implications of skills gaps in selected Local Enterprise Partnerships, 2017

Share of firms having skills gaps
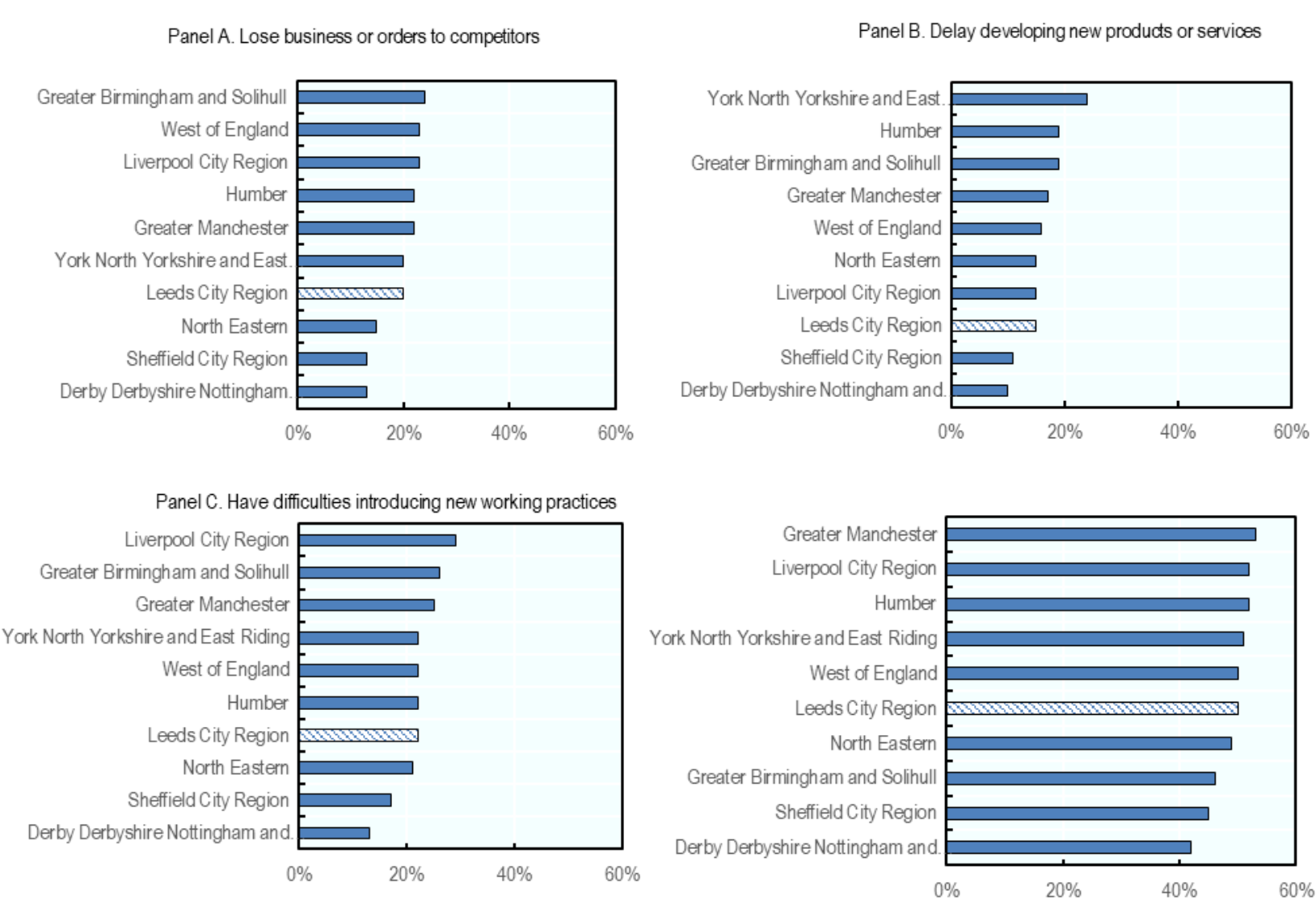

Note: This figure shows 10 LEPs, including Leeds City Region, of a total of 38 LEPs across England. These benchmark LEPs were chosen based on consultations with the Leeds City Region and the OECD's Expert Advisory Group that was established for this project. These LEPs include eight core city LEPs as well as the Humber and the York, North Yorkshire and East Riding LEPs because of their geographical proximity to Leeds.

Source: UK employer Skills Survey.

\section{Training provision and better business planning can help reduce skills gaps}

Participation in training plays a central role in improving the productivity of workers and reducing turnover. Across the United Kingdom, two thirds of employers have provided training to their staff in the last 12 months. With $65 \%$ of firms reporting training provision in 2017 , the Leeds City Region falls behind leading Local Enterprise Partnership, such as the West of England, Greater Manchester, the Liverpool City Region, Humber and Greater Birmingham and Solihull (see Figure 3.8). 
Figure 3.8. Training provision in the last 12 months in selected Local Enterprise Partnerships, 2017

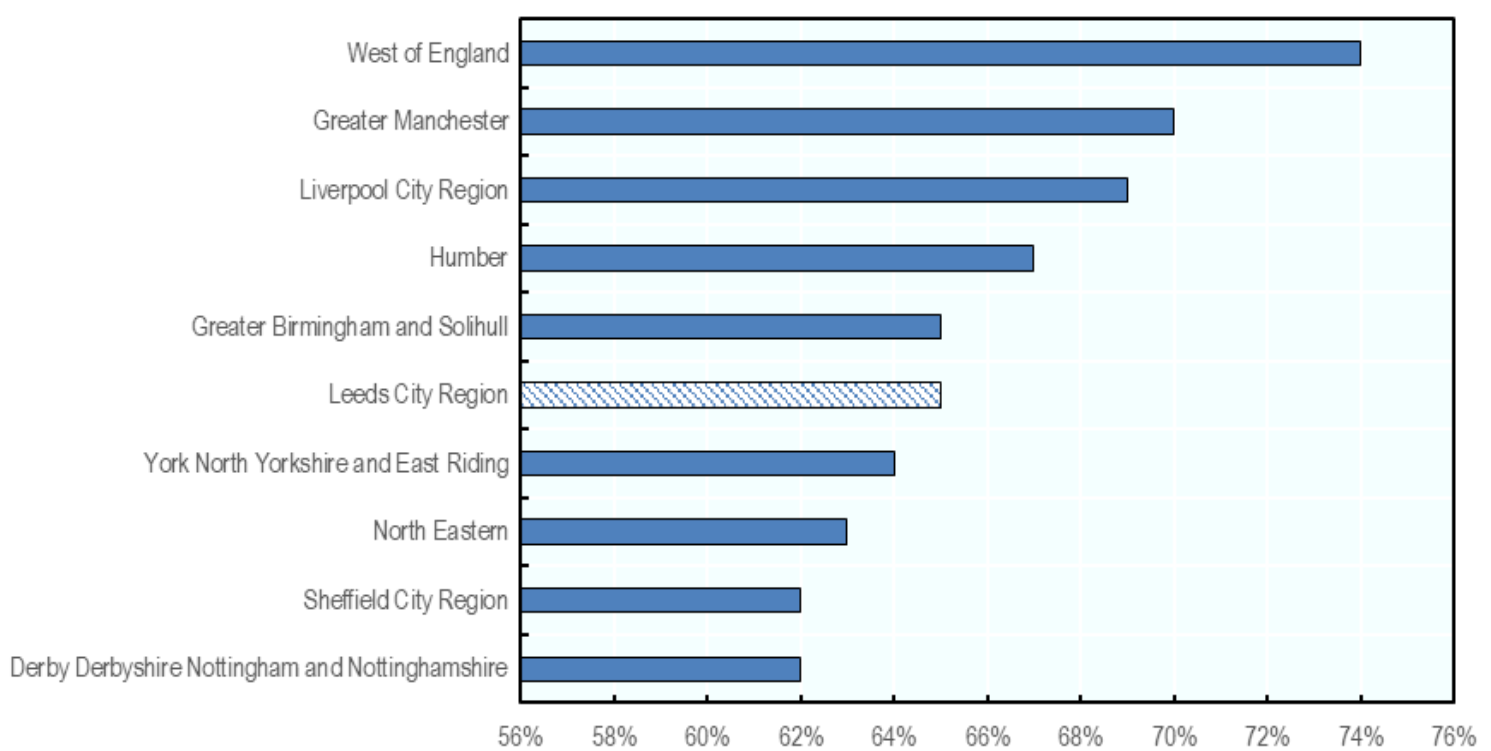

Note: This figure shows 10 LEPs, including Leeds City Region, of a total of 38 LEPs across England. These benchmark LEPs were chosen based on consultations with the Leeds City Region and the OECD's Expert Advisory Group that was established for this project. These LEPs include eight core city LEPs as well as the Humber and the York, North Yorkshire and East Riding LEPs because of their geographical proximity to Leeds.

Source: UK Employer Skills Survey.

Training is critical to enable people to stay relevant in the labour market. OECD research highlights the importance of assessing specific barriers to training for low-skilled people in order to help them stay in employment. Occupations that require low and middle-levels of skills have a higher risk of job loss from automation (OECD, 2019 $\left.{ }_{[51]}\right)$. Across the OECD, about two in five adults participate in education and training in any given year. The most disadvantaged are least likely to train, with low-skilled adults three times less likely to undertake training than the high-skilled ( $20 \%$ vs $58 \%$ ). Other groups falling behind include older people, low-wage and temporary workers, and the unemployed (OECD, $\left.2019_{[52]}\right)$. Evidence from the UK Employer Skills Survey shows that across the UK, highly skilled workers are more likely to take part in training than middle-skill and lower skilled workers. This is a similar situation in the Leeds City Region, where $60 \%$ of managers took part in a training, compared to $19 \%$ of elementary staff. Among medium-skilled occupations, participation in training is highest for administrative and clerical staff at $35 \%$ (see Figure 3.9). 
Figure 3.9. Incidence of training by occupation in the Leeds City Region and the United Kingdom, 2017

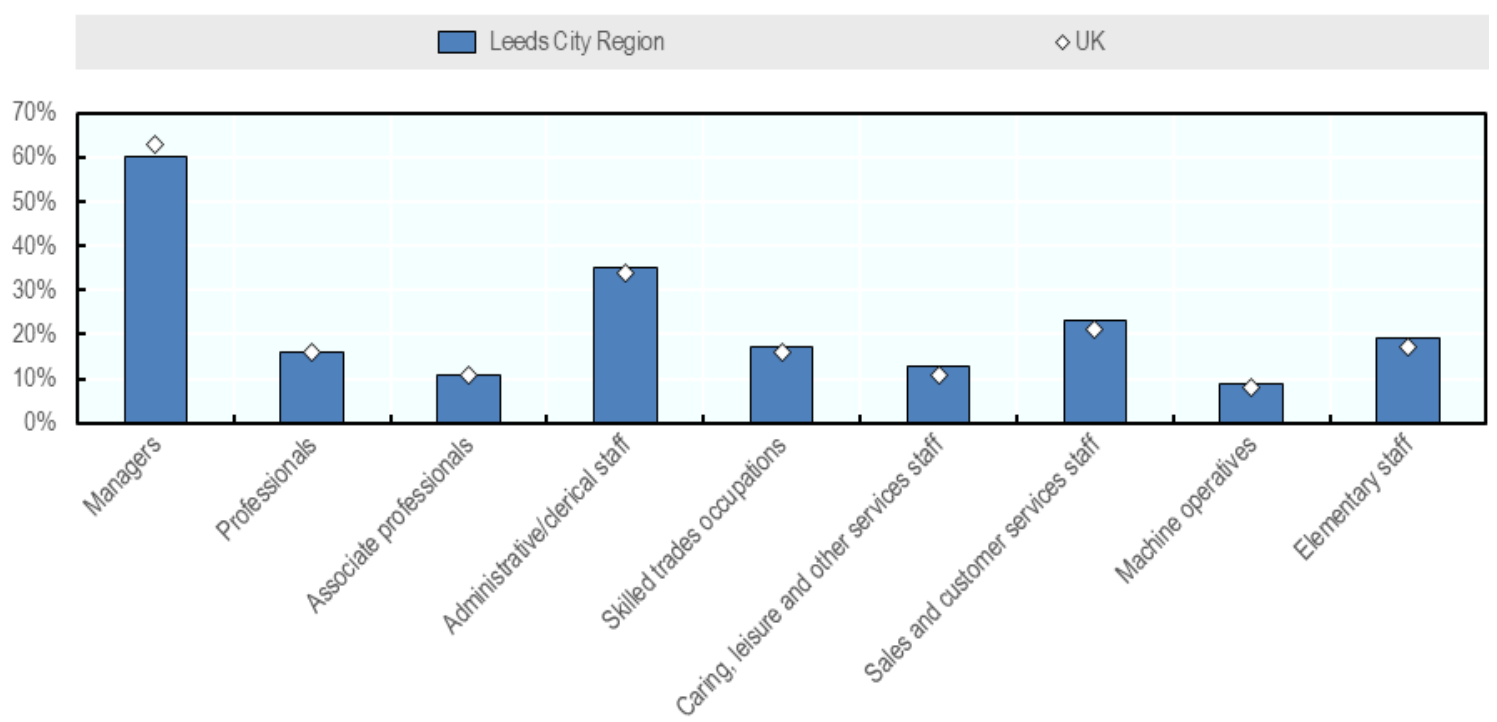

Source: UK Employer Skills Survey.

\section{There are a number of firms in the Leeds City Region reporting vacancies and overall shortages}

OECD research shows that both skills and jobs are unevenly distributed within countries, with some regions and sectors experiencing a number of challenges in the recruitment process. As shown in Figure 3.10, the incidence of vacancies is particularly high in the hotels and restaurants sector in the Leeds City Region. This sector represents $28 \%$ of total employment in the Leeds City Region compared to $6 \%$ in the UK. The primary, manufacturing and construction sectors have the highest shares of skills shortages vacancies in the Leeds City Region. Some vacancies can be hard to fill for a number of different reasons including the low number of applicants, the lack of interest in the position, the poor working conditions or the low competition with other firms in the area. In the Leeds City Region, these vacancies exist in more than 10\% of firms in the hotels and restaurants as well as the health and social work sectors. 
Figure 3.10. Type and incidence of vacancies by sector in the Leeds City Region, 2017

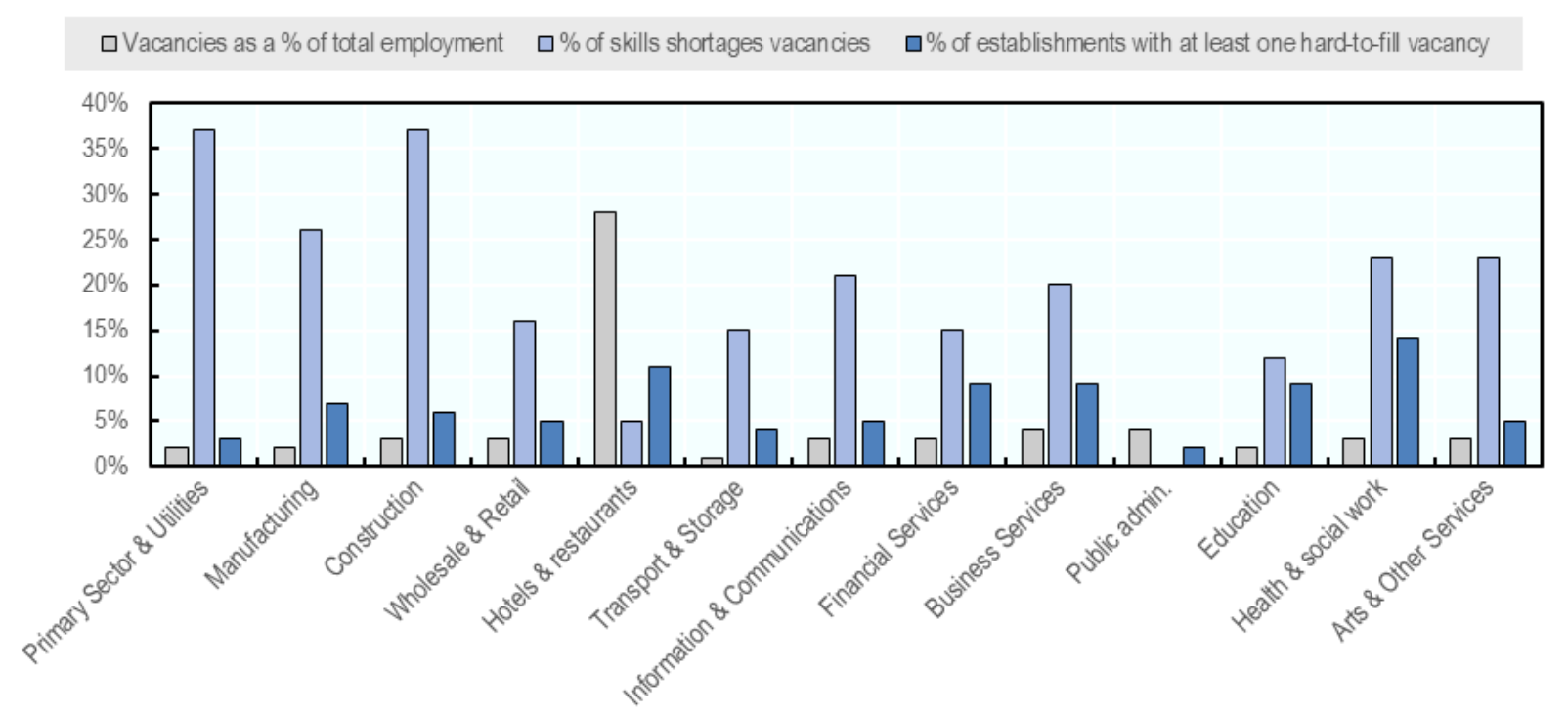

Source: UK Employer Skills Survey.

In the Leeds City Region, 92\% of firms have tried to overcome difficulties related to hard-to-fill vacancies, compared to $88 \%$ of establishments in the UK. This demonstrates that employers in the Leeds City Region are taking responsibility for addressing skills shortages and their associated challenges. National data show that firm size has an impact on the type and prevalence of actions taken, with firms having more than 250 employers being more likely than smaller firms in expanding training programmes and increasing salaries. In comparison to the other LEPs included in the analysis, the Leeds City Region performs around the average in relation to increasing training (see Figure 3.11 Panel B.) but below average on the other three dimensions, namely increasing salaries, redefining existing jobs and making the job more attractive (Figure 3.11 Panels A., C. and D.), which are all critical components of high performance workplace practices. 
Figure 3.11. Actions taken to overcome difficulties finding candidates to fill hard-to-fill vacancies in selected Local Enterprise Partnerships, 2017

Share of firms with hard-to-fill vacancies
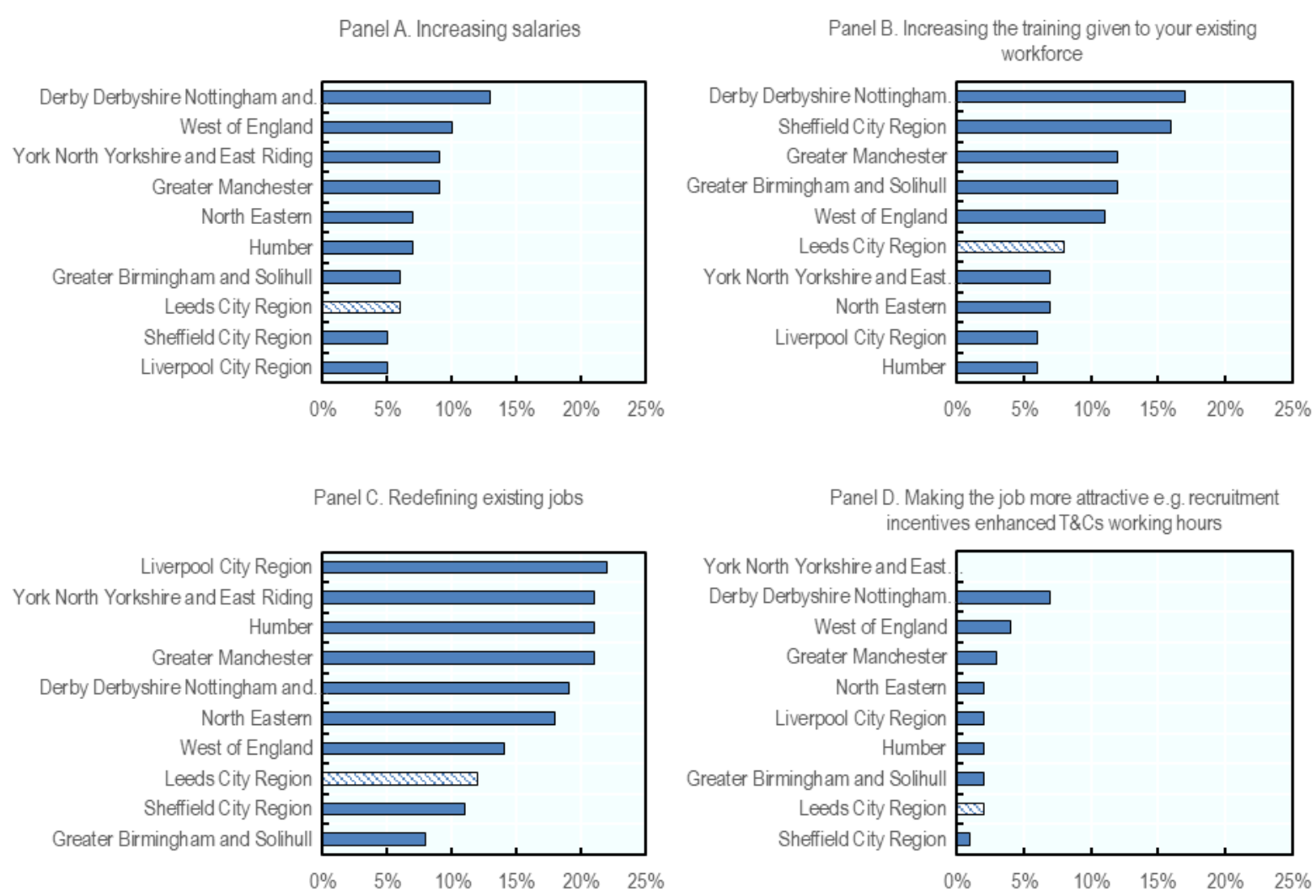

Note: This figure shows 10 LEPs, including Leeds City Region, of a total of 38 LEPs across England. These benchmark LEPs were chosen based on consultations with the Leeds City Region and the OECD's Expert Advisory Group that was established for this project. These LEPs include eight core city LEPs as well as the Humber and the York, North Yorkshire and East Riding LEPs because of their geographical proximity to Leeds.

Source: UK Employer Skills Survey.

In sum, the overall data presented in this section of the paper shows that skills gaps in the Leeds City Region are not extensive and that any gaps that are occurring do not seem to have serious implications for firms. By contrast, the data demonstrates that skill under-utilisation can undermine firm performance. As a result, it is important to look at how identifying and promoting workplace practices in the Leeds City region could generate economic benefits. 


\section{Making intensive use of skills through high-performance work practices}

The organisation of work and how a job is performed can have significant implications for how skills are used in the workplace. The evidence shows that there is a strong link between firms that adopt high-performance work practices and skills use. The share of firms adopting these practices in the Leeds City Region is 10\%, which is slightly above the UK average of $9 \%$. However, only $50 \%$ of these local firms are likely to conduct training needs assessments. To improve local productivity outcomes, there is an opportunity in the Leeds City Region to promote high-performance work practices to more firms.

High-performance work practices can help to better use skills among workers in the Leeds City Region

\section{High-performance work practices (HPWPs) are associated with higher skills use}

The literature has well documented that productivity gaps across firms are determined to a great extent by the different use of advanced management practices (i.e. monitoring, goal setting, and financial incentives). Overall better managed firms tend to hire highly skilled workers and to have lower turnover, which results in higher productivity (Bender et al., 2016[6]). The role of management practices, together with technology adoption, as tools for increasing productivity have been broadly discussed in the 2019 Business Productivity Review (BEIS and HM Treasury, 2019 ${ }_{[53]}$ ). Among the actions identified, the review highlighted a number of initiatives to better develop leadership and management skills, with a specific focus on SMEs.

Jobs that involve simple and repetitive tasks are less likely to result in strong engagement from employees, and are therefore less likely to have employees fully applying their talent within the workplace. Work practices need to enhance the notion of career, participation, ownership and well-being, which are factors that make employees engaged or committed to the organisation and therefore willing to maximise the use of their skills $\left(\mathrm{OECD} / \mathrm{ILO}, 2017_{[7]}\right)$. A number of theories have tried to explain what shapes the organisation and management of work and, with it, skills use. Examples include: 1 ) national cultures (Hofstede, 2001 [54]); 2) national institutional arrangements (Hall and Soskice, n.d.[55]); 3) national or sectoral business systems (Whitley, 1992[56]) and (Smith and Meiksins, 1995[57]); 4) product market strategies (Schuler and Jackson, $2011_{[58]}$ ); and 5) technology (Autor, Levy and Murnane, 2003[59]). All, however, have limitations and there is increasingly acceptance that employer choices also have a role, particularly when it comes to skills use (see for example (Sung and Ashton, 2015[60])). 


\section{Box 4.1. Good work - The Taylor Review of modern working practices, United Kingdom}

Similar to other OECD countries, the UK labour market is going through deep changes as a consequence of automation and technological change. The Taylor Review of modern working practices, released in 2017, analysed the implications of new forms of work for both workers and employers.

The Review examines modern working practices and highlights that employers play a major role in improving workers outcome through good workplace practices. In addition, the Review states that improving work design can make an important contribution to tackling issues related to the UK's low productivity. In relation to management practices, it affirms that "Good Work is shaped by working practices that benefit employees through good reward schemes and terms and conditions, having a secure position, better training and development, good communication and ways of working that support task discretion and involve employees in securing business improvements."

Source: (Taylor et al., 2017[611])

Although there is no agreement on the range and type of practices that constitute high-performance work practices, the higher use of skills is generally associated with such work practices. HPWPs are generally defined as including employee reward programmes, flexible job descriptions, regular performance appraisals, and mentoring and leadership development courses in the workplace (OECD/ILO, 2017[7]) (OECD, 2016[62]). Based on US research, (Appelbaum et al., 2000[63]) have argued that HPWPs provide the optimal system for employers that fosters a skilled, committed, involved workforce and elicits discretionary effort from workers. In UK policy parlance, it is "a general approach to managing organisations that aims to stimulate more effective employee involvement and commitment to achieve high levels of performance" (Belt and Giles, 2009[64]).

Effective HPWPs are characterised by three main components: i) workers having the ability to use their skills (A); ii) workers having the motivation to use their skills (M); and iii) workers having the opportunity to use their skills (O) - the so-called "AMO" framework (Appelbaum et al., 2000[63]). The components and definitions of the framework are presented in detail in Table 4.1. Effective skills utilisation only occurs when all three components of the AMO framework are in place (Warhurst and Findlay, 2017[65]). The enablers approach provides a framework for identifying management practices that induce better skills utilisation. The suggestion is that through HPWPs, firms can lever increased productivity and profits, the benefits of which are also shared with employees. 
Table 4.1. The AMO (Ability - Motivation - Opportunity) framework to skills utilisation

\begin{tabular}{|c|c|}
\hline Component & Definition \\
\hline Ability & $\begin{array}{l}\text { Having an appropriately skilled workforce, through recruitment, selection and training. These skills include } \\
\text { general as well as occupation- and firm-specific skills and being multi-skilled. }\end{array}$ \\
\hline Motivation & $\begin{array}{l}\text { Three types: } \\
\text { - } \quad \text { extrinsic/financial, meaning 'gainsharing' reward systems, distilled down to 'pay-for- } \\
\text { - intrinsic, meaning workers being challenged in work, thereby inducing greater satisfaction and } \\
\text { commitment; } \\
\text { induced through an organisational 'climate of trust' and workers having long-term stake in the } \\
\text { organisation. }\end{array}$ \\
\hline Opportunity & $\begin{array}{l}\text { Workers having substantive participation in work, which requires them having: } \\
\text { - } \quad \text { responsibility and authority to problem solve; } \\
\text { - } \quad \text { greater autonomy and control over decisions; }\end{array}$ \\
\hline
\end{tabular}

Source: (Appelbaum et al., 2000[63])

Several studies provide compelling evidence of a strong and positive relationship between HPWPs and firm productivity (e.g. (Combs et al., 2006[66]); (Jiang et al., 2012[67]). Illustratively, in their Australian survey, (Boedker et al., 2011[68]) found that firms with HPWPs out-performed firms classified as being low performance workplaces. Those firms classified as HPWPs:

- had $12 \%$ higher productivity, meaning that for every USD 1 of investment, they made 12 cents more revenue;

- had higher profits, with margins being three times higher, and they were more likely to meet their financial targets;

- were more innovative, with product innovation being $25 \%$ higher and process innovations being $30 \%$ higher;

- offered better employee experiences, resulting in lower turnover, higher job satisfaction, and more employee learning and development;

- had an average gain per firm of USD 40000 per employee.

Reference to HPWPs helps identify the point of intervention for improving skills use - management and organisational practices, specifically those practices that provide for suitably skilled workers and the motivation and opportunity for those workers to use those skills. What it also does is link skills utilisation to business performance though those practices. As (Findlay, Commander and Warhurst, 2011[69]) explain: "Effective skills utilisation requires management and organisational practices that support, inspire and enable employees to use their skills to best effect to improve business or organisational outcomes."

There may be a number of triggers for firms to start focusing on better skills use (for example, moving into new product markets, having recruitment and retention problems, or government regulation) and there may be a number of outcomes from this better skills use (for example increased productivity, innovation and employee engagement), but the route from the first to the last is through the management and organisational practices (Warhurst, 2014[70]). The right workplace environment has to be created for skills utilisation to flourish. According to Skills Australia (Skills Australia, 2012[26]), these enabling practices include leadership and management values and style, organisational culture, good communication and job design that offers workers autonomy and participation. To this end, if better skills use is to occur there needs to be organisational development within firms that introduces and embeds such practices.

The solid line in Figure 4.1 show the old emphasis on workforce development in which, while it was recognised that workforce development needed to contribute to business development, how it did so was 
something of a black box because too little attention was made to management practices that levered the ability of workers. The broken lines show that the link between the two is organisational development that is, the internal introduction of ways of managing organisations that support workforce development including better skills use. Moreover, this new approach also recognises that the direction of change can be two way. Workforce development can require organisational development in order to deliver business development. It can also be the case that business development, whether driven by positive or negative circumstances, can lead to internal organisational changes which in turn impact workforce development.

Figure 4.1. Linking business, organisational and workforce development

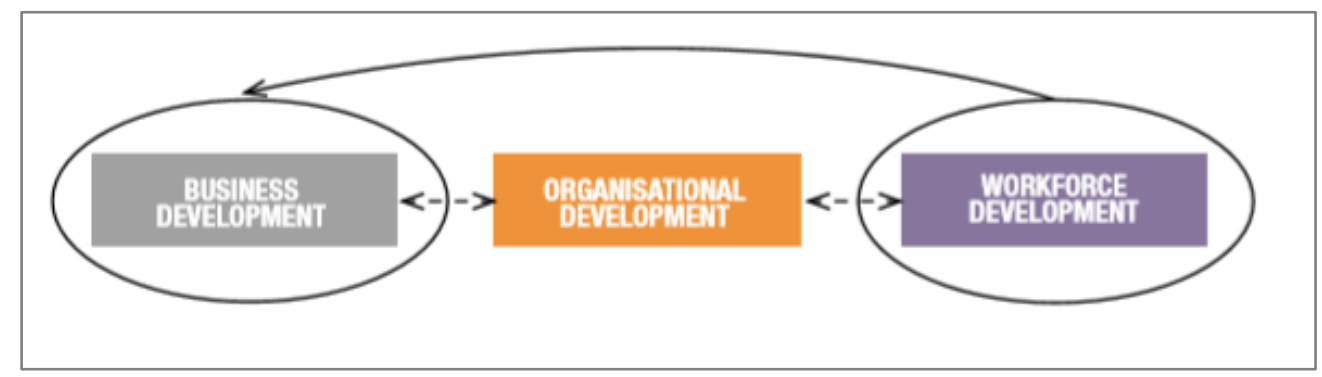

Source: (Warhurst, 2014[70])

Despite the evidence of performance benefits for firms, there can be many reasons why firms do not already have HPWPs, particularly in SMEs. In addition to the lack of managerial skills noted above, SMEs, for example, can have particular challenges. Owner/managers of SMEs tend to work under heavy, immediate pressures and have little time for long-term market analysis and business planning. Even in larger firms, frontline managers or supervisors often have very immediate concerns - operations, making sure customers are served or hotel rooms are cleaned, for example. They often do not have, or are not able to see the big picture; they just need and want workers to focus on the task at hand. Even when managers in SMEs and larger firms know that change is needed, and better using the skills of their workers would be advantageous, these managers do not have the capabilities and/or capacities to make those changes alone.

Better use of skills can improve firm productivity, innovation and profitability as well as improve employee job satisfaction, engagement and retention (Jensen et al., 2007[71]) (Skills Australia, 2012[26]) (OkaySomerville and Scholarios, 2013[72]). A key premise is that skills utilisation will be high in companies with HPWPs. Better use of skills can thus help improve workers' material and non-material wellbeing, improve firm performance across a number of measures and lay the basis for local skills policy that can support positive change in local economies. There is thus good reason and, through the enablers approach, a framework through which firms might be encouraged by government to support better skills utilisation in firms to their own and their workers' benefit (Warhurst and Findlay, 2017[65]) (OECD/ILO, 2017[7]).

There tends to be a strong relationship between the adoption of high-performance practices and skills use in the workplace (see Figure 4.2). England (UK), Australia, New Zealand, the United States, Canada and the Nordic countries show high performance on both the intensive use of skills and the use of HPWPs. 
Figure 4.2. High performance work practices and the use of skills in the workplace in OECD countries

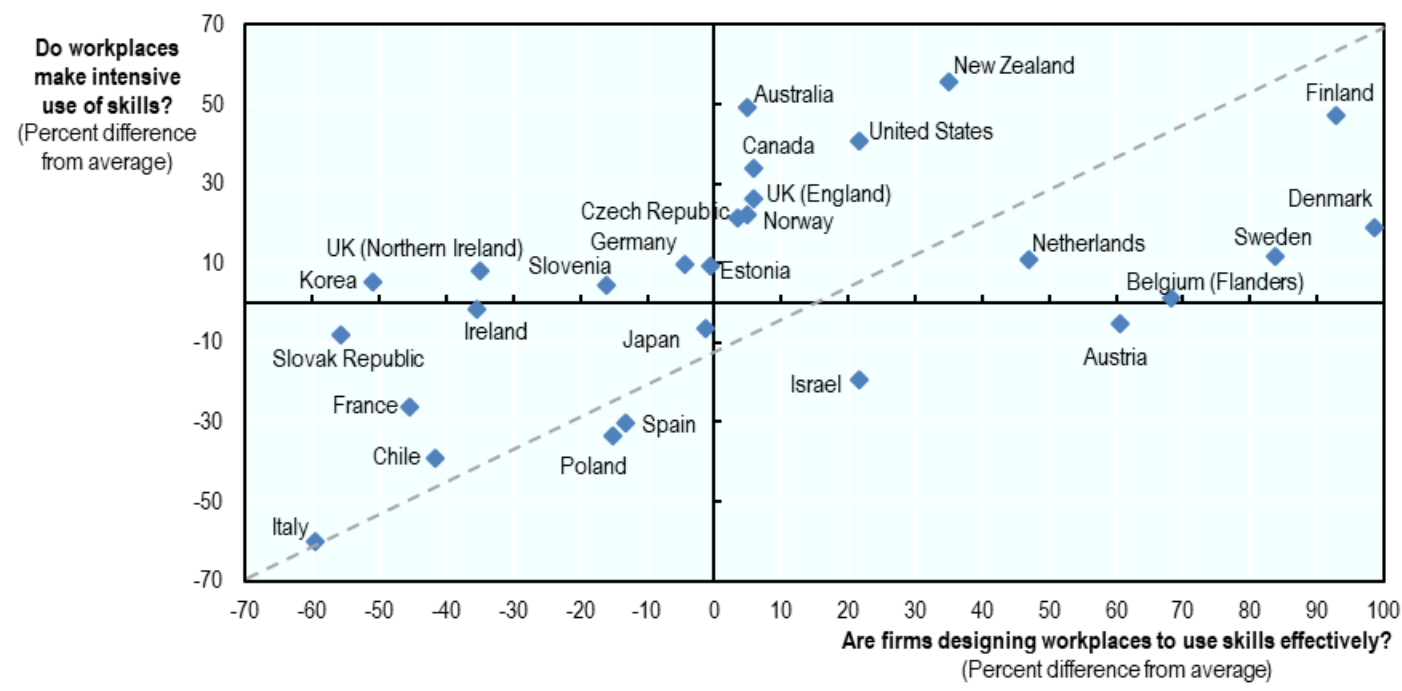

Note: Note: The figure is based on indicators from the Skills Strategy Dashboard, using normalised scores of the following aggregated indicators: "Do workplaces make intensive use of skills?" and "Are firms designing workplaces to use skills effectively?", both based on PIAAC.

Source: OECD (2019), Skills Strategy, https://doi.org/10.1787/9789264313835-en.

\section{Assessing the prevalence of high-performance workplace practices in England}

\section{The prevalence of high performance workplace practices in England is high but there is room for improvement}

On average across OECD countries, about one in four jobs apply HPWPs more than once a week. The average share of jobs adopting HPWPs is the highest in Denmark (42\%), followed by Finland (41\%), Sweden (40\%) and Flanders, Belgium (36\%). The mean HPWP index of England (UK) is $27 \%$, slightly above the OECD average (Figure 4.2, Panel A). When considering work organisation only, about $23 \%$ of jobs in England (UK) demonstrate high adoption of HPWPs, again slightly above the OECD average of $22 \%$ (Figure 4.2, Panel B). In terms of management practices, bonuses are less used in England than across the OECD $(25 \%$ vs $46 \%)$, while training and flexible working hours are more common (Figure 4.2 , Panel C). On average, $62 \%$ participate in training in England vs. $55 \%$ across the OECD and $74 \%$ enjoy flexible working hours vs. $68 \%$.

Work organisation and management practices are associated with the higher use of workers' skills at work. HPWP practices can also affect the intensity of skills use at work, as highlighted in PIAAC. English workers who benefit from work flexibility in the sequence of tasks, speed of work, how to do the work; instructing, teaching and training others; sharing information with co-workers; organising own time; and planning own activities tend to make better use of their reading, writing, numeracy, ICT and problem-solving skills at work than those who do not.

Low work flexibility in how a worker performs tasks on the job is often associated with a poorer use of numeracy and problem-solving skills at work than on average across the OECD. Management practices influence the intensity of skills use at work. PIAAC data illustrate that flexible working hours, training opportunities, and bonus payments are associated with high use of skills at work among English workers. This association with flexible working hours is the strongest for ICT skills, followed by numeracy and problem solving skills at work. When comparing the English average to the OECD average, skills use at work is especially responsive to flexible working hours. Offering training opportunities tends to be highly correlated with the frequent use of writing and ICT skills. 
Figure 4.3. High-performance work practices in OECD countries

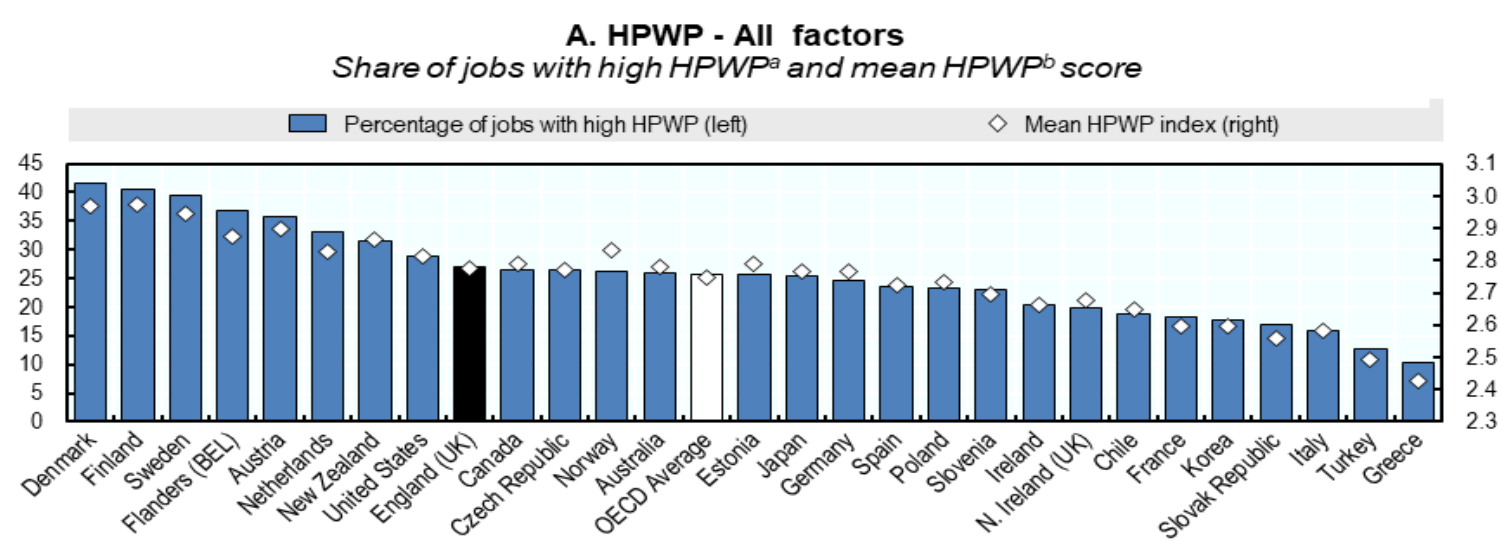

B. HPWP - Work organisation only

Share of jobs with high HPWPa (work organisation only) and mean HPWP (work organisation

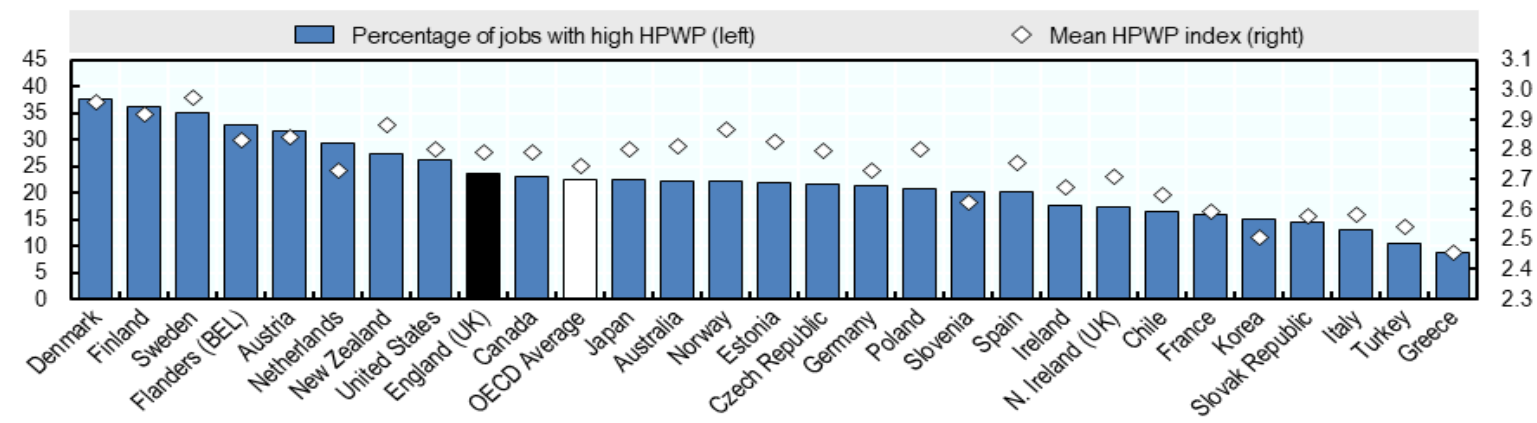

C. HPWP - Management practices

Prevalence of HPWP management practices

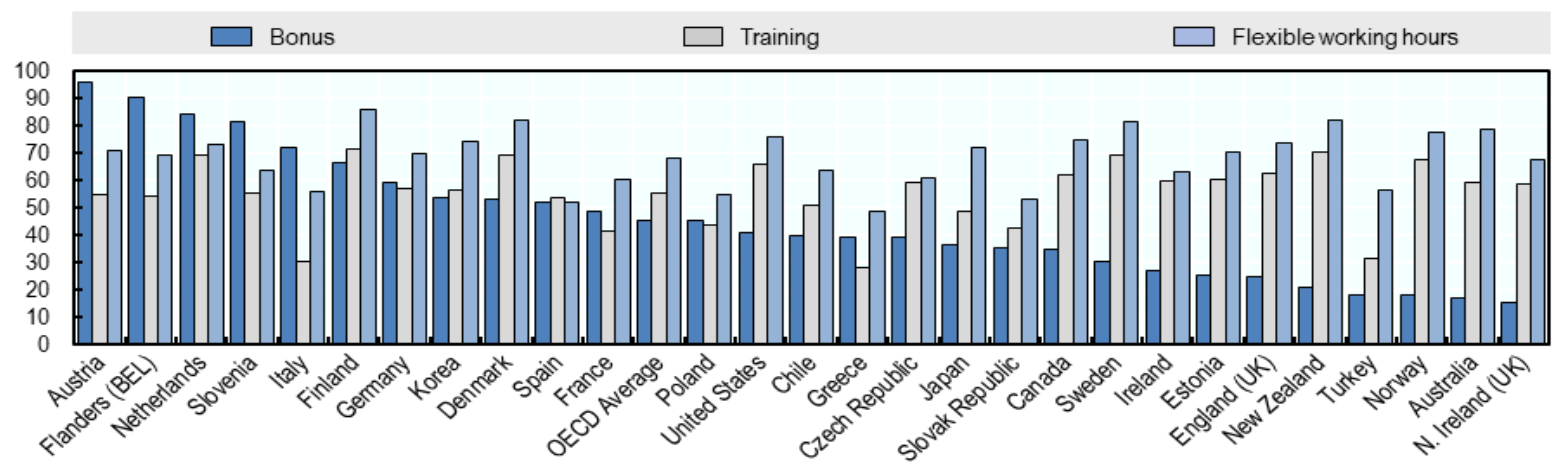

Note: a) Share of workers in jobs where the summary HPWP is above the top 25th percentile of the pooled distribution. b) Average value, across jobs, of the HPWP index. The HPWP index is a sum scale of all subcomponents shown in Panel I or summing the scales of the work organisation subcomponents only (Panel II). c) Share of workers receiving bonuses (bonus), having participated in training over the previous year (training) or enjoying flexibility in working hours (flexible working hours).

Source: OECD (2016), OECD Employment Outlook 2016, OECD Publishing, Paris, http://dx.doi.org/10.1787/empl_outlook-2016-en . 


\section{Assessing the prevalence of high-performance workplace practices in the Leeds City Region}

The UK Employment Skills Survey considers 21 HPWPs practices divided into 5 main dimensions: planning, organisation, skills, rewards and autonomy. Based on the idea that the adoption of more practices maximises their impact, HPWPs firms are those having adopted at least 14 out the 21 HPWPs. The share of firms adopting HPWPs practices in the Leeds City Region is slightly above the UK average (10\% vs. 9\%). However, the City Region performs below leading regions among those used for comparison, such as Greater Manchester, Greater Birmingham and Solihull, and the Humber.

Figure 4.4. Share of firms having adopted HPWPs in selected Local Enterprise Partnerships, 2017

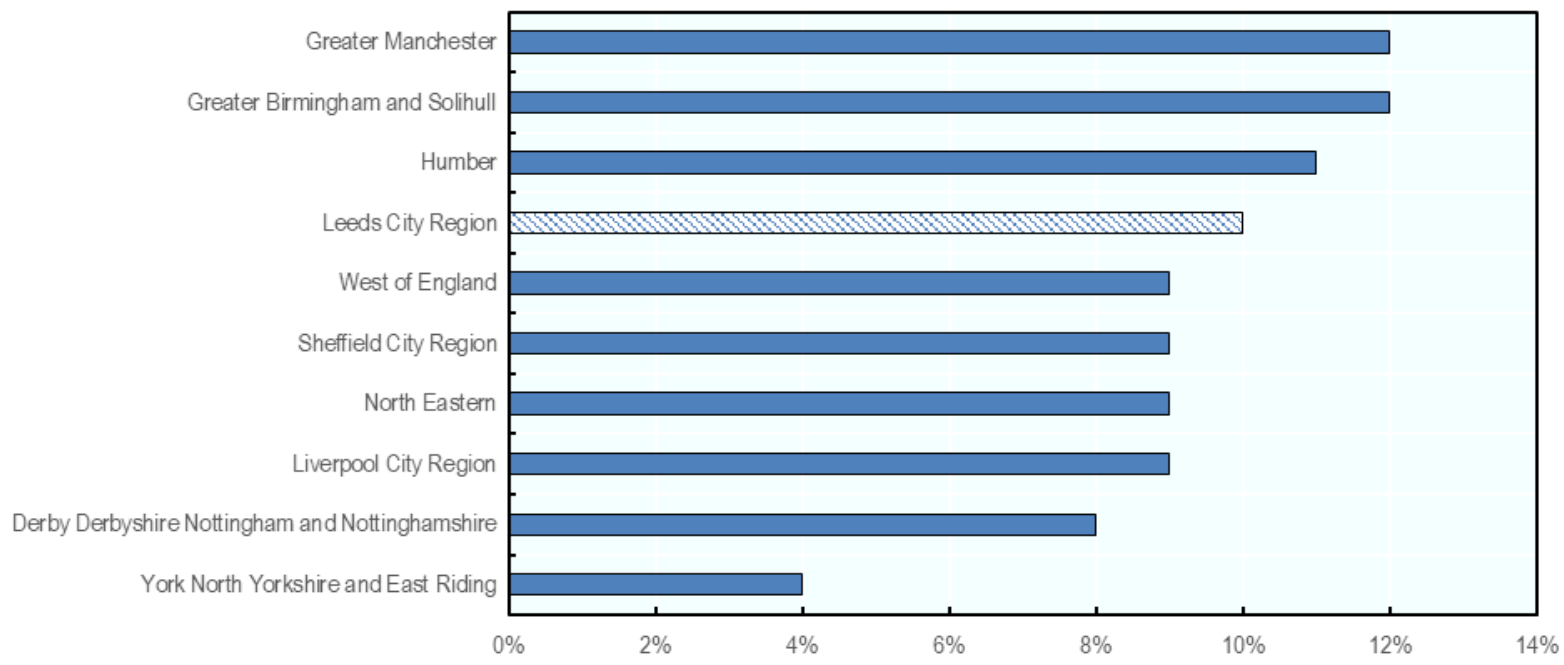

Note: Data refers to firms having adopted at least 14 out of 21 HPWPs as defined by the UK Employer Skills Survey. This figure shows 10 LEPs, including Leeds City Region, of a total of 38 LEPs across England. These benchmark LEPs were chosen based on consultations with the Leeds City Region and the OECD's Expert Advisory Group that was established for this project. These LEPs include eight core city LEPs as well as the Humber and the York, North Yorkshire and East Riding LEPs because of their geographical proximity to Leeds.

Source: UK Employer Skills Survey.

When looking more in detail at the different types of high-performance work practices, the Leeds City Region performs among the lower end in relation to conducting training needs assessment (Panel A). The City Region is in the middle of the distribution on the other two dimensions considered, namely bonuses based on the overall performance of the organisation and the flexible working arrangements (Panels $B$ and D). The Leeds City Region is one of the top LEPs in terms of giving discretion to employees (Panel C). 
Figure 4.5. Different types of HPWPs in selected Local Enterprise Partnerships, 2017

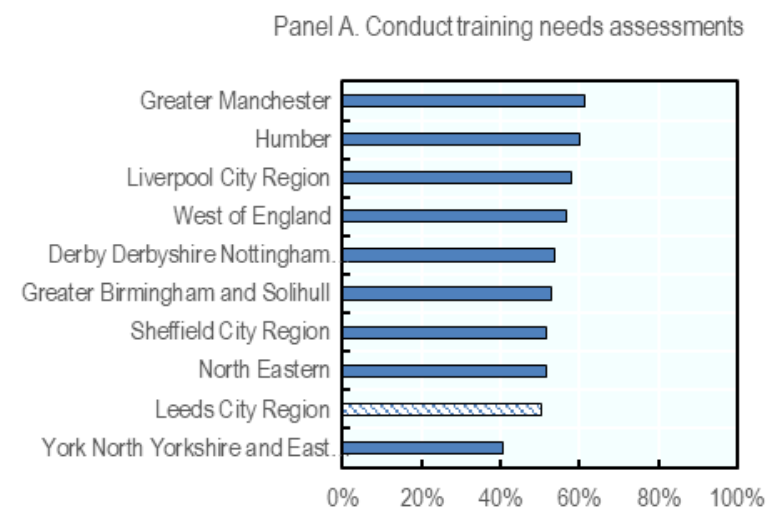

Panel C. Employees discretion on their work

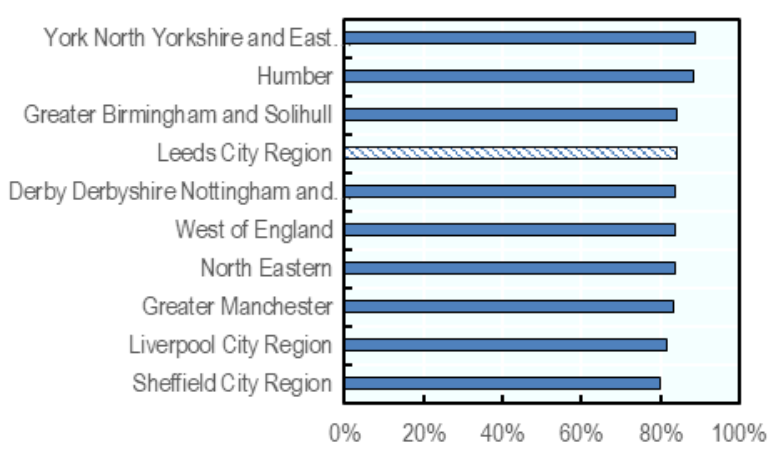

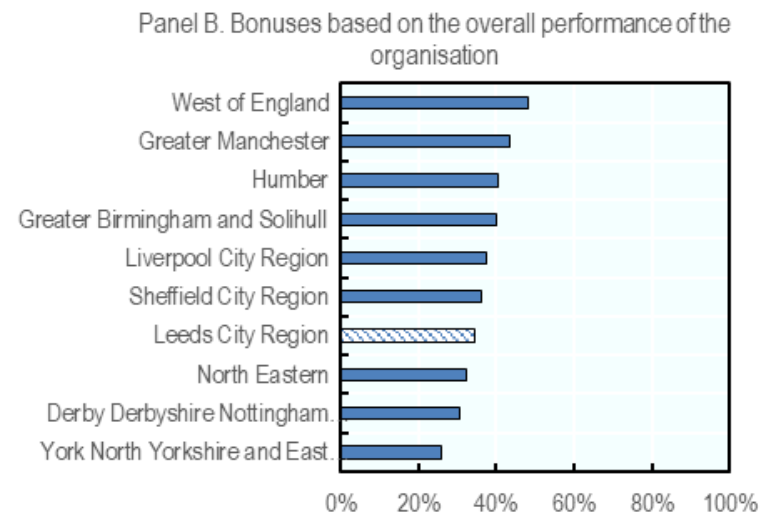

Panel D. Flexible working arrangements

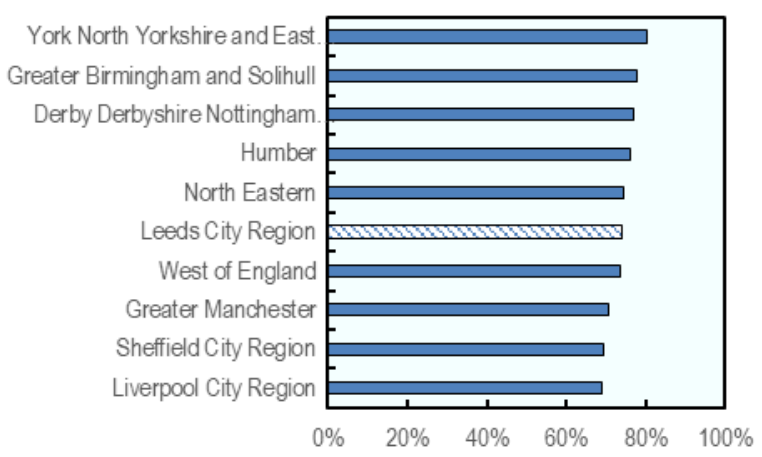

Note: In panel $\mathrm{C}$ and $\mathrm{D}$ the share corresponds to firms answering "To a large extent" or "To some extent". This figure shows 10 LEPs, including Leeds City Region, of a total of 38 LEPs across England. These benchmark LEPs were chosen based on consultations with the Leeds City Region and the OECD's Expert Advisory Group that was established for this project. These LEPs include eight core city LEPs as well as the Humber and the York, North Yorkshire and East Riding LEPs because of their geographical proximity to Leeds.

Source: UK Employer Skills Survey.

\section{What are the barriers to the introduction of more HPWPs within firms?}

HPWS indicate how firms could be encouraged away from the low road and on to the high road. Indeed, given that HPWPs positively impact productivity, innovation and profitability, introducing more HPWPs into UK firms thus makes common sense. Given the evidenced benefits, the obvious question is why common sense has not translated into common practice (Warhurst, 2018[73]). The answer is that a number of related barriers exist. First of all, there is no consensus on which bundle of practices is indicative of highperformance working. Different suggestions exists across the range of research, with wide variations in the number of practices suggested. For example, (Delery and Doty, 1996[74]) suggest 7, (Boedker et al., 2011[68]) 18, (Ramsay, Scholarios and Harley, 2000[75]) 24 and (Sung and Ashton, 2005[76]) 35 practices. Whilst there is overlap amongst these suggestions, they are also different. With such variation, the tipping point at which a system can be said to exist rather than merely a collection of piecemeal practices is not clear. Some practices are widespread but there are variations by sector and industry (Martin and Healy, $2009_{[77]}$ ). Examining 18 practices in 237 UK firms, (Guest, 2000[78]) found that only $1 \%$ used all of them, $25 \%$ used more than half and $20 \%$ used fewer than a quarter. The point at which these practices cohere into a step-change system is therefore hard to judge.

Another issue relates to measurement, which can be very blunt. For example, (Huselid, 1995[79]) includes formal skills development through training but, significantly, not skills utilisation; the assumption is that the 
latter follows the former. However whilst through training workers gain the ability $(A)$, if the motivation (M) and the opportunity $(\mathrm{O})$ (see AMO model in Table 4.1) are missing, that skills acquisition will be wasted and not translated into the potential benefits. Another barrier is related to the fact that research tends to focus more on workers having the ability $(\mathrm{A})$ more than the motivation $(\mathrm{M})$ and the opportunity $(\mathrm{O})$ (Warhurst and Luchinskaya, 2018[28]). There is little examination of whether, and if so how, this ability is levered through practices that facilitate employees having the motivation and opportunity to use their ability. In this respect, skills utilisation still tends to be overlooked.

Managers have to be aware of the benefits of HPWPs and be able to implement them in their workplaces. However this awareness and ability cannot be taken for granted. Aware of limitations in both respects, the UK's Economic and Social Research Council has recently funded a series of large-scale research projects intended to improve managerial practices in the UK. ${ }^{2}$ Findings and recommendations from these projects are not expected for a number of years. In the meantime, Scotland's economic development agency, Scottish Enterprise, has introduced a series of workshops and masterclasses for managers to support their awareness of and ability to introduce progressive people management. The assumption is that these workshops will improve skills use, innovation and productivity in Scottish firms. While there are conceptual and measurement problems with HPWPs, and challenges centred on managerial awareness and abilities, there is also clear recognition that these barriers should and can be addressed if firms are to be encouraged to adopt the high road and, with it, better use of workers' skills. What the example of Scottish Enterprise shows is that an equally clear role exists for development agencies in this endeavour (see Box 4.2).

\section{Box 4.2. People, place and practice workshops in Scotland, United Kingdom}

One of the major ways to improve productivity of a business is through workplace innovation, which is change driven by people to develop new and improved ways of working. Scottish Enterprise organises workshops to work with firms to equip them with tried and tested tools and techniques to develop and implement an action plan around three themes:

- People - what it means to have an engaged workforce and the benefits this will bring to a firm. They also look at how effective communication and the development of staff can bring positive change.

- Place - what culture an organisation has and how the physical and virtual workspace can help.

- Practice - what workplace practices a firm can adopt to help nurture creativity, productivity and growth.

Workshops are either run as three half-day sessions or one full-day session exploring all three themes. Scotland Enterprise also offers workplace innovation masterclasses, which are a series of thought leadership events that brings together academic research with the experience of inspirational business leaders from across the UK to explore a variety of emerging workplace practices and leadership challenges.

Source: (Scottish Enterprise, 2019[80])

2 For more information, see https://esrc.ukri.org/files/funding/funding-opportunities/management-practices-andemployee-engagement-call-specification-final/. 


\section{What can the Leeds City Region do to improve skills use?}

The current devolution of skills policies in the United Kingdom provides Local Enterprise Partnerships with a unique opportunity to design customised programmes to their local labour market conditions. The Leeds City Region has introduced a number of programmes that aim to smooth the transition to work for young people, while also providing re-skilling opportunities to adults facing transition. Going forward, there is an opportunity to consider what local actions could be piloted to focus on working closer with firms on skills use. This section of the paper provides recommendations that could be considered by the Leeds City Region.

\section{Skills policy in the United Kingdom is increasingly being devolved to the local level}

\section{Local Enterprise Partnerships are driving the local economic and jobs agenda}

Responsibility for skills policy has developed within the UK in recent years and is increasingly being devolved away from central government. Local Enterprise Partnerships (LEPs) first emerged in 2010 following the UK Government's White Paper Local Growth: Realising Every Place's Potential. By 2012, all areas of England had a LEP. A LEP is a locally-owned partnership between local authorities and businesses. The Leeds City Region is one of the 38 Local Enterprise Partnerships (LEPs) in England. LEPs play a central role in deciding local economic priorities and undertaking activities to drive economic growth and create local jobs (see Box 5.1).

LEPs provide local strategic leads for business growth, housing, worklessness, and sustainable development. Whilst not overtly stated, skills was a key element of their responsibilities, both in terms of meeting the labour market needs of local businesses and in assisting workless people into or towards the labour market. In both regards, LEPs did not initially possess any financial, policy or operational control over skills policies in their areas. 


\section{Box 5.1. Local Enterprise Partnerships (LEPs)}

The Government's proposals for LEPs in England were set out in June 2010 in a joint letter from Secretaries of State at the Department for Communities and Local Government (DCLG) and the Department for Business, Innovation and Skills (BIS) to local councils and business leaders. The letter invited local consortia to submit proposals for partnerships with local business and civic leaders, operating in local areas making economic sense, to provide the vision, knowledge and strategic leadership to set local economic priorities.

In practice, the role of LEPs has expanded over time. By 2014, they had responsibility for the Growing Places Fund and Enterprise Zones. The Heseltine Report No Stone Unturned: In Pursuit of Growth recommended a greater devolution of funding from central government to LEPs in order that government investment in economic development could be tailored directly to the individual challenges and opportunities of local communities and could be augmented by private sector investment. Central government therefore began the process of setting up Growth Deals with LEPs to operate from 201516. These Growth Deals include the Local Growth Fund through which funding for skills, housing and transport is distributed through a mix of allocation and competition, based on LEPs' Strategic Economic Plans (SEPs). As of 2014, LEPs assumed responsibility for delivering part of the EU Structural and Investment Funds to 2020.

In 2017, as part of the Industrial Strategy, the Government committed to work with Local Enterprise Partnerships in all regions of England and to further support their economic growth. The Industrial Strategy also highlights the need to reform the leadership, governance, accountability, financial reporting and geographical boundaries of LEPS.

Source: (OECD, 2015[81]) (HM Government, 2018[82])

This situation changed in 2013 with the announcement of local Growth Deals and the 2014-2020 European Structural Funds programme. LEPs were tasked with developing strategies for both these programmes, Strategic Economic Plans (SEPs) for Growth Deals and European Structural Investment Funds strategies (ESIFs) for European funds. The two programmes were expected to be complementary. The SEPs and the ESIFs were developed through an evidence base, which included analysis of supply and demand in the local labour market. Such analyses helped justify the priorities which then became the focus for the funding. The SEPs and the ESIFs therefore became the strategic framework for local economic development strategies within LEP areas.

Part of the strategic synergy between the SEPs and ESIFs was the identification and sharing of priority sectors (such as Advanced Manufacturing, Digital and Creative, and Construction), population groups (for example, young people not in education, employment or training (NEET), people with no/low qualifications, under-represented groups in the workforce) and geographic areas (e.g. economic priority areas, deprived areas, rural areas). Other funding programmes, such as Opportunity Areas, were implemented locally within the strategic context of the SEPS and ESIFs.

Alongside LEPs, Mayoral Combined Authorities (MCAs) began to be developed from 2014. These combined authorities brought together neighbouring local authorities with the intention of giving greater control over local needs. Devolution Deals between the MCAs and the Government were and still are being developed, with ultimate governance and responsibility to be provided by an elected mayor. There are currently eight Devolution Deals plus London. Devolution confers a range of powers and funding covering, for example, skills, business support, transport and some fiscal powers. However, the range, level and 
funding of these devolved powers varies across the eight MCAs. MCAs have developed local skills plans underpinned by the work of the SEPs and ESIFs.

In 2017, the UK Government then introduced a new Industrial Strategy. The objective of the strategy is to boost productivity and reduce inequality. The strategy is based on five foundations: ideas (the UK being the world's most innovative economy), people (good jobs and greater earning power for all), infrastructure (upgrading the UK's infrastructure), business environment (making the UK the best place to start and grow a business) and places (ensuring prosperous communities across the UK) (HM Government, 2017[83]). Skills is a central focus of the people foundation. MCAs and LEPs have been called on to develop Local Industrial Strategies (LIS) as the sub-regional economic development strategic framework. To date, four MCAs/LEPs have published a LIS: Greater Manchester Combined Authority (GMCA), West Midlands Combined Authority (WMCA), West of England Combined Authority (WECA) and Cambridgeshire and Peterborough (CPCA). These LISs identify a number of challenges, most notably: low skills, low social mobility, social exclusion, ill health, low productivity and low-quality jobs.

However, skills priorities can vary across MCAs. For example, GMCA has a focus on early years and supporting children at the start of their education with schooling, health and housing. WMCA is supporting inclusion through support for employers to develop flexible working and carer friendly policies. A Local Industrial Strategy is being developed also in Leeds City Region, in collaboration with the neighbouring York, North Yorkshire and East Riding Enterprise Partnership to maximise opportunities across the whole of North and West Yorkshire. Skills priorities for Leeds City Region focus on helping people improve their skills through participation in training and development activities and providing support to the most disadvantaged groups who are outside the labour force.

Each MCA and LEP has a skills board, although its title varies by area. Its constitution and board members also differ, although they tend to be drawn from local authorities, local training providers (including further education (FE), higher education (HE), and private training providers), the third sector and employer representatives. Encouraged by the UK Government's Department for Education (DfE), Skills Advisory Panels (SAPs) are being created in each MCA and LEP area in order to inform sub-regional skills policy. DfE has developed an analytical framework and methodology to provide evidence and skills supply and demand in local areas. It is intended that the SAPs will use this framework and methodology to create more informed skills policy and programme decision-making. An increasing and interesting development is the focus on inclusive growth as the context for MCA and LEP strategic developments across a range of policy areas. This focus recognises that whilst there has been economic growth since the global financial crisis, the outcomes have not been equally shared across people and communities. It also recognises that people's wellbeing is not just dependent on economic growth but the intersection of different policy areas - health, skills, housing and transport - for which MCAs now have responsibility. Skills policies can help to address policy aspirations such as social inclusion, improved productivity and social mobility but only in conjunction with other agendas such as decent and affordable housing, high-quality public transport and access to digital infrastructure. 


\section{Skills development programmes in the Leeds City Region}

\section{The Leeds City Region has implemented a wide range of employment and skills programmes}

As shown in Figure 5.1, there are a comprehensive range of employment and skills programmes in the Leeds City Region that are targeted to the needs of young people and adults as well as local businesses.

Figure 5.1. Employment and skills programmes in Leeds

\begin{tabular}{|c|c|c|c|c|}
\hline $\begin{array}{l}\text { FUTURECOALS for } \\
\text { young people }\end{array}$ & $\begin{array}{l}\text { FUTUREGCALS } \\
\text { for adults }\end{array}$ & $\begin{array}{l}\text { Apprenticeship } \\
\text { Levy Transfer }\end{array}$ & \multirow{2}{*}{$\begin{array}{l}\text { Employment Hub } \\
\text { Provides businesses } \\
\text { with access to } \\
\text { employment/ } \\
\text { recruitment } \\
\text { support (including } \\
\text { apprenticeships) } \\
\text { and a talent } \\
\text { matching service }\end{array}$} & \multirow{2}{*}{$\begin{array}{l}\text { Future Ready Skills } \\
\text { Commission } \\
\text { Designing a blueprint } \\
\text { for a national skills } \\
\text { commission in a } \\
\text { devolved UK }\end{array}$} \\
\hline $\begin{array}{l}\text { Campaign to inspire } \\
\text { and inform young } \\
\text { people about careers }\end{array}$ & $\begin{array}{l}\text { Campaign to inspire } \\
\text { and inform adults } \\
\text { about careers and } \\
\text { support them to } \\
\text { upskill or change } \\
\text { career. (Includes } \\
\text { Discover Digital and } \\
\text { Earnlt) }\end{array}$ & $\begin{array}{l}\text { Support to help } \\
\text { businesses and } \\
\text { training providers get } \\
\text { the most out of the } \\
\text { apprenticeship levy }\end{array}$ & & \\
\hline$\uparrow$ & $\uparrow$ & 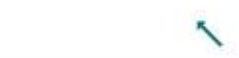 & $\nearrow$ & $\uparrow$ \\
\hline $\begin{array}{c}\text { Young People } \\
\downarrow\end{array}$ & Adults & \multicolumn{2}{|c|}{ Businesses } & $\begin{array}{c}\text { Policy } \\
\downarrow\end{array}$ \\
\hline Employment Hub & [ro]boot & Skills Service & $\begin{array}{l}\text { Business/education } \\
\text { engagement }\end{array}$ & Delivery agreements \\
\hline $\begin{array}{l}\text { Linking } 15-24 \\
\text { year olds with } \\
\text { employment and } \\
\text { apprenticeship } \\
\text { opportunities }\end{array}$ & $\begin{array}{l}\text { Courses for } \\
\text { individuals to retrain } \\
\text { and upskill in the } \\
\text { digital, construction, } \\
\text { manufacturing and } \\
\text { engineering and } \\
\text { production sectors }\end{array}$ & $\begin{array}{l}\text { Signposting to } \\
\text { appropriate training } \\
\text { and funding for SMEs } \\
\text { (delivered by West } \\
\text { Yorkshire Consortium } \\
\text { of Colleges) }\end{array}$ & $\begin{array}{l}\text { engagement } \\
\text { Promoting links } \\
\text { between industry } \\
\text { and education. } \\
\text { (Give an hour, } \\
\text { Enterprise Adviser } \\
\text { Network, Skills for } \\
\text { Growth, Cornerstone } \\
\text { Employers) }\end{array}$ & $\begin{array}{l}\text { Influencing provision } \\
\text { through published } \\
\text { agreements with } \\
7 \text { West Yorkshire } \\
\text { Colleges }\end{array}$ \\
\hline
\end{tabular}

There has been a strong focus on strengthening the linkages between the education system and employers

Looking at programmes in the Leeds City Region that aim to build stronger business-education partnerships, the Enterprise in Education programme ${ }^{3}$ - co-funded by the Careers and Enterprise Company with a contribution from the Burberry Foundation - builds career readiness of young people by making links between senior business leaders (Enterprise Advisers) and schools. A team of 13 members of staff (Enterprise Coordinators) is currently engaged with $175(86 \%)$ secondary schools and colleges to improve employer linkages, careers information and inspiration, to bring about better outcomes for young people. The team is working with schools to support them to achieve the national Gatsby benchmarks for best practice in careers education. Through this programme, over 134000 employer encounters have been delivered, including 37771 employer encounters for disadvantaged young people. Intensive activity is being carried out with 35 targeted schools and the college in Kirklees via a Careers Hub. A Raising Aspirations fund is currently open to applications from schools to pilot innovative approaches to tackling disadvantage.

Through the Skills Capital programme, The Leeds City Region has invested GBP 79 million in improving college facilities to ensure that young people and employers, particularly in our key sectors, are supported by high quality skills and education facilities. The Delivery Directorate is overseeing the delivery of these

\footnotetext{
${ }^{3}$ More information is available at: $\underline{w w w . f u t u r e g o a l s . c o . u k}$. 
schemes, which have improved facilities at the several colleges: Kirklees, Shipley, Leeds, Calderdale, Wakefield, Selby, Bradford and Leeds College of Building.

\section{Invest in skills development and training}

Within the Leeds City Region, there has been a strong focus on expanding access to training. This includes the GBP 9 million Employment Hub - funded through the European Social Fund (ESF) and delivered in partnership with Local Authorities - launched in March 2019. The Hub will aim to support over 6000 young people to access apprenticeships and employment. The devolved Apprenticeship Grant for Employers provides a grant of up to GBP 2500 to incentivise small and medium sized businesses to engage with apprenticeships. Through this scheme almost 3000 businesses have recruited apprentices for the first time.

\section{Raise awareness of career opportunities}

In 2019/20, the Leeds City Region will aim to engage 250000 people through careers campaigns to raise awareness about job career opportunities in the region, including through:

- \#futuregoals futuregoals.co.uk/ - A campaign designed by young people for 11 - 19 year olds and their influencers, to inspire young people about the career opportunities available in the City Region with engaging content based on robust labour market evidence.

- Discover Digital discoverdigital.org.uk/ - A business-led media campaign raising awareness of digital job opportunities in the city region.

- \#earnit www.the-lep.com/skills-and-training/earnit/ - A campaign stimulating demand for training among people in low-paid and low-skilled occupations.

\section{Adult learning programmes have been introduced in response to the future of work}

Recognising the importance of re-skilling those individuals who might be vulnerable to changes in the future of work or who would like to focus on a second career, the Leeds City Region is launching in 2019/20 the innovative [re]boot programme. This programme will support adults (particularly under-employed graduates and those in low quality and low paid jobs) to re-train in evidenced skills shortage areas - digital skills, construction and engineering. This GBP 2.6 million programme is co-funded through the ESF.

There is also a Skills Service that is funded through ESF and delivered by the West Yorkshire Consortium of Colleges to support businesses to identify their training and workforce development needs linked to their growth ambitions, to source training provision, and access subsidy for training. Additionally, there is also a work wellness pilot in York and Calderdale that is testing approaches to enable individuals who are currently off sick to remain in work and/or return to the workplace.

\section{Work is underway to future-proof the Leeds economy}

Leeds has established the Future Ready Skills Commission, which aims to explore the opportunity of devolution and to create a workable blueprint for a devolved skills system in order to better meet the needs of individuals, businesses and the overall local economy. The activity of the Commission focuses on three key areas: i) Improving technical education and training; ii) Enhancing workforce skills; and iii) Guaranteeing access to quality careers information and inspiration. The blueprint is a forward looking and takes into consideration the rapid changes of the world of work. In particular, it looks at how jobs have been displaced or transformed and which new jobs have been created. Delivery priorities within the Leeds City Region for the biennium 2019-20 include an enhanced model of employability, enterprise and careers education to 18000 disadvantaged students. Actions include: 
- Refresh and monitor delivery agreements with FE colleges, to deliver skills outcomes which support economic priorities and inclusive growth ambitions.

- Influence 1000 businesses to engage with education, apprenticeships and sector skills initiatives.

- Reach 250000 people with information on careers linked to labour market information, thus promoting better informed choices.

- Upskill 1000 people in skills shortage areas.

Services will be adapted where possible to the changing needs of businesses in response to Brexit. Businesses with a high volume of EU migrant workers may respond to greater controls on movement of labour by recruiting greater numbers of local people in future. Alternatively, businesses may respond by automating routine processes and replacing high volumes of low skilled jobs with fewer higher skilled employees. In either of these scenarios, support is available for businesses and individuals with the Growth Service providing an initial point of entry to all business support services. It will be important to work closely with firms in key sectors heavily reliant on European Economic Area (EEA) migrant workers to support their skills needs and to make sure they have access to a local workforce that meets their labour needs. Support available to business to become more inclusive employers will be further developed, including by support to develop skills plans to support staff at all levels, to create apprenticeship opportunities, and by supporting employees with disabilities and health issues.

\section{Creating an action plan for skills use policies in the Leeds City Region}

\section{Towards an action plan on skills use policies}

The general evidence from both the UK and internationally indicates that better skills use generates positive performance outcomes for organisations. Local evidence from the Leeds City Region also indicates that there is significant under-use of skills amongst its local workforce and the productivity gap has increased in comparison with the rest of the country. Developing policy that helps organisations better use the skills of their workforce could therefore make a significant difference to local economic development. There are two types of policy initiatives that would help. First, there are broad policy initiatives that are needed to change the focus and intent of skills policy generally, primarily but not exclusively at government level. What might be called "tone-setting" policy actions. Second, there are targeted, locally specific policy initiatives that can be developed and which respond to local needs and circumstances.

\section{Table 5.1. Key requirements for an action plan on skills use in the Leeds City Region}

\begin{tabular}{l}
\hline Requirements at the start of the initiative \\
\hline - $\quad$ Initiative stakeholders and partners having good local labour market information to plan and monitor needs and progress \\
Good governance structures for the initiative with codification of concept and problem agreement, and actors' roles and responsibilities \\
and resource inputs clarified \\
A fine-grained understanding of skills use in the local context \\
An openness amongst stakeholders and partners to broad and narrow, immediate and longer term benefits needs to exist \\
With formal, intentional initiatives, codification of concept and problem agreement and actors' roles, responsibilities and resource inputs \\
is important \\
A broad range of stakeholders and partners need to be involved, and employer engagement has to be achieved \\
Initiatives require sustained government support, political and resource, whether local or national \\
Sustained funding of activities is required that supports both the implementation of the initiative and its evaluation \\
\hline \\
- $\quad$ Requirements during delivery \\
Knowledgeable and entrepreneurial intermediaries, coordinators or champions with good analytical and political/organisational skills are \\
needed to engage and coordinate the stakeholders and partners
\end{tabular}

Source: Authors elaboration based on outcome of meetings with OECD Expert Advisory Group. 


\section{Key recommendations}

Guided by these high-level considerations, and in the context of a Local Industrial Strategy, the Leeds City Region could take the following actions:

\section{Local skills policies in the Leeds City Region could be augmented to extend their scope to include a more specific focus on better using skills in the workplace}

National and local skills policies are most optimal when they address the full skill cycle of skills support including the development of both the supply and demand of skills. While the Leeds City Region has a comprehensive range of skills development programmes in the region, there is no explicit skills use policy as a priority. Therefore, there is an opportunity for the City Region to outline a strategy which emphasizes skills use policies. Such a strategy would help to join-up thinking and action to support short-term employer skills needs, and linking those needs to firm performance and development as well as longer-term local economic development aspirations. Initially at least, expertise and experience is needed to support this new policy focus both at the national and regional levels. Translating this new policy emphasis into successful workplace practices will require a range of expertise, experience and skillsets. Stakeholders, experts and change agents in the Leeds City Region will need an operational framework that outlines their responsibilities, engagement and resource needs.

\section{A local coordinator could be appointed to act as a catalyst for change}

To help operationalize the strategy on skills use policies, the Leeds City Region could pilot the appointment of a local coordinator. The success and sustainability of any new initiative focused on better skills use within local businesses requires the coordination and marshalling of local stakeholders, needs and resources. Having an identifiable person who can engage and coordinate business stakeholders and link with experts and policymakers is vital. Working with the Employment and Skills Unit of the Leeds City Region, the local coordinator could be given a mandate to: 1) identify local champions of change from existing local firms and their practices; 2) develop peer learning networks using these champions as business mentors; 3 ) develop and test a local business case narrative about better skills use to employers; 4) identify local businesses for support, including through a skills use audit (see Box 5.2); 5) develop a peer network with mentors for the support of change within industries and along supply chains; and 6) organise awareness-raising and advocacy workshops for local business stakeholders.

\section{Identify local businesses that already demonstrate good company practices and can provide champions for change among other local businesses}

Local advocacy based on first-hand experience of good practice is vital if awareness and adoption of better skills use is to be developed. A peer network with mentors drawn from exemplar local business can help provide mentoring with support and advice, particularly for SMEs and start-ups, as well as within industries and supply chains. These champions could help develop a narrative about why and how better skills use would benefit local businesses. The under-use of skills exists across a number of industries important because they either provide large numbers of jobs or are vital for the continued redevelopment of the Leeds City Region. Interventions, initially using the skills use audit, could then identify and prioritise particular businesses that offer good opportunity for successful supported change and, just as importantly, that could offer demonstration effects for other businesses.

It would be important to work with local business representative bodies, trade unions and education and training providers to offer workshops on the benefits and implementation of better skills use. Awareness raising within the local economy of both the current weaknesses with skills use along with the benefits of 
better skills use is important. These expert workshops will provide an advocacy and educative function that will increase not only awareness, but also build understanding and support for the policy shift.

\section{Encourage appropriate programmes through the training and local business development system}

Awareness of the business performance benefits of better skills use amongst local managers and owners is currently limited, as are the skills needed by managers and owners to implement changes to improve skills use within their workplaces. Therefore, the Leeds City Region could look at how to structure support for these managers which would be important if their awareness and capabilities are to be raised.

Ensuring that students, who are next-generation managers, have more awareness about good management practices is also important to ensure sustained change. The Leeds City Region could work with national departments to initiate a review of management education across the further and higher education sectors to identify human resources management gaps. Where gaps identified relate to the better use of skills within sectors or specific firms, further and higher education providers could be encouraged to develop new pedagogical resources to address needs.

\section{Benchmark and measure progress on better using skills through the development of a self- assessment tool with local firms}

In the Leeds City Region, there is an opportunity to develop a business assessment tool that could help local firms to identify how they are currently using the skills of their workers and how this could be improved through better company management practices. Such a self-assessment tool would serve as a "skills audit" of local firms to help benchmark and measure local efforts to improve skills use (see Box 5.2 for more information on how this concept could be implemented).

\section{Box 5.2. Opportunity to introduce a skills use audit in the Leeds City Region: What is it and how could it work?}

Most firms do not know the levels and type of skills available to them among their workforce. As a consequence, firms do not maximise the use of those skills. A skills use audit could be designed in the Leeds City Region as an online or paper-based diagnostic tool for use by firms and administered by a local coordinator in Leeds. It would comprise a number of questions about the skills of employees and how those skills are used. It would link these questions to other information about firms' management practices and business strategy. This type of audit could be both a stock-take and health-check. It is a stock-take in that it would identify the extent to which firms make best use of the skills available to them among their workforce, and a health-check in that it would identify how those skills could be better used to support business outcomes. The aim would be to assess whether and how firms can make more effective use of their employees' skills in a way that can help improve organisational performance.

Most current firm-level or employee-level skill surveys focus on skills development through training or skills acquisition through hiring. The skills use audit tool would be new and trialled by the Leeds City Region. It could be designed based on a new module on skill use that is being tested within the 2019 European Company Survey (Warhurst and Luchinskaya, 2018[28]). 


\section{What UK and international examples could inspire action in the Leeds City Region on skills use policies?}

To best take forward these local policy options, analysis of local skills polices and skills utilisation initiatives in the United States, Australia and Scotland highlight a number of important criteria (Buchanan, Anderson and Power, 2017[84] $)$ (Green et al., 2017[85]) (Warhurst and Findlay, 2017 ${ }_{[65]}$ ) (Warhurst, 2018[73]). These include the following key lessons from international experience.

\section{Ensuring economic development agencies contribute to a local strategy focusing on skills use in the workplace}

Economic development policies have historically focused on the quantity of jobs, not necessarily the quality of jobs. Regional and local economic development agencies often have an overview role which makes them natural brokers and catalysts for bringing together those involved in both skills supply and skills demand in a local economy. In addition to galvanising a local community approach, it is also important that they make use of their capacity to better train and utilise skills within their own workforce, while influencing change as a local purchaser of services. At the local level, a place-based approach can also be taken to create a community-wide vision for how the local economy should be organised. This could include bringing together firms to collaborate on a common marketing strategy, while also pooling investment in training provision and helping firms to collectively upgrade their product market strategies. In the United Kingdom, the Innovative Workplaces programme was an example of one regional development agency focusing on workplace innovation.

\section{Box 5.3. Innovative workplaces in East Midlands, United Kingdom}

The Innovative Workplaces programme was a regional pilot initiative in 2009-10, funded by the East Midlands Development Agency (EMDA). While initially the East Midlands Development Agency did not include workplace innovation as a means of achieving its strategic goals relating to competitiveness and skills, matters began to change when the focus of national policy began to embrace skills utilisation as well as skills supply. In 2008, EMDA's annual Corporate Plan contained the following commitment:

Developing new ways of organising work and utilising more effective deployment of people in the workplace will be needed for businesses to remain globally competitive and ensure business survival. EMDA will focus activity on supporting organisations to stimulate learning amongst their employees and developing collaboration within and between organisations. This activity will seek to change organisational culture and develop strong, inspirational leaders, as well as building effective employee relations.

It was intended that the project would benefit a small cohort of business leaders, managers and supervisors across ten organisations, each of which would benefit from long-term organisational change. The project was a means of breaking out of the low skills equilibrium by developing and unleashing the enterprise skills and competencies of those in work, enabling employees to use their initiative to innovate and create new business strategies and solutions whilst achieving maximum productivity. Both UK WON, a not-for-profit body involved in disseminating and developing innovative workplace practice, and Acas, a UK government body with a tripartite structure charged with promoting and facilitating strong employment relations, were involved in the design and delivery.

Source: (OECD/ILO, 2017[7]) 


\section{Raising awareness of the importance of skills use policies}

Promoting better use of skills could also be supported amongst local business and the public by developing an overarching local narrative about better skills use. This narrative would house, advocate, showcase and measure the progress and effectiveness of the initiative. These frameworks are generally underpinned by the principles of the "good work/fair work" agenda (HM Government, 2018[86]) (Scottish Government, $2019_{[87]}$ ), which seeks to generate mutual gains for business and workers (Warhurst and Findlay, 2017 ${ }_{[65]}$ ) by fostering HPWP that facilitate employees having the motivation and opportunity to use their ability. This approach is usefully illustrated by the Scottish Government's Fair Work First plan. This plan includes short and longer term commitments for employers, one of which is to support progressive workforce engagement. Many programmes currently in place in Leeds are similar to those showcased under the badge Fair Work First. More recently, Greater Manchester's Good Employment Charter provide lessons that link to City Region's forward plans.

\section{Box 5.4. Drawing on interesting examples from Scotland and Manchester, United Kingdom}

\section{Fair Work First Scotland}

The Scottish Government is working with employers and partners to deliver its Fair Work plan. Examples of effective initiatives under the Fair Work First banner include The Scottish Business Pledge which asks firms to make commitment to nine pledges (some in the shorter term and all in the longerterm): 1) paying the living wage; 2) not using exploitative zero hours contracts; 3 ) supporting progressive workforce engagement; 4) investing in youth; 5) making progress on diversity and gender balance; 6) committing to an innovation programme; 7) pursuing international business opportunities; 8) playing an active role in the community; and 9) committing to prompt payment. The Business Pledge has already been signed up by 650 businesses, and businesses logos are displayed on the pledge wall.

\section{The Greater Manchester Good Employment Charter}

The Greater Manchester Good Employment Charter is a voluntary membership and assessment scheme which is being developed through a process of co-design, involving the Greater Manchester Combined Authority (GMCA), all GM districts, employers from all sectors, as well as trades union employees and other experts. The Charter requires employers to demonstrate an ongoing commitment to excellence in seven areas of employment practice: 1) Secure work; 2) Flexible work; 3) A real living wage; 4) Workplace engagement and voice; 5) Excellent recruitment practices and progression; 6) Excellent people management; and 7) A productive and healthy workplace. The Charter Supporters' Network launched mid-2019 with more than 60 businesses signing up to its aims.

\section{Working at the level of sectors and employer networks}

Where interventions directly targeted to an individual workplace may not be feasible, there is also an opportunity to introduce programmes and measures targeted to multiple employers simultaneously, creating or leveraging employer networks or working at the level of sectors. Evidence suggests that such approaches are not only efficient in terms of the cost of delivery, but also are potentially more effective at catalysing change. According to (Totterdill and Dhondt, 2016[88]), workplace innovation "programmes have re-focused from case work policy models towards networking strategies" as "evidence suggests that when clusters of enterprises work together, this proves cost effective for public agencies and are likely to deliver sustainable results" Likewise, (Erickson and Jacoby, 2002[89]) found that managers who participated in industry and cross-industry associations, civic organisations and internal networks of multi-unit firms were more likely to adopt high-performance work practices and employee training programs. 
A similar approach can be seen in the UK Futures Programme, which entailed a series of "productivity challenges". One particular strand of this work sought to improve management practices by sharing skills, ideas and values through existing business relationships such as supply chains. Using research from the former United Kingdom Commission for Employment and Skills (UKCES) through the UK Employer Skills Survey, sectors were identified where management and leadership problems were more prevalent (e.g. manufacturing, construction, insurance and legal). Not all of these sectors recognised the concept of supply chains. Wider UKCES research suggested that whilst supply chains were not prevalent in insurance and legal firms, other forms of business relationships were likely through networks of dependency (e.g. insurance advisers, sub-contracted specialist legal services). The scope was then extended to include the notion of networked organisations (see Box 5.5).

\section{Box 5.5. The United Kingdom Commission for Employment and Skills (UKCES) Futures Programme: Learning from past programme interventions}

Launched in 2014, the former United Kingdom Commission for Employment and Skills introduced a Futures Programme investing around GBP 5 million annually to support employers who wanted to work collaboratively to test new ways to boost workforce skills. The programme included a series of productivity challenges testing innovative solutions with businesses to identify what works in addressing specific workforce development problems. A feature of each challenge was that participating firms were brought together throughout the life of the programme to share their experiences, challenges and learning and to cross fertilise ideas. As an example, one of the productivity challenges focused on enhancing management and leadership capability within firms in the manufacturing, construction and legal sectors, by supporting "prime" organisations to work with their supply chains to develop skills and embed effective management practices.

The manufacturing projects funded as part of this productivity challenge explored how to help small businesses manage and commercialise innovation. In doing, they found that there was a limited definition of innovation. For example, for legal firms in the programme, where networks dominate more than supply chains, innovation was more about developing new or improving existing business practices, organisation structures or marketing approaches. Regardless of which notion of innovation is appropriate, it was evident that if left unrecognised, small businesses may not be reaping the rewards of the innovations of their staff.

The evaluation report of the overall programme highlights various means to improve innovation including the following three tips:

- Innovation should be at the forefront of a company's strategic thinking. This can be done by firms establishing an innovation strategy or even just as a standing agenda item to maintain focus.

- Engaging staff is critical. Senior managers need to provide vision and leadership, but good communications and encouraging contribution amongst all staff helps grow a culture of innovation. Innovation should be open to everyone not just the preserve of a discrete few.

- Ensure that training and development are prioritised to build skills and capabilities because people are the key ingredient to innovation and its success.

Source: (UKCES, 2016[900)

In line with that, the Taylor Review on Modern Working Practices highlighted that employer practices vary significantly across sectors, resulting in significant sectoral differences in both pay and productivity levels. Among the seven steps towards fair and decent work, the Review indicates that sectoral strategies 
engaging employers, employees and stakeholders should accompany the National Living Wage to ensure low-paid workers in specific industrial sectors can progress in their career and improve their labour market outcomes (Taylor et al., 2017[61]).

Working at the sector level can take a number of forms - from creating enabling conditions for sectors to shift to higher value added products and services (e.g. through applied research and technology transfer projects) to improving skills use and job quality in sectors with high rates of low paid, low-skill jobs (e.g. through development of career ladders, and work re-organisation). The use of a sectoral strategy can create eco-systems that encourage skills utilisation as part of a "competitive model of choice" for employers (Ashton and Sung, 2009 $\left.{ }_{[19]}\right)$. Sector-based strategies can be particularly effective as they are better able to take into account the overall skills ecosystem that serves as the broader context for how skills are used in the workplace. An example of a successful sectoral strategy in the manufacturing sector in the United States is the Manufacturing Extension Partnership (see Box 5.6).

For example, (Wright, 2012[91]) identified that in the UK, the key challenges for the retail sector are to improve the quality and completion rates of apprenticeships and create more intermediate supervisor roles. In the hospitality sector, there is ample room for improvement in skills utilisation and in employers taking a more holistic vision of what skills are and how they are rewarded (e.g. to better take soft skills into account), but low firm profitability is a key barrier.

\section{Box 5.6. The Manufacturing Extension Partnership, United States}

The Manufacturing Extension Partnership (MEP) National Network is a public-private partnership that delivers solutions to US manufacturers, with a special focus on small and medium-sized enterprises. The main activities of the MEP network are:

- Empower manufacturers by assisting firms in implementing innovative manufacturing technologies and in recruiting and retaining a skilled and diverse workforce.

- Champion manufacturing by promoting the importance of a strong manufacturing sector for the US economy, creating awareness of innovations in manufacturing, creating enabling workforce development partnerships to build a stronger and diverse workforce pipeline, and maximizing awareness of the MEP National Network.

- Leverage partnerships at all government levels by helping the MEP National Network become a recognized manufacturing resource brand and supporting manufacturing technology advances.

- Transform the network by operating as an integrated National Network, improve efficiency by employing a Learning Organization platform

The MEP National Network comprises the National Institute of Standards and Technology's Manufacturing Extension Partnership (NIST MEP), 51 MEP Centers located in all 50 states and Puerto Rico, and more than a thousand advisors and experts. Partners of the MEP National Network TM focus on educational institutions, state governments, NIST and other federal research laboratories and agencies. In 2018, the MEP Centres served more than 28000 manufacturers, helped create or retain around 115000 jobs and produced USD15.7 billion in sales.

Source: https://www.nist.gov/mep 


\section{Embedding HR practices in the strategic objectives}

One of the barriers to improving the use of skills is a low level of awareness amongst managers, social partners and business support organisations that skills under-utilisation is an issue. Previous OECD research has highlighted the importance of networking firms together to share best practices around human resource management practices (OECD/ILO, 2017[7] $)$. A coherent system of HR practices includes a wide range of actions that range from skills development to increasing employee autonomy and discretion (Cedefop, 2017[92]). When HR practices are well managed and embedded in the overall strategic objectives of firms, they can contribute to improving the skills and motivation of their employees, resulting in increasing productivity and competitiveness (Chowhan, 2016[93]).

While employer engagement has increasingly become a mantra across a variety of employment and training systems, securing high levels of buy-in and engagement from employers is even more critical in the field of skills utilisation. Additionally, while promoting employer leadership in shaping skills agendas is increasingly seen as a means of ensuring the labour market relevance of education and training, there are also risks involved. Such an approach can be especially problematic when employer needs are taken as a given in places where there is a concentration of employers using low-road strategies and focused on low value-added activities. This highlights the importance of broad based representation from employers and worker organisations within governance and regulatory bodies to ensure that programmes develop a broad set of skills required across occupation and sector, rather than narrow or firm-specific skillsets. A good example is practice labs, which were introduced in Flanders, Belgium (see Box 5.7).

\section{Box 5.7. Practice labs for workforce innovation in Flanders, Belgium}

In Flanders (Belgium), practice labs for innovative work organisation have been set up to work with businesses on work organisation issues. The Confederation of Christian Trade Unions (ACV) has played a key role in establishing and implementing the initiative. The practice labs have been set up in the construction, logistics, healthcare, social economy, social service/care and agricultural sectors. Separate labs were established for each sector but in fact, labs can work with mixed groups, and can support both large and small firms. With the support of consultants, eight workshops took place in 2013/14, each involving 6-8 companies. They function as a learning network where companies share experience. Managers are encouraged to consider where they can effect change to make sure that workers have more involvement in the way that the firm operates. Each lab covers seven themes, each of which is a different area where the manager can have an influence. This includes exploring new ways that firms can expand their market base to improve the quality of their organisation (in terms of efficiency, flexibility, quality, innovation, sustainability) while also improving job quality. Supervisors play the role of coach and act as a sounding board for participants who have questions, both within and outside of the lab sessions. Participants receive assignments to translate theory into practice when they return to the workplace. Unions report that the workshops have improved their relationships with local employers.

Source: (OECD, 2015[94)

\section{Providing support for employers to reshape workplaces}

More direct interventions involve funding or other types of interventions to support employers to reshape workplace practices or move to higher value-added production. Such support can take the form of staff or management training, using consultants or other external experts, to support management in diagnosing and upgrading workplace organisation and technology, supporting action-oriented research in businesses. 
Recent work in the UK identified the range of informal learning opportunities that can occur at the workplace and highlighted how work organisation can influence opportunities for the development and utilisation of skills (Felstead et al., 2011 ${ }_{[95])}$. The paper presents the Working as Learning Framework (WALF), which can be used as a tool to examine how productive systems, worker discretion and managerial decision influence workplace organisation. These three elements can be seen as the underlying conditions which would facilitate or inhibit skills utilisation. This framework can help employers reshape the way they organise work, by embedding workforce development in their broader business strategy agenda.

In Singapore, the Enterprise Training Support (ETS) scheme was introduced in 2013 to (1) raise employees' productivity and skills levels; (2) attract and retain valued employees by developing good human resource (HR) and management systems and practices tied to training; and (3) attract and retain valued employees by benchmarking compensation and benefits. ETS seeks to make skills development relevant to workplace performance and link skills acquisition and utilisation to retention. Another good example can be found from the Scottish Funding council (Box 5.8).

\section{Box 5.8. Scottish Funding Council Skills Utilisation Projects, United Kingdom}

Since 2009, Scotland funded 12 projects aimed at improving skills utilisation by strengthening collaboration between colleges and universities with employers. Projects were selected by the Scottish Funding Council through a competitive tendering process. They included the following:

- The Glasgow School of Art ran a "Creating Cultures of Innovation through Creativity and Design" project that aimed to help business leaders use the skills of their entire workforce to solve business problems by developing a creative thinking process. This approach involved a number of different activities, including workshops to brainstorm solutions to a problem facing the firm. People involved in the workshops were selected to be broadly representative in terms of their position within the firm, gender, function, age and length of service.

- The Open University in Scotland worked with organisations in the social care sector to make better use of newly-acquired skills of students who had just completed a management level qualification for supervisory staff. Previously, students had complained that when they returned to work after completing this course, their responsibilities did not change, despite their new skills. The Open University helped social care organisations to re-think and broaden the role of students' jobs to more fully use their new skills. The qualitative evaluation found evidence that universities and colleges can make a positive contribution to skills utilisation, but flagged several issues, including the need, if the approaches were to be scaled up, of developing expertise in helping organisations to re-think work organisation, job design and their approaches to innovation.

\section{Promoting workforce development strategies}

Workforce development strategies generally refer to a labour market strategy that focuses on both skills supply and demand and complements the existing employment and training services. These strategies identify alternative solutions to better align education and training with job opportunities and focus on offering solutions to a group of people and involve multiple employers. This is the main difference with traditional employment services (Zizys, 2018[96]). This requires the involvement of various stakeholders, both from the public and private sectors, that help workers or unemployed people to acquire the right set of skills and evolve in their careers (Jacobs and Hawley, 2009[97]). 
By raising the productivity and the engagement of people employed, workforce development strategies are beneficial for businesses and contribute more broadly to fostering economic growth. Case studies from the UK and North American countries show how these strategies can be helpful to improve economic conditions of the most disadvantaged areas in the country (Taylor, 2001 [98]). In recent year, six workforce innovation centres have been implemented in Canada. These centres explore opportunities to share and implement innovative approaches to workforce development (see Box 5.9).

\section{Box 5.9. Workforce Innovation Centres, Canada}

Workforce Innovation Centres (WICs) have recently been implemented in 6 Canadian provinces. The role of the Centres is to share knowledge and information on new research, test new initiatives related to workforce development and coordinate and engage with a wide range of stakeholders involved in labour market and skills policies. Exchange among the Workforce Innovation Centres takes place on a regular basis. While in most provinces the role of WICs is to fund research to address workforce development challenges, additional objectives can vary across them. In Newfoundland and Labrador, outcomes from the research is mainly addressed to increase employability, foster entrepreneurship and strengthen attachment to the workforce, while in Nova Scotia the focus of research is on improving the quality of employment services.

In Ontario, the activity of the centre is to identify and coordinate best practices on how to deliver evidence-based employment and training programmes. In Quebec, the Centre helps strengthen the collaboration among stakeholders to improve training systems. In Manitoba, the Centre facilitates workforce transitions from training to employment. In British Columbia, the Centre supports the research and information needs of the stakeholders involved in the employment services sector.

\section{Leveraging the role of anchor institutions and trade unions}

There may also be opportunities to leverage the influence of "anchor institutions" to create change in local economies. Research from the former UKCES has pointed to the importance of anchor institutions in helping to address productivity issues related to the poor use of skills (UKCES, 2015[99]). An anchor institution is one that has a strong local presence and makes a strategic contribution to the local economy. They include universities, vocational education and training institutions, chambers of commerce, banks and major employers. The OECD's research into this area has demonstrated the important role that can be played by vocational education institutions (OECD, 2014 $\left.{ }_{[100]}\right)$.

In Ontario (Canada), local community colleges and universities appear to be particularly useful partners in helping to raise product market strategies locally (Verma, 2012[101]). Niagara College, for example, has not only geared its curricula towards meeting local industrial demands in horticulture and wine making (an example being the Winery and Viticulture Technician programme), but has also set up an applied research unit which helps local firms to upgrade their products and business strategies. It collaborates with firms in areas such as product and process applied research, engineering design, technology development, product testing, proof of concept, piloting and problem solving.

In addition to anchor institutions, trade unions play a major role in promoting better skills use. Unionlearn has conducted extensive work to analyse and evaluate the role of unions in better using existing and newly acquired skills, while also supporting the workforce to improve their skills. Research conducted by the University of Strathclyde highlights a number of ways in which trade unions can help improve skills utilisation, including working with employers to shape training provision, conducting joint work to identify 
new progression routes, and providing support to workers willing to access training for higher skilled roles (Unionlearn, 2012[102]).

A case study analysis showed that unions are well positioned to help firms change their working practices and influence business strategy. In Germany and in Scandinavian countries, trade unions have supported employers to move up the value chain by improving the quality of goods and services. In this way they contributed to creating more highly skilled jobs and promoting good skills use to ensure higher productivity standards (Unionlearn, 2012[102]).

The Scottish Trades Union Congress (STUC) established a partnership with the Scottish Government and other key local stakeholders to support the better skills utilisation agenda. A recent evaluation conducted by the Scottish Centre for Employment Research (SCER) highlighted that, when undertaken in partnership with employers and other key stakeholders, union-led initiatives "can contribute significantly to the design, development and implementation of skills utilisation initiatives to produce identifiable benefits" (Findlay, Commander and Warhurst, 2011 [69])

\section{How can the Leeds City Region evaluate success of skills use policies?}

Once a project or intervention would be implemented in the Leeds City Region, evaluation of what change occurs, how and why as well as their outcomes is essential. Likewise what changes are not feasible, and why not, also needs to be evaluated. Two types of evaluation would be useful:

- Formative evaluation: occurs during any project or intervention and can be used to monitor progress; and via feedback loops, identify, firstly, good practice as well as, secondly, barriers and problems, and how the first can be sustained and the second addressed. It is about finding ways to correct weaknesses and amplify successes.

- Summative evaluation: occurs at the end of the project or intervention to measure how they have fared in terms of meeting their objectives. It also identifies the reasons underpinning the meeting or shortfall in objectives being attained, including success factors. It allows stakeholders to assess the relative costs, benefits and applicability of the different interventions.

Evaluation needs to be integral to the projects and interventions, built into their architecture and design from the outset rather than bolted on as an afterthought. Formative evaluations should only occur once the projects or interventions are fully operational and summative evaluations at a time when measurement of outcomes is feasible. Fortunately, in thinking about how to undertake this task and what measures to use, there are precedents, as the Scottish Government - the UK pioneer in this field of policy - has already been working on these issues (Payne, 2010[103]) (Payne, 2011[104]) (Scottish Funding Council, 2012[105]).

\section{What does success look like?}

Unlike traditional skills supply initiatives, for which success can be relatively easily measured through the number of workers or students trained or the number and level of qualifications gained, skills utilisation interventions require their sponsors to think through what constitutes success. Success can relate to changes in how skills are used in work and/or the outcomes of that changed skills use, recognising that the first is a necessary condition for the second.

It should also be recognised that there is likely to be different interests focused on these projects and interventions, and that a range of performance measures might be necessary to address these interests. It is important therefore that these interests are involved in the setting of objectives so that there is consensus-based agreement on the intended objectives before projects or interventions start. For a more detailed exploration of these issues, see (Eddington and Eddington, 2010[106]). These objectives can then inform the approach to evaluation and the use of "hard" and/or "soft" measures. 


\section{Hard measures}

Depending on the aims of the project or intervention, it may be possible to put hard numbers on the gains that are generated, not least so that some form of cost/benefit calculation can be made that allows a rate of return on (public) investment to be calculated. For an example of one attempt to put hard numbers on the outcomes from a set of workplace interventions, see the (Harris et al., 2011 [107]) evaluation of the Acas innovative workplaces projects. In trying to quantify gains, a key issue concerns the choice of measures to use.

Nevertheless, gauging the impact of attempts to improve skills utilisation is fraught with difficulty, not least because the traditional battery of skill and training measures is of little use in this context. If both the matching and enablers approaches to skills utilisation are to be covered, the following are some of the outcome indicators that might be used for such interventions at firm or sector level:

- Levels of training incidence that ensure worker ability

- Percentage increase in workers who report having a match between the skills possessed and used

- Proportion of workers with matched skills possession and use

- Productivity increases

- Higher levels of innovation in the workplace

- Cost savings

- Increased turnover or sales

- Quality improvements to products or services

- Loss due to waste or need to re-work items reduced

- Reduced employer and employee perceptions of skills mismatches

- Reduced staff turnover

- Reductions in hard-to-fill vacancies

- Enhanced employee satisfaction and motivation

Data on most of these will not always be readily available at the workplace or organisational levels for individual firms. This situation is particularly likely in SMEs for which it would be unwise to assume that the organisation will have the managerial capacity or information and monitoring systems in place to routinely gather such data. In other words, the project teams and/or whoever is evaluating their work may need to gather this information, which has cost implications.

Once gathered, there are also questions about how to read such data. For example, what ought to be the relative weighting between different indicators? In addition, there is the question of how to disentangle the impact of the policy intervention from broader impacts being generated by other factors in the firm's operating environment (for example, Brexit and changes in the overall state of the economy, interest rates, exchange rates, inflation, consumer spending patterns, public investment decisions, etc.). The other major problem relates to time lags. Outcomes need time to emerge, and changes may only impact on organisational performance after the project or intervention has finished. They are certainly unlikely to always be instantaneous. Lessons from other initiatives to improve skills supply and demand highlight that evaluation occurred too early to fully capture organisational impacts (Buchanan et al., 2017).

\section{Soft measures}

The hard measures highlighted would be a long-term goal. It is worth noting that the Scottish Funding Council's (SFC) Skill Utilisation Projects (conducted between 2010 and 2013) and the various Scandinavian countries' workplace innovation programmes, have used soft measures which depend in large measure on the subjective perceptions of staff in participant organisations (managers and workers) 
of both the intervention process and the outcomes and benefits which they believe it to have generated (Payne, 2006 $\left.{ }_{[108]}\right)$ (Payne, 2004[109]). It has also been based on small-scale surveys among participants or case studies (Harris et al., 2011 [107]) (Scottish Funding Council, 2012[105]). These perceptions can still have targeted foci, most obviously reflecting the AMO framework through which changes to management practices to lever organisational performance improvements can be identified:

- Enhanced opportunities to use skills e.g. through more participatory mechanisms or workers having more responsibility for, autonomy in, and control over work

- Clear motivations to use skills e.g. the introduction of gain-sharing arrangements or more meaningful/challenging work

- Improvements in management-worker relations that create climates of trust

- Greater levels of employee satisfaction and commitment. 


\section{Annex A. Framework for developing a project/intervention-specific evaluation design}

To design a case study approach that can support both formative (i.e. occurring during the project or intervention to monitor progress) and summative (i.e. occurring at the end of the project or intervention to assess success) evaluation of skills use pilots, the following framework of issues and questions may be used. This framework was originally developed by the Scottish Funding Council in designing their evaluation model for the Scottish skill utilisation pilot projects. It is structured around 3 phases:

\section{Phase 1: before the project starts}

\section{Questions to probe and data to gather before projects/interventions start in order to establish a baseline assessment of the workplaces/employers/forms of employment and work organisation:}

- What specific aspects of skills use is the project aiming to target and change and to what ends?

- Who defined these aspects and ends as problems to be addressed (employers, workers, the external change facilitator/agent or another actor)?

- Are all of the relevant stakeholders identified and involved in problem definition and solution?

- How is change expected to be bought about and how can progress be measured against these expectations?

- Are there sufficient resources available to make the necessary changes and is there concept and role clarity amongst the participants (project/intervention team and subject organisations)?

\section{Phase 2: during the project lifetime}

\section{Questions to probe and data to gather during the lifetime of the project to capture process and management issues:}

- Within the projects are there significant moments or decision points that mark shifts, successes or failures?

- What are the stakeholder perceptions of the projects in terms of the quality and effectiveness of processes and outcomes?

- What is the effectiveness of project/intervention management structures, participant roles and responsibilities, and leadership functions?

- Is there adequate communication about the project amongst the participants to ensure continued buy-in and relevance?

- Is there monitoring of possible mission draft, with corrective actions identified if required? 


\section{Phase 3: after the project completion}

\section{Questions to probe and data to gather after project completion to measure outcomes and generate lessons:}

- What are the impact/success measures and over what timescale will they need to be monitored?

- What worked, what did not work and why in each case?

- How did participants rate their experiences of the project and, with hindsight, what, if anything, would they want to do differently?

- How best can the projects be up-scaled and generalised? What kinds of capacity and resources would be required for this to happen?

Whilst the suggests outlined above are focused upon a set of general considerations, it is easier to develop more fine-grained evaluation framework once the exact nature and scope of what is being evaluated has been settled. The key point is that evaluation works best when, from the outset, it forms an integral part of the overall design process of the project or intervention. It needs to be a consideration embedded in the overall planning process (Green et al., 2017[85]). 


\section{Bibliography}

Adalet McGowan, M. and D. Andrews (2017), "Skills mismatch, productivity and policies: Evidence from the second wave of PIAAC", OECD Economics Department Working Papers, No. 1403, OECD Publishing, Paris, https://dx.doi.org/10.1787/65dab7c6-en.

Adalet McGowan, M. and D. Andrews (2015), "Labour Market Mismatch and Labour Productivity: Evidence from PIAAC Data", OECD Economics Department Working Papers, No. 1209, OECD Publishing, Paris, https://dx.doi.org/10.1787/5js1pzx1r2kb-en.

Alasoini, T. (2015), "Two decades of programme-based promotion of workplace innovation in Finland: past experiences and future challenges", European Journal of Workplace Innovation, Vol. $1 / 1$.

Appelbaum, E. et al. (2000), Manufacturing Advantage: Why High-performance Work Systems Pay Off, http://dx.doi.org/DOl: 10.2307/259189.

Ashton, D. and J. Sung (2009), Product Market Strategies and Workforce Skills, Futureskills Scotland, https://www.webarchive.org.uk/wayback/archive/20180520130515/http://www.gov.scot/Publicat ions/2009/06/22085911/8.

Autor, D., F. Levy and R. Murnane (2003), "The skill content of recent technological change: An empirical exploration”, Quarterly Journal of Economics, Vol. 118/4, pp. 1279-1333, http://dx.doi.org/10.1162/003355303322552801.

Becker, G. (ed.) (1993), Human Capital: A Theoretical and Empirical Analysis with Special Reference to Education, The University of Chicago Press, Chicago, http://www.nber.org/chapters/c11227.

BEIS and HM Treasury (2019), Business Productivity Review, https://assets.publishing.service.gov.uk/government/uploads/system/uploads/attachment data/ file/844506/business-productivity-review.pdf (accessed on 30 January 2020).

Belt, V. and L. Giles (2009), "High performance working: a synthesis of key literature", https://www.researchgate.net/publication/242773757 High Performance Working A Synthesi s of Key Literature (accessed on 17 September 2019).

Bender, S. et al. (2016), "Management practices, workforce selection and productivity", No. NBER Working Paper 22101, https://www.nber.org/papers/w22101 (accessed on 23 January 2020).

Bender, S. et al. (2016), "Management Practices, Workforce Selection and Productivity".

Black, S. and L. Lynch (2005), Measuring Organizational Capital in the New Economy, University of Chicago Press, https://www.nber.org/chapters/c10622.pdf.

Black, S. and L. Lynch (2005), "Measuring Organizational Capital in the New Economy", in Measuring capital in the new economy, University of Chicago Press, 2005, https://www.researchgate.net/publication/5135738 Measuring Organizational Capital in the New Economy (accessed on 14 February 2020). 
Boedker, C. et al. (2011), Leadership, Culture and Management Practices of High Performing Workplaces in Australia: The High Performing Workplaces Index, http://www.unsw.edu.au (accessed on 17 September 2019).

Buchanan, J., P. Anderson and G. Power (2017), "Skill Ecosystems", in Buchanan, J. et al. (eds.), The Oxford Handbook of Skills and Training, Oxford University Press, http://dx.doi.org/10.1093/oxfordhb/9780199655366.001.0001.

Buchanan, J. et al. (eds.) (2017), Measuring Skills Stock, Job Skills, and Skills Mismatch, Oxford University Press, http://dx.doi.org/10.1093/oxfordhb/9780199655366.013.16.

Buchanan, J. et al. (eds.) (2017), Skill Under-utilization, Oxford University Press, http://dx.doi.org/10.1093/oxfordhb/9780199655366.013.14.

Buchanan, J. et al. (2010), "Skills Demand and Utilisation: An International Review of Approaches to Measurement and Policy Development", OECD Local Economic and Employment Development (LEED) Working Papers, No. 2010/4, OECD Publishing, Paris, https://dx.doi.org/10.1787/5km8zddfr2jk-en.

Cedefop (2017), "Skill utilization at work: Opportunity and motivation", IZA World of Labor, http://dx.doi.org/10.15185/izawol.409.

Cedefop (2012), "Sectoral perspectives on the benefits of vocational education and training" 22, http://dx.doi.org/10.2801/75439.

Cedefop (2011), "The impact of vocational education and training on company performance", No. 19.

CFE (2008), Skills Utilisation Literature Review, https://dera.ioe.ac.uk/9416/1/0075479.pdf.

Chowhan, J. (2016), "Unpacking the black box: understanding the relationship between strategy, HRM practices, innovation and organizational performance", Human Resource Management Journal, Vol. 26/2, pp. 112-133, http://dx.doi.org/10.1111/1748-8583.12097.

Clark, J. (1995), Managing innovation and change : people, technology and strategy, Sage Publications.

Combs, J. et al. (2006), How much do High-Performance Work Practices Matter? A meta-analysis of their effects on organisational performance.

Dearden, L., H. Reed and J. Van Reenen (2006), "The Impact of Training on Productivity and Wages: Evidence from British Panel Data*", Oxford Bulletin of Economics and Statistics, Vol. 68/4, pp. 397-421, http://dx.doi.org/10.1111/j.1468-0084.2006.00170.x.

Delery, J. and D. Doty (1996), "Modes of theorizing in strategic human resource management: Tests of universalistic, contingency, and configurational performance predictions", Academy of Management Journal, Vol. 39/4, pp. 802-835, http://dx.doi.org/10.2307/256713.

Dortmund Brussels Position Paper on Workplace Innovation (2012), , http://www.sfs.tudortmund.de/cms/de/DieSFS/Gremien Netzwerke/EUWIN/Dortmund Brussels Position Pape r on Workplace Innovation 12th June 2012.pdf.

Eddington, N. and I. Eddington (2010), "Methods and Instruments for the Evaluation and Monitoring of VET Systems", SKOPE Research Paper No. 98, http://www.skope.ox.ac.uk/wp- 
content/uploads/2014/04/RP98.pdf (accessed on 11 September 2019).

ERC (2019), UK Local Growth Dashboard, https://www.enterpriseresearch.ac.uk/wpcontent/uploads/2019/03/ERC-Insight.-Job-Creation-and-Destruction-in-the-UK- (accessed on 14 February 2020).

Erickson, C. and S. Jacoby (2002), The Effect of Employer Networks on Workplace Innovation and Training.

Eurostat and OECD (2007), Eurostat-OECD Manual on Business Demography Statistics, https://www.oecd.org/sdd/business-stats/eurostatoecdmanualonbusinessdemographystatistics.htm.

Felstead, A. et al. (2011), "Working to learn, learning to work", https://www.researchgate.net/publication/279475896 Praxis Working to learn learning to w ork (accessed on 4 February 2020).

Felstead, A. et al. (2007), Skills at Work, 1986 to 2006.

Findlay, P., J. Commander and C. Warhurst (2011), The role of trade unions in effective skills utilisation: three Scottish case studies, https://pureportal.strath.ac.uk/en/publications/the-roleof-trade-unions-in-effective-skills-utilisation-three-sc (accessed on 18 September 2019).

Findlay, P. and C. Warhurst (2012), More Effective Skills Utilisation: Shifting the Terrain of Skills Policy, Cardiff University, https://www.researchgate.net/publication/267381449 More Effective Skills Utilisation Shiftin $g$ the Terrain of Skills Policy in Scotland.

Finegold, D. and D. Soskice (1988), "The Failure of Training in Great Britain: Analysis and Prescription”, Oxford Review of Economic Policy, Vol. 4/3, pp. 21-53.

Froy, F., S. Giguère and M. Meghnagi (2012), "Skills for Competitiveness: A Synthesis Report", OECD Local Economic and Employment Development (LEED) Papers, No. 2012/9, OECD Publishing, Paris, https://dx.doi.org/10.1787/5k98xwskmvr6-en.

Fuller, A. et al. (2018), "Innovating for a cause: the work and learning required to create a new approach to healthcare for homeless people", Journal of Education and Work, Vol. 31/3, pp. 219-233, http://dx.doi.org/10.1080/13639080.2018.1447654.

Gal, P. and J. Egeland (2018), "Reducing regional disparities in productivity in the United Kingdom", OECD Economics Department Working Papers, No. 1456, OECD Publishing, Paris, https://dx.doi.org/10.1787/54293958-en.

GLA (2014), Growing Together II: London and the UK economy, http://www.london.gov.ukenquiries02079834100minicom02079834458 (accessed on 14 February 2020).

Green, A. (2012), "Skills for Competitiveness: Country Report for United Kingdom", OECD Local Economic and Employment Development (LEED) Working Papers, No. 2012/5, OECD Publishing, Paris, https://dx.doi.org/10.1787/5k9bb1vc6skf-en.

Green, A. et al. (2017), Local skills case study, Department for Education.

Guest, D. (2000), The Future of Work, CIPD. 
Guthrie, J. (2001), "High-involvement work practices, turnover, and productivity: Evidence from

New Zealand", Academy of Management Journal, Vol. 44/1, pp. 180-190, http://dx.doi.org/10.2307/3069345.

Hall, P. and D. Soskice (n.d.), An Introduction to Varieties of Capitalism.

Harley, B., B. Allen and L. Sargent (2007), "High Performance Work Systems and Employee Experience of Work in the Service Sector: The Case of Aged Care", British Journal of Industrial Relations, Vol. 45/3, pp. 607-633, http://dx.doi.org/10.1111/j.1467-8543.2007.00630.x.

Harris, L. et al. (2011), "Unlocking Engagement: A Review of the 'Innovative Workplaces' Initiative", https://www.acas.org.uk/media/3060/Unlocking-Engagement-A-Review-of-theInnovative-Workplaces-Initiative/pdf/Unlocking-Engagement-a-review-of-the-InnovativeWorkplaces-Initiative April 2011.pdf (accessed on 11 September 2019).

HM Government (2018), Good Work Plan, https://www.gov.uk/government/publications/goodwork-plan (accessed on 19 September 2019).

HM Government (2018), Strengthened Local Enterprise Partnerships, https://www.gov.uk/government/publications/strengthened-local-enterprise-partnerships (accessed on 25 February 2020).

HM Government (2017), Industrial Strategy: building a Britain fit for the future, https://assets.publishing.service.gov.uk/government/uploads/system/uploads/attachment data/ file/664563/industrial-strategy-white-paper-web-ready-version.pdf (accessed on 17 September 2019).

Hofstede, G. (2001), "Culture's Consequences", International Journal of Cross Cultural Management, Vol. 1/1, pp. 11-30.

Huselid, M. (1995), "The impact of human resource managements practices on turnover, productivity and corporate financial performance", Academy of Management Journal, Vol. 38/3, pp. 635-872.

ILO (2011), A Skilled Workforce for Strong, Sustainable and Balanced Growth A G20 Training Strategy, http://www.ilo.org/publns (accessed on 14 February 2020).

Jacobs, R. and J. Hawley (2009), "The Emergence of 'Workforce Development': Definition, Conceptual Boundaries and Implications", in International Handbook of Education for the Changing World of Work, Springer Netherlands, http://dx.doi.org/10.1007/978-1-4020-52811167.

Jacobs, R. and J. Hawley (2009), "The Emergence of 'Workforce Development': Definition, Conceptual Boundaries and Implications", in International Handbook of Education for the Changing World of Work, Springer Netherlands, Dordrecht, http://dx.doi.org/10.1007/978-14020-5281-1 167.

Jensen, M. et al. (2007), "Forms of knowledge and modes of innovation", Research Policy, Vol. 36/5, pp. 680-693, http://dx.doi.org/10.1016/j.respol.2007.01.006.

Jiang, K. et al. (2012), "How does human resource management influence organizational outcomes? A meta-analytic investigation of mediating mechanisms", Academy of Management Journal, Vol. 55/6, pp. 1264-1294, http://dx.doi.org/10.5465/ami.2011.0088. 
Johnston, R. and G. Hawke (2002), Case studies of organisations with established learning cultures, NCVER, https://www.ncver.edu.au/research-and-statistics/publications/allpublications/case-studies-of-organisations-with-established-learning-cultures (accessed on 14 February 2020).

Keep, E. (2016), Improving Skills Utilisation in the UK - Some Reflections on What, Who and How?, Oxford University, http://www.skope.ox.ac.uk/wp-content/uploads/2016/09/Keep.Improving-Skills-Utilisation-in-the-UK-Some-reflections-on-What-Who-and-How.pdf.

Lloyd, C., C. Warhurst and E. Dutton (2013), "The weakest link? Product market strategies, skill and pay in the hotel industry", Work, Employment and Society, Vol. 27/2, pp. 254-271, http://dx.doi.org/10.1177/0950017012460310.

Martin, B. and J. Healy (2009), Changing Work Organisation and Skill Requirements, https://www.researchgate.net/publication/228196438 Changing Work Organisation and Skill Requirements (accessed on 14 February 2020).

Mincer, J. (1974), "Schooling, Experience, and Earnings".

OECD (2020), Enhancing Productivity in UK Core Cities.

OECD (2020), Enhancing Productivity in UK Core Cities, OECD Urban Policy Reviews, OECD Publishing, Paris, https://dx.doi.org/10.1787/9ef55ff7-en.

OECD (2020), "Regional economy", OECD Regional Statistics (database), https://dx.doi.org/10.1787/6b288ab8-en (accessed on 13 February 2020).

OECD (2019), Getting Skills Right Engaging low-skilled adults in learning, http://www.oecd.org/employment/emp/engaging-low-skilled-adults-2019.pdf (accessed on 18 September 2019).

OECD (2019), Getting Skills Right: Future-Ready Adult Learning Systems, Getting Skills Right, OECD Publishing, Paris, https://dx.doi.org/10.1787/9789264311756-en.

OECD (2019), OECD Skills Strategy 2019: Skills to Shape a Better Future, OECD Publishing, Paris, https://dx.doi.org/10.1787/9789264313835-en.

OECD (2018), Good Jobs for All in a Changing World of Work: The OECD Jobs Strategy, OECD Publishing, Paris, https://dx.doi.org/10.1787/9789264308817-en.

OECD (2018), The Productivity-Inclusiveness Nexus, OECD Publishing, Paris, https://dx.doi.org/10.1787/9789264292932-en.

OECD (2017), Getting Skills Right: United Kingdom, Getting Skills Right, OECD Publishing, Paris, https://dx.doi.org/10.1787/9789264280489-en.

OECD (2017), OECD Economic Surveys: United Kingdom 2017, OECD Publishing, Paris, https://dx.doi.org/10.1787/eco surveys-gbr-2017-en.

OECD (2016), Getting Skills Right: Assessing and Anticipating Changing Skill Needs, Getting Skills Right, OECD Publishing, Paris, https://dx.doi.org/10.1787/9789264252073-en.

OECD (2016), Job Creation and Local Economic Development 2016, OECD Publishing, Paris, https://dx.doi.org/10.1787/9789264261976-en. 
OECD (2016), OECD Employment Outlook 2016, OECD Publishing, Paris, http://dx.doi.org/10.1787/empl outlook-2016-en.

OECD (2016), Skills Matter: Further Results from the Survey of Adult Skills, OECD Skills Studies, OECD Publishing, Paris, https://dx.doi.org/10.1787/9789264258051-en.

OECD (2015), Employment and Skills Strategies in England, United Kingdom, OECD Reviews on Local Job Creation, OECD Publishing, Paris, https://dx.doi.org/10.1787/9789264228078-en.

OECD (2015), Employment and Skills Strategies in Flanders, Belgium, OECD Reviews on Local Job Creation, OECD Publishing, Paris, https://dx.doi.org/10.1787/9789264228740-en.

OECD (2014), Job Creation and Local Economic Development, OECD Publishing, Paris, https://dx.doi.org/10.1787/9789264215009-en.

OECD (2012), Key Facts about the Survey of Adult Skills (PIAAC), https://www.oecd.org/skills/piaac/Key\%20facts\%20about\%20the\%20Survey\%20of\%20Adult\% 20Skills.pdf.

OECD (2011), Towards an OECD Skills Strategy, http://www.oecd.org/education/47769000.pdf.

OECD/ILO (2017), Better Use of Skills in the Workplace: Why It Matters for Productivity and Local Jobs, OECD Publishing, Paris, https://dx.doi.org/10.1787/9789264281394-en.

Office for National Statistics (2019), Regional and sub-regional productivity in the UK, https://www.ons.gov.uk/employmentandlabourmarket/peopleinwork/labourproductivity/articles/r egionalandsubregionalproductivityintheuk/february2019\#quality-and-methodology (accessed on 12 February 2020).

Okay-Somerville, B. and D. Scholarios (2013), "Shades of grey: Understanding job quality in emerging graduate occupations", Human Relations, Vol. 66/4, pp. 555-585, http://dx.doi.org/10.1177/0018726712465094.

Orellana, E. (2018), "Regional, sub-regional and local gross value added estimates for London, 1997-2016”, GLA Economics Current Issues Note 57, http://www.london.gov.uk (accessed on 14 February 2020).

Osterman, P. (2008), "Improving Job Quality: Policies Aimed at the Demand Side of the LowWage labor Market", in A Future of Good Jobs? America's Challenge in the Global Economy, W.E. Upjohn Institute, http://dx.doi.org/10.17848/9781435641037.ch6.

Payne, J. (2011), "In search of a measurement and evaluation framework for skill utilisation", SKOPE Issue Paper No. 25, https://pdfs.semanticscholar.org/dcb1/fa65030690af5155a352e5e9677512a50a84.pdf? ga=2. 167640958.1938093358.1568200065-620348862.1568200065 (accessed on 11 September 2019).

Payne, J. (2010), "Skill Utilisation: Towards a Measurement and Evaluation Framework", SKOPE Research Paper, Vol. No. 93, http://citeseerx.ist.psu.edu/viewdoc/download?doi=10.1.1.602.4761\&rep=rep1\&type=pdf (accessed on 11 September 2019).

Payne, J. (2006), "The Norwegian competence reform and the limits of lifelong learning", International Journal of Lifelong Education, Vol. 25/5, pp. 477-505, 
http://dx.doi.org/10.1080/02601370600912063.

Payne, J. (2004), "Re-Evaluating the Finnish Workplace Development Programme: Evidence from Two Projects in the Municipal Sector", Economic and Industrial Democracy, Vol. 25/4, pp. 485524, http://dx.doi.org/10.1177/0143831x04047157.

Prescott, E. and M. Visscher (1980), "Organization Capital", Journal of Political Economy, Vol. 88/3, pp. 446-461, http://dx.doi.org/10.1086/260879.

Ramsay, H., D. Scholarios and B. Harley (2000), Employees and High-PerformanceWork Systems:Testing inside the Black Box.

Schuler, R. and S. Jackson (2011), "Linking Competitive Strategies with Human Resource Management Practices.", Academy of Management Executive, Vol. 1/3, pp. 207-219, http://dx.doi.org/10.5465/ame.1987.4275740.

Scottish Enterprise (2019), Workshops and masterclasses, https://www.scottishenterprise.com/support-for-businesses/improve-productivity-and-skills/workshops-andmasterclasses.

Scottish Funding Council (2012), "Skills Utilisation Report", No. Skills Committee Paper SC/12/23. [105]

Scottish Government (2019), Fair Work Action Plan: Boosting productivity by developing Scotland as a world-leading Fair Work Nation, https://economicactionplan.mygov.scot/fair-work/.

Skills Australia (2012), Better use of skills, better outcomes: A research report on skills utilisation in Australia, https://www.voced.edu.au/content/ngv\%3A51508 (accessed on 17 September 2019).

Smith, C. and P. Meiksins (1995), System, Society and Dominance Effects in Cross-National Organizational Analysis, https://engagedscholarship.csuohio.edu/clsoc crim facpubhttps://engagedscholarship.csuohio .edu/clsoc crim facpub/84 (accessed on 23 October 2019).

Sung, J. and D. Ashton (2015), Skills in business: the role of business strategy, sectoral skills development and skills policy.

Sung, J. and D. Ashton (2005), High Performance Work Practices: Linking Strategy and Skills to Performance Outcomes, http://www.cipd.co.uk. (accessed on 18 September 2019).

Taylor, M. et al. (2017), Good work: the Taylor review of modern working practices, Department for Business, Energy and Industrial Strategy, London.

Taylor, S. (2001), Getting employers involved - improving work-based learning through employer links, Learning and Skills Development Agency, http://www.LSagency.org.uk (accessed on 5 February 2020).

Totterdill, F. and P. Dhondt (2016), Workplace innovation: European policy and theoretical foundation, http://www.goodworkplaces.net. (accessed on 25 October 2019).

Tsvetkova, A. et al. (2020), "The spatial dimension of productivity: Connecting the dots across industries, firms and places", OECD Regional Development Working Papers, No. 2020/01, OECD Publishing, Paris, https://dx.doi.org/10.1787/ba5edb47-en. 
UKCES (2016), Evaluation of the UK Futures Programme: Conclusions and guidance, https://assets.publishing.service.gov.uk/government/uploads/system/uploads/attachment data/ file/547769/Evaluation of UK Futures Programme - conclusions and guidance.pdf.

UKCES (2015), Anchor institutions and small firms in the UK: A review of the literature on anchor institutions and their role in developing management and leadership skills in small firms, https://assets.publishing.service.gov.uk/government/uploads/system/uploads/attachment data/ file/414390/Anchor institutions and small firms.pdf (accessed on 25 October 2019).

Unionlearn (2012), Making the most of skills. A guide for Union reps, https://www.unionlearn.org.uk/sites/default/files/publication/Making\%20the\%20most\%20of\%20 skills\%20-\%20a\%20guide\%20for\%20reps.pdf (accessed on 23 January 2020).

Van Klaveren (2008), The position, design, and methodology of the industry studies, https://www.researchgate.net/publication/286762318 The position design and methodology of the industry studies (accessed on 14 February 2020).

Verma, A. (2012), "Skills for Competitiveness: Country Report for Canada", OECD Local Economic and Employment Development (LEED) Working Papers, No. 2012/3, OECD Publishing, Paris, https://dx.doi.org/10.1787/5k9bb1vz5jhb-en.

Warhurst, C. (2018), "If high performance working delivers productivity gains, why isn't common sense common practice amongst UK firms?", State of the Art Review, Enterprise Research Centre, Universities of Aston \& Warwick., https://www.enterpriseresearch.ac.uk/publications/high-performance-working-deliversproductivity-gains-isnt-common-sense-common-practice-amongst-uk-firms-sota-no-14/.

Warhurst, C. (2014), Skills for success: Getting better use of your employees' skills, Service Skills Australia.

Warhurst, C. and P. Findlay (2017), "More Effective Skills Utilisation: Shifting the Terrain of Skills Policy in Scotland", SKOPE Research Paper No. 107, https://www.researchgate.net/publication/267381449 More Effective Skills Utilisation Shiftin $\mathrm{g}$ the Terrain of Skills Policy in Scotland/citation/download (accessed on 17 September 2019).

Warhurst, C. and D. Luchinskaya (2018), "Definition, theories, approaches and measures, Background paper for European Company Survey", https://www.researchgate.net/publication/331473965 Skills utilisation Definition theories app roaches and measures (accessed on 17 September 2019).

West Yorkshire Combined Authority (2018), Labour Market Report 2018.

West Yorkshire Combined Authority (n.d.), Leeds City Region Labour Market Analysis 2018, https://minsthorpe.cc/wpcontent/uploads/2018/11/Leeds City Region Labour Market Analysis 2018.pdf.

Whitley, R. (1992), European business systems: firms and markets in their national contexts, Sage Publications.

Wright, J. (2012), The skills dilemma: skills under-utilisation and low-wage work, The Work Foundation. 
Youndt, M., M. Subramaniam and S. Snell (2004), "Intellectual Capital Profiles: An Examination of Investments and Returns", Journal of Management Studies, Vol. 41/2, pp. 335-361, http://dx.doi.org/10.1111/j.1467-6486.2004.00435.x.

Zizys, T. (2018), Workforce development, demand-led strategies and the goal of good jobs., Prepared for: Ontario Centre for Workforce Innovation, https://ocwi-coie.ca/wpcontent/uploads/2018/08/01-018-01-Zizys-Tom-Final-Report.pdf (accessed on 29 August 2019). 


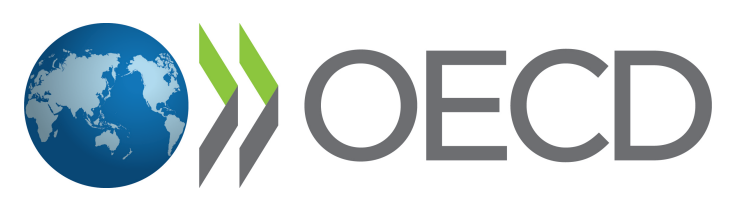

For more information:

http://www.oecd.org/employment/leed 